\title{
Hydrodynamic and morphodynamic responses to surfzone seafloor perturbations
}

\author{
by \\ Melissa Moulton \\ B.A., Amherst College, 2009 \\ Submitted in partial fulfillment of the requirements for the degree of \\ Doctor of Philosophy \\ at the \\ MASSACHUSETTS INSTITUTE OF TECHNOLOGY \\ and the \\ WOODS HOLE OCEANOGRAPHIC INSTITUTION \\ June 2016 \\ (C) 2016 Melissa Moulton. All rights reserved. \\ The author hereby grants to MIT and WHOI permission to reproduce and \\ to distribute publicly paper and electronic copies of this thesis document \\ in whole or in part in any medium now known or hereafter created.
}

Signature of author

Joint Program in Oceanography/Applied Ocean Science and Engineering Massachusetts Institute of Technology and Woods Hole Oceanographic Institution Certified by

February 5, 2016

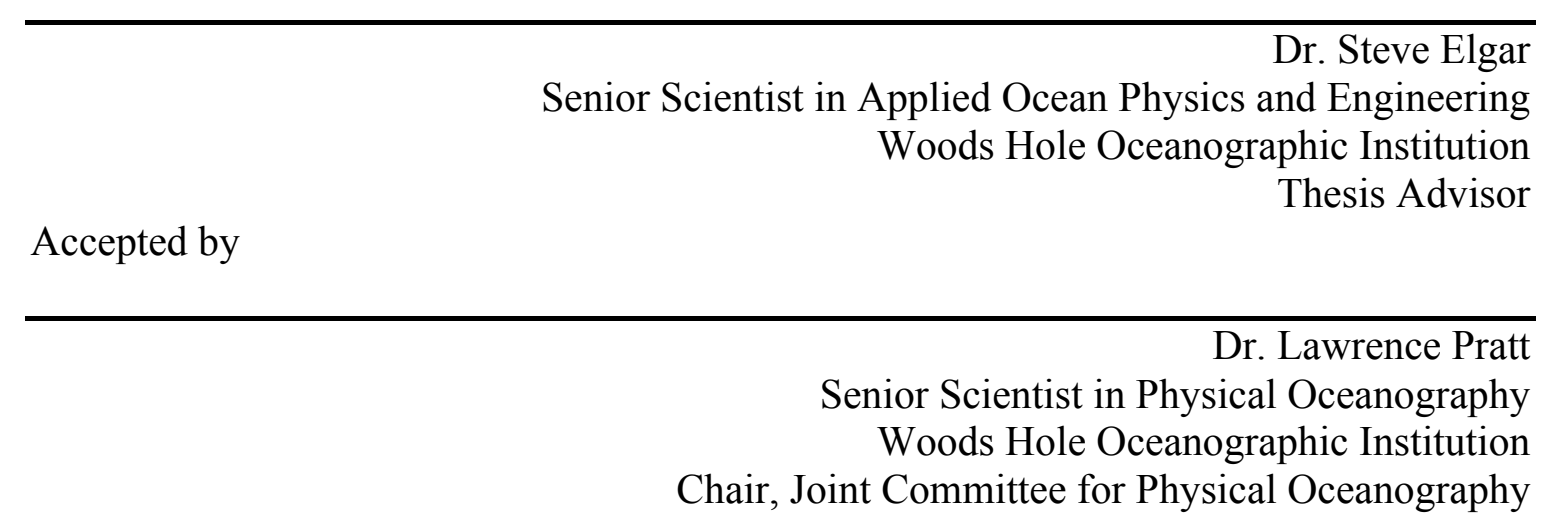




\title{
Hydrodynamic and morphodynamic responses to surfzone seafloor perturbations
}

\author{
by \\ Melissa Moulton \\ Submitted to the MIT/WHOI Joint Program in Oceanography/Applied Ocean Science \\ and Engineering on February 5, 2016 in partial fulfillment of the requirements of the \\ degree of Doctor of Philosophy in Physical Oceanography
}

\begin{abstract}
Holes and channels were excavated in the surf zone on an ocean beach near Duck, NC, and observations of the subsequent evolution of waves, currents, and the modified seafloor were used to investigate nearshore dynamics. In one set of seafloor perturbation experiments, deep holes with steeply sloping sides were excavated in the inner surfzone seafloor. Observations of the infilling holes were used to make the first field estimates of the surfzone morphological diffusivity, which describes the rate of seafloor smoothing by downslope sediment transport. To improve the temporal resolution of bathymetric estimates, a mapping method was developed to combine infrequent, spatially dense watercraft surveys with continuous, spatially sparse in situ altimeter estimates of the seafloor location. In another set of seafloor perturbation experiments, channels were dredged across the surf zone with the propellers of a landing craft. Alongshore variations in wave breaking caused by the perturbed bathymetry resulted in strong rip currents in the channels under some conditions, whereas alongshore currents bypassed the channels under other conditions. The dynamics of the circulation response for changing wave forcing, bathymetry, and tidal elevation are investigated using the observations, a numerical model, and a parameter based on wave properties and bathymetry.
\end{abstract}

Thesis supervisor: Steve Elgar

Title: Senior Scientist in Applied Ocean Physics and Engineering Woods Hole Oceanographic Institution 


\section{Acknowledgements}

First I would like to thank my advisor, Dr. Steve Elgar, and the defense chair, Dr. Britt Raubenheimer. I have benefitted immensely from their insightful comments, absolute generosity with their time, and high expectations. I will never forget the exciting, surprising, and challenging times in the field, and I'm grateful to have gained such excellent colleagues and friends.

I have very much enjoyed meetings with my thesis committee members Dr. Steve Lentz, Dr. Tuba Özkan-Haller, Dr. Taylor Perron, and Dr. John Trowbridge. I am lucky to have had the opportunity to interact with and learn from this outstanding group of scientists, and the thesis work benefitted substantially from their comments and criticism.

I am extremely grateful for the support of the knowledgeable and compassionate staff in the Academic Programs Office. We are fortunate to have such a dedicated group of people making sure the program runs smoothly and responding promptly to any question or concern! I'd also like to thank the administrative staff in the AOPE department for essential support for proposal submissions and travel arrangements.

This work would not have been possible without a talented field crew and the rigorous training that our group received through the WHOI scientific diving program. I'd like to thank the many members of the evolving team that has spent months in the field programming, deploying, and recovering hundreds of sensors. On top of that, thank you for spending hours surveying on the jetski, on the surfboard, or with the dreaded GPS pole system. It has been a privilege to get to know you all!

The experiments presented here took place at the USACE Field Research Facility in Duck, NC. The quality of the infrastructure and the dedication of the staff made it possible to succeed in this risky field experiment that probably could not have been performed anywhere else.

In addition, I would like to thank members of the COAWST user community for providing assistance with the numerical model development. In particular, Dr. John Warner and Dr. Nirnimesh Kumar have been extremely generous with their time in helping me develop a model configuration. I've had a lot of fun and have learned a lot from our discussions of numerical modeling and nearshore dynamics.

This work was supported by the Assistant Secretary of Defense for Research and Engineering, the National Science Foundation, the Office of Naval Research, the WHOI Coastal Ocean Institute, the National Science Foundation Graduate Research Fellowship Program, and a National Defense Science and Engineering Graduate Fellowship.

Finally, I would like to thank my family and friends for supporting me through the challenges of graduate school, and for sharing many adventures in Woods Hole, Boston, and elsewhere! 


\section{Contents}

$\begin{array}{ll}\text { Abstract } & 3\end{array}$

Acknowledgements $\quad 5$

1 Introduction 9

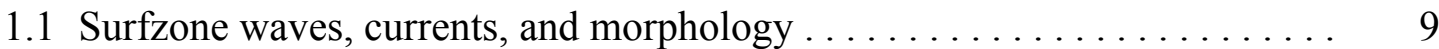

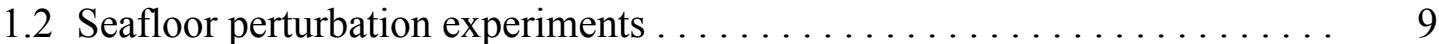

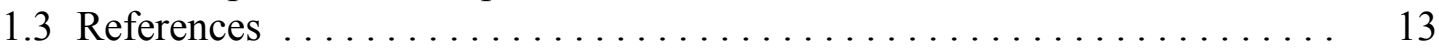

2 A surfzone morphological diffusivity estimated from the evolution of $\begin{array}{ll}\text { excavated holes } & 15\end{array}$

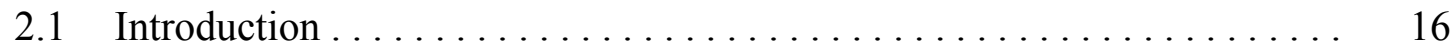

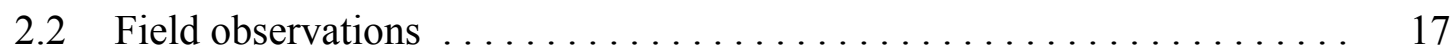

2.3 Theoretical morphological diffusivity . . . . . . . . . . . . . . 19

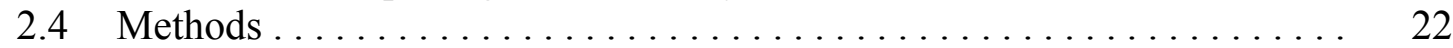

2.4.1 Inferring a morphological diffusivity from evolving bathymetry . . 22

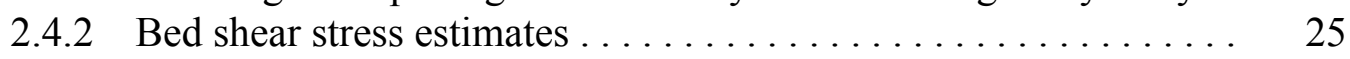

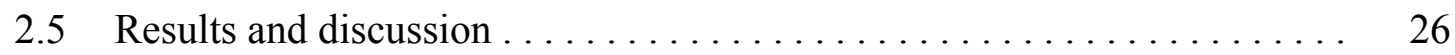

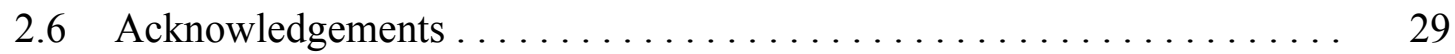

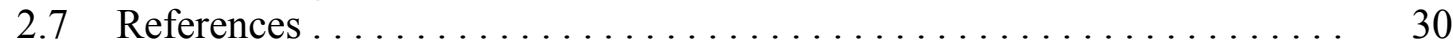

3 Improving the time resolution of surfzone bathymetry using in situ altimeters

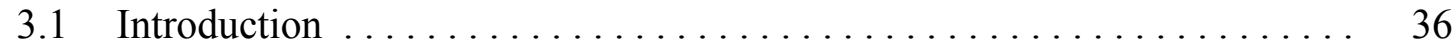

3.2 Direct estimation of seafloor location $\ldots \ldots \ldots \ldots \ldots \ldots \ldots \ldots \ldots$

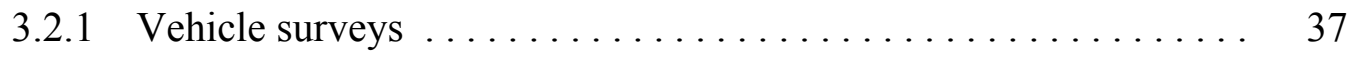

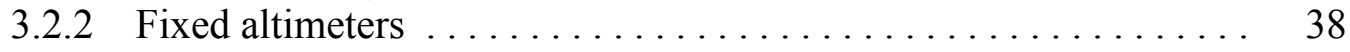

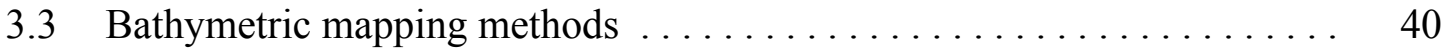

3.3.1 Spatially dense watercraft surveys . . . . . . . . . . . . . . . 40

3.3.2 Temporally dense altimeter bed levels . . . . . . . . . . . . 41

3.3.3 Update method for combining all observations . . . . . . . . . 42

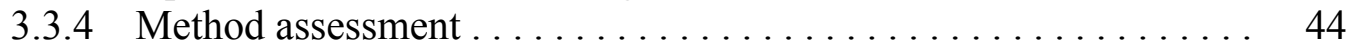

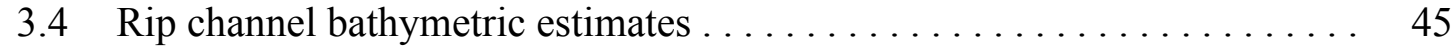

3.4.1 Overview of field observations and mapping of dredged rip

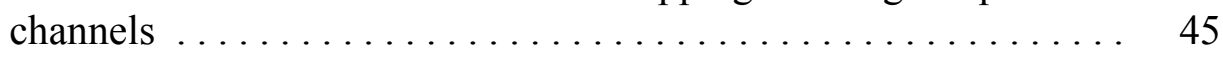

3.4.2 Assessment of rip channel maps ... . . . . . . . . . . . . 49

3.4.3 Application of update method to rip channel cross-section evolution ........................ 53 
$3.5 \quad$ Sandbar profile estimates .......................... 55

3.5.1 Overview of field observations and mapping of natural sandbars . . 55

3.5.2 Assessment of sandbar profile maps . . . . . . . . . . . . 58

3.5.3 Application to sandbar migration ................... 60

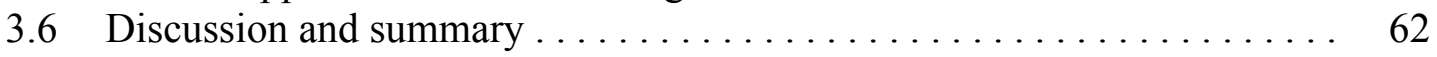

3.7 Appendix: Interpolation and mapping of irregularly sampled observations . . . . . . . . . . . . . . . . . . . . . . . . . . . 63

3.8 Acknowledgements . . . . . . . . . . . . . . . . . . . . . . . . 66

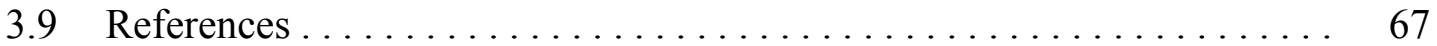

4 Rip currents and alongshore flows in dredged channels $\quad 71$

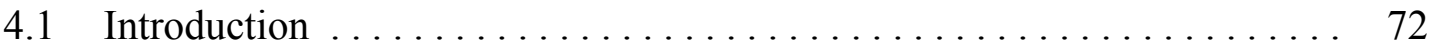

4.2 Field observations ................................. 74

4.3 Numerical simulations . . . . . . . . . . . . . . . . . . . . . 76

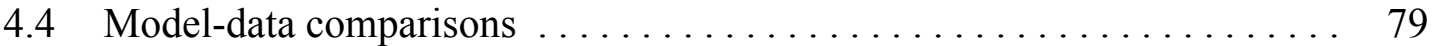

4.4 .1 Time series ................................... 79

$4.4 .2 \quad$ Flow patterns . . . . . . . . . . . . . . . . . . . . . 81

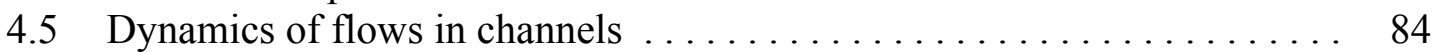

4.5.1 Breaking-wave driven setup and flows $\ldots \ldots \ldots \ldots \ldots \ldots .64$

4.5.2 Momentum balances ............................ 87

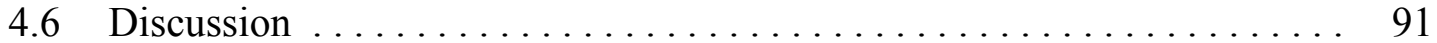

4.7 Conclusions ...................................... 96

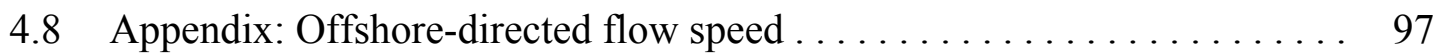

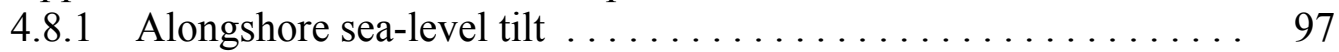

4.8.2 Flow speed as a function of alongshore sea-level difference ..... 99

4.9 Acknowledgements . . . . . . . . . . . . . . . . . . . . . . . . . . . . 101

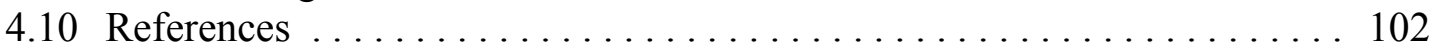

5 Conclusions and future work 109

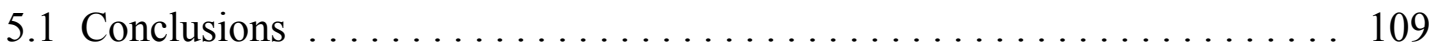

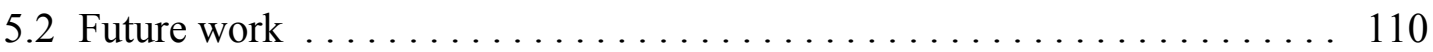

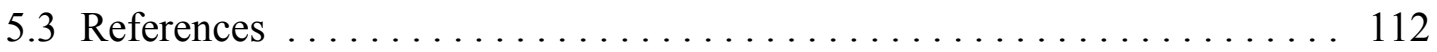




\section{Chapter 1:}

\section{Introduction}

\subsection{Surfzone waves, currents, and morphology}

Wind-generated ocean waves propagate toward the shoreline, refract, steepen, and break in a region known as the surf zone (Figure 1.1). Breaking waves drive an increase in the mean water level (setup) and drive currents that transport sand and change the shape of the seafloor (bathymetry or morphology). To predict important events including flooding, erosion, and structural damage during storms, as well as subsequent beach recovery, the feedbacks between waves, currents, sediment transport, and morphology must be understood. Field observations of complex flow patterns and rapid morphological evolution are needed to test theories, numerical models, and parameterizations of surfzone processes [Elko et al., 2014].

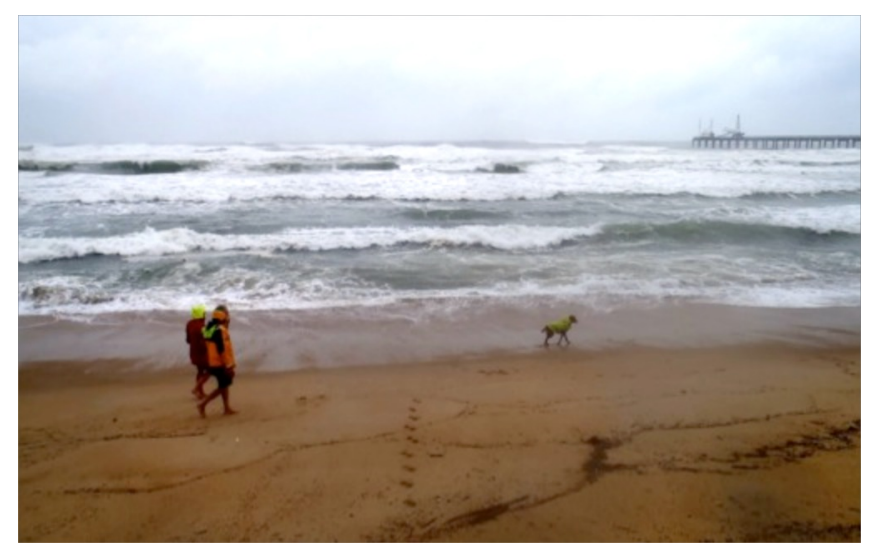

Figure 1.1. Photograph of the surf zone (white foam is from breaking waves) near Duck, NC, during a hurricane in August 2010 that resulted in beach erosion.

\subsection{Seafloor perturbation experiments}

The broad goal of this work is to improve the understanding of the feedbacks between waves, currents, sediment transport, and morphological change in the surf zone. The approach is to investigate the hydrodynamic and morphodynamic responses to large perturbations to the surfzone seafloor. In 2010 and 2012, holes (Figure 1.2) and channels (Figure 1.3) were excavated in the surf zone near Duck, NC at the US Army Corps of 
Engineers Field Research Facility (FRF, http://frf.usace.army.mil/frf.shtml). By excavating or dredging the seafloor and instrumenting the surrounding surf zone, it was possible to obtain a strong signal of the coupling of waves, currents, and evolving bathymetry at a known place and time. The observations from the seafloor perturbation experiments were used to test theories and numerical models of wave-current-seafloor interactions.

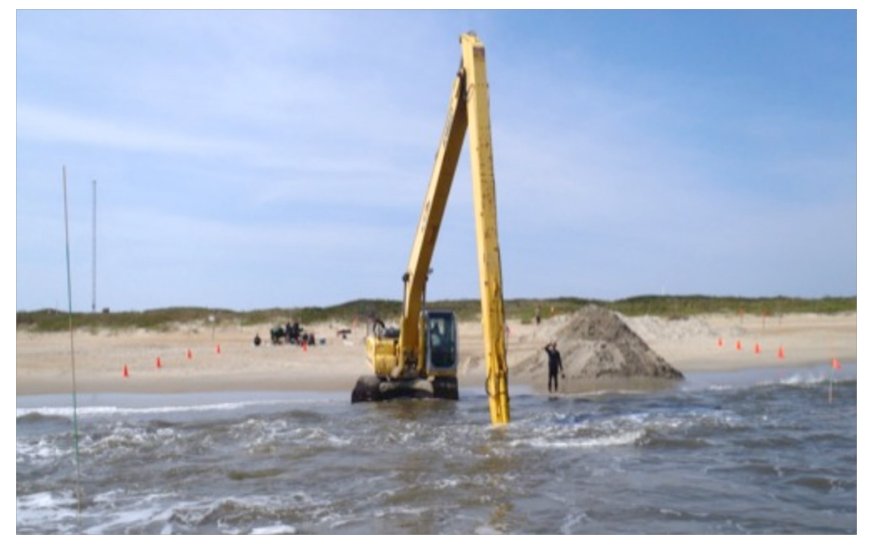

Figure 1.2. Photograph of equipment used to excavate holes in the inner surf zone near Duck, NC in 2010. The pile of sand was removed after the hole was excavated.

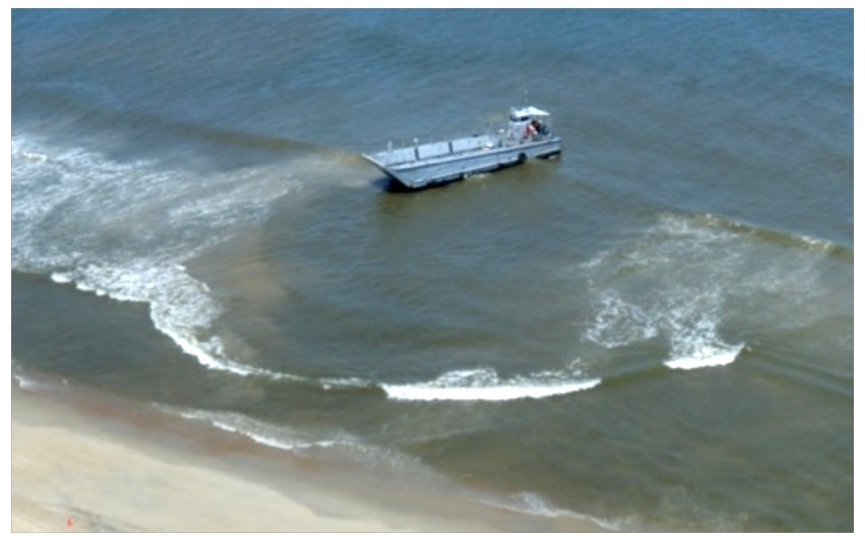

Figure 1.3. Photograph of a landing craft that was used to dredge shore-perpendicular channels across the surf zone by suspending sediment with its propellers near Duck, NC in 2012 .

In one set of experiments (Duck, NC, 2010), deep holes with steeply sloping sides were dug in the inner surfzone seafloor with an excavator (Figure 1.2). Numerical models have limited skill simulating field observations of surfzone sediment transport and morphological change, and the relative importance of wave-, current-, and gravity-driven 
suspended and bedload transport is not known for a wide range of conditions [Amoudry and Souza, 2011]. The importance of gravity-driven sediment transport in the surfzone is unknown, in part because there is a lack of field observations of the evolution of steep bathymetric features. Here (Chapter 2), observations of the infilling holes were used to make the first field estimate of the surfzone morphological diffusivity, which describes the rate of seafloor smoothing by downslope sediment transport [Moulton et al., 2014a].

Often, the largest errors in nearshore hydrodynamic models are associated with errors in the estimates of the bathymetry [Wilson et al., 2010], in part because it is difficult to observe the rapidly evolving surfzone seafloor, and remote sensing techniques may not have sufficient vertical accuracy [Holman et al., 2013]. Watercraft-based surveying methods can be used to map the seafloor with high spatial resolution in relatively calm conditions before and after storms, whereas in situ altimeters can provide frequent estimates of the seafloor elevation at fixed locations, even during storms. Here (Chapter 3), a method is developed to estimate the bathymetry by updating infrequent, spatially dense watercraft surveys with temporally continuous, spatially sparse altimeter estimates of seafloor elevation change, and the method is tested with observations of evolving channels and sandbars [Moulton et al., 2014b].

In another set of seafloor perturbation experiments (Duck, NC, 2012), channels were dredged across the surf zone with the propellers of a landing craft (Figure 1.3). Rip currents [MacMahan et al., 2006; Dalrymple et al., 2011] are strong shore-perpendicular jets that are hazardous to swimmers and are an important mechanism for transporting biota, pollutants, and sediment from the shoreline to the inner shelf. Rip currents can be caused by alongshore variations in wave breaking and often occur in channels or gaps in sandbars. Predicting the presence and strength of rip currents, and the transition to other circulation patterns, is important for predicting surfzone hazards, transport, and mixing, but there are few field observations of flows and morphological evolution near highly nonuniform bathymetry. Here (Chapter 4), field observations of waves, currents, and seafloor evolution near dredged channels are used with a numerical hydrodynamic model 
to investigate the dynamics of rip currents for a range of wave conditions and bathymetries.

In summary, this thesis uses observations from seafloor perturbation experiments, along with theory and numerical simulations, to investigate surfzone processes. In Chapter 2, field observations of excavated holes are used with a sediment transport theory to make the first field estimate of the morphological diffusivity in the surf zone. In Chapter 3, a method is developed to improve the temporal resolution of surfzone bathymetry by combining observations from watercraft surveys and in situ altimeters. In Chapter 4, the dynamics of rip currents are investigated using field observations in dredged channels and numerical simulations. In Chapter 5, the results are summarized and future work is discussed. 


\subsection{References}

Amoudry, L. O., and A. J. Souza (2011), Deterministic coastal morphological and sediment transport modeling: A review and discussion, Rev. Geophys., 49, RG2002, doi:10.1029/2010RG000341.

Dalrymple, R., J. MacMahan, A. Reniers, and V. Nelko (2011), Rip Currents, Ann. Rev. Fluid. Mech., 43, 551-581, doi:10.1146/annurev-fluid-122109-160733.

Elko, N., R. Holman, F. Feddersen, D. Foster, J. McNinch, H. T. Özkan-Haller, N. Plant, and B. Raubenheimer (2014), The Past and Future of Nearshore Processes Research: Reflections on the Sallenger Years and a New Vision for the Future, Shore and Beach, 83(1), 13-38.

Holman, R. A., M. C. Haller (2013), Remote Sensing of the Nearshore, Ann. Rev. of Mar. Sci., 5(1), 95-113, doi:10.1146/annurev-marine-121211-172408.

MacMahan, J. H., E. B. Thornton, and A. J. H. M. Reniers (2006), Rip current review, Coast. Eng., 53(2-3), 191-208, doi:10.1016/j.coastaleng.2005.10.009.

Moulton, M., S. Elgar, and B. Raubenheimer (2014a), Improving the time resolution of surfzone bathymetry using in situ altimeters, Oc. Dynam., 64(5), 755-770, doi:10.1007/s10236-014-0715-8.

Moulton, M., S. Elgar, and B. Raubenheimer (2014b), A surfzone morphological diffusivity estimated from the evolution of excavated holes, Geophys. Res. Lett., 41, doi:10.1002/2014GL060519.

Wilson, G. W., H. T. Özkan-Haller, and R. A. Holman (2010), Data assimilation and bathymetric inversion in a two-dimensional horizontal surf zone model, $J$. Geophys. Res., 115, C12057, doi:10.1029/2010JC006286. 


\title{
Chapter 2:
}

\section{A surfzone morphological diffusivity inferred from the evolution of excavated holes ${ }^{1}$}

\begin{abstract}
Downslope gravity-driven sediment transport smooths steep nearshore bathymetric features, such as channels, bars, troughs, cusps, mounds, pits, scarps, and bedforms. Downslope transport appears approximately as a diffusive term in the sediment continuity equation predicting changes in bed level, with a morphological diffusivity controlling the rate of seafloor smoothing. Despite the importance of surfzone sediment transport and morphological evolution, the size of the downslope transport term in nearshore models varies widely, and theories have not been tested with field measurements. Here, observations of the infill of large excavated holes in an energetic inner surf zone provide the first opportunity to infer the morphological diffusivity in the field. The estimated diffusion coefficient is consistent with a theoretical bedload morphological diffusivity that scales with the three-halves power of the representative bed shear stress.
\end{abstract}

\footnotetext{
${ }^{1}$ This chapter is the accepted version of the following article: Moulton, M., S. Elgar, and B. Raubenheimer (2014), A surfzone morphological diffusivity estimated from the evolution of excavated holes, Geophysical Research Letters, 41, 4628-4636, which has been published in its final form at http://dx.doi.org/10.1002/2014GL060519. Used with permission as granted in the original copyright agreement.
} 


\subsection{Introduction}

The coupling of surfzone waves, currents, and bathymetry leads to complex patterns of sediment transport and morphological evolution. Nearshore sediment transport results in beach erosion and accretion [Aubrey, 1979], the migration of sandbars [Thornton et al., 1996; Gallagher et al., 1998; Plant et al., 1999; Ruessink et al., 2000; Hoefel and Elgar, 2003; Henderson et al., 2004], and the evolution of rip current channels [Falqués et al., 2000; van Enckevort and Ruessink, 2003; MacMahan et al., 2008; Garnier et al., 2013], and provides a mechanism for the movement of pollution and biota between land and the inner shelf [Jumars and Nowell, 1984; Feng et al., 2013]. Sediment transport parameterizations and quantitative transport estimates vary considerably (see Amoudry and Souza, 2011 for a review), but most theories and numerical models include a component of sediment transport in the direction of the instantaneous near-bed velocity (in response to fluid drag) and a downslope component (in response to gravity). Downslope transport appears (to first order) as a diffusive term in the sediment continuity equation used to predict temporal changes in the bed elevation [Trowbridge and Young, 1989; Kovacs and Parker, 1994; Caballeria et al., 2002], and acts to smooth the surfzone seafloor. The "morphological diffusivity," related to the size of the downslope transport, is important to the evolution of steep nearshore features, including sandbars, cusps, troughs, channels, mounds, pits, scarps, and bedforms [Douglass, 1995; van de Kreeke et al., 2002; Garnier et al., 2006], and is a mechanism by which equilibrium beach states are reached [Bailard, 1981; Dean, 1991; Calvete et al., 2005; Garnier et al., 2008].

Despite the tremendous importance of surfzone sediment transport and shoreline morphological evolution, numerical models have limited skill simulating observations, and the impact of bed slope on sediment transport in the field has not been tested [Garnier et al., 2008]. There are few field observations of the evolution of steep surfzone bathymetric features, partially because it is difficult to make accurate measurements of sediment transport and bed evolution for steep morphologies that change rapidly under energetic conditions. Here, the surfzone seafloor is perturbed artificially to allow investigation of the morphological evolution of steep bathymetric features. Large holes

(initially about 10-m wide and 2-m deep) were excavated in the inner surf zone of an 
ocean beach (Figure 2.1), and waves, currents, and the evolving bathymetry were measured. The holes evolve predominantly by downslope sediment transport that can be modeled as a diffusive process, and thus the perturbations provide an opportunity to estimate the morphological diffusivity that best explains the observed seafloor evolution. The morphological diffusivity estimated from the evolution of the holes is consistent with a bedload transport theory for which the diffusivity is proportional to the three-halves power of the bed shear stress.

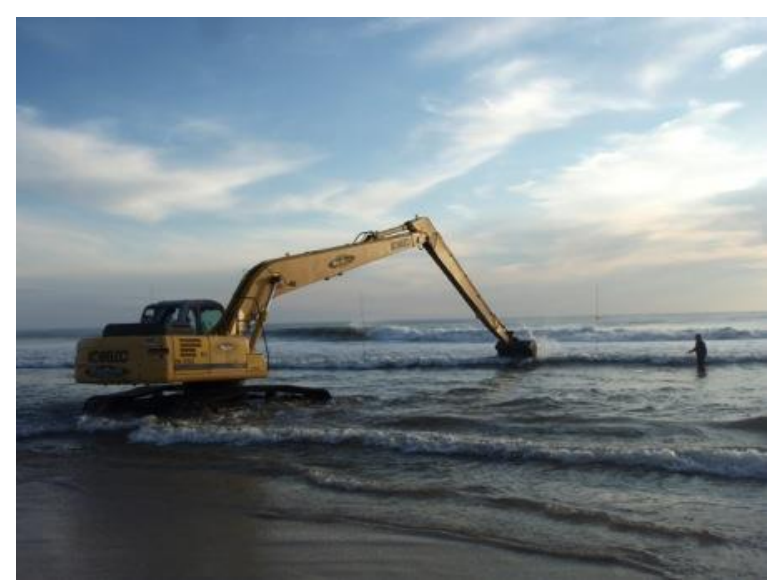

Figure 2.1. Backhoe excavating a hole in the inner surf zone near Duck, NC at low tide.

\subsection{Field observations}

Four large holes were excavated (Figure 2.1) in the inner surf zone. The mean water depth surrounding the holes was $1.5 \mathrm{~m}$ and the tidal range was approximately $1 \mathrm{~m}$. The initial (ranging from several hours to several days after excavation) bathymetry of each hole was surveyed with a surfboard-mounted GPS-sonar system and a diver-carried GPSpole system, yielding a set of bed-level observations for each hole (Figure 2.2, squares). The holes were approximately Gaussian (Figure 2.2, Gaussian fit to survey shown with contours in A and curves in B and C), and initially were between 1.9 and $2.7 \mathrm{~m}$ deep relative to an ambient bed elevation (Figure 2.3A, initial values of black curves) with widths (defined as 4 times the standard deviation of the Gaussian shape from a fit to an elliptical Gaussian) between 14 and $17 \mathrm{~m}$ in the alongshore (Figure 2.2C) and between 9 and $14 \mathrm{~m}$ in the cross-shore (Figure 2.2B). The root-mean-square (rms) differences between the observed elevations and the Gaussian fits for the four holes (in the order 
shown in Figure 2.3) are $0.28 \mathrm{~m}, 0.17 \mathrm{~m}, 0.25 \mathrm{~m}$ (the survey shown in Figure 2.2), and $0.17 \mathrm{~m}$, approximately the same size as the expected rms measurement error $(0.20 \mathrm{~m})$ for the watercraft and diver survey methods [Moulton et al., 2014]. Shortly after each excavation, an altimeter was deployed above (near the ambient bed elevation) the center of the hole (triangle in Figure 2.2). The altimeters sampled continuously (2 MHz acoustic profilers, 1-minute-average samples, 10-cm vertical bins), and backscatter amplitudes (not shown) were used to make hourly estimates of the seafloor elevation. A 7-hour running mean was applied to the hourly seafloor elevation estimates to remove migrating bedforms (e.g., megaripples) from the signal. Waves and currents used to estimate bottom stress were measured with 4 to 6 acoustic-Doppler velocimeter and pressure gage pairs (sampled at $2 \mathrm{~Hz}$ ) deployed 10 to $30 \mathrm{~m}$ apart near each hole (e.g., circles in 2.2A) with transducers approximately $0.7 \mathrm{~m}$ above the bed. Significant wave heights (defined as 4 times the sea-surface elevation standard deviation) near the holes ranged from 0.2 to 1.2 $\mathrm{m}$, and mean current speeds ranged from 0.1 to $1.2 \mathrm{~m} / \mathrm{s}$. The median grain diameter $\left(d_{50}\right)$ near the holes was $0.3 \mathrm{~mm}$.

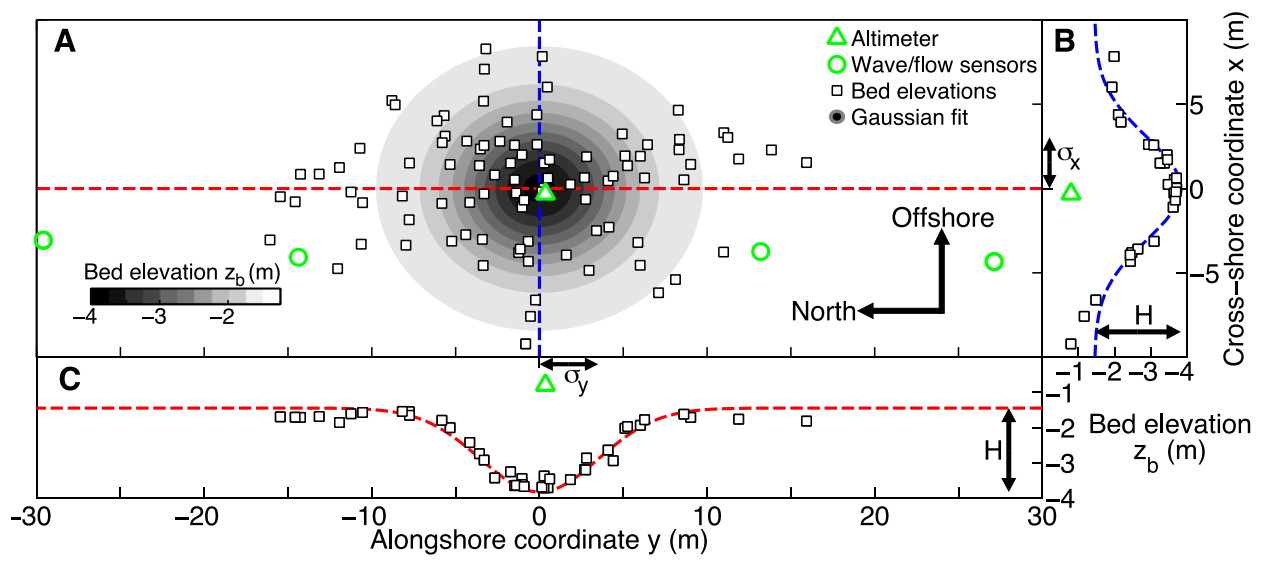

Figure 2.2. (A) Plan view of altimeter location (green triangle near the center), wave and velocity sensor locations (circles), bed-elevation survey locations (squares), and Gaussian fit to surveyed bed elevations (grey-scale contours every $0.25 \mathrm{~m}$ ) for one of the excavated holes as a function of cross- $(x)$ and alongshore $(y)$ coordinates. The hole center is located at $x=0$ (red dashed curve), $y=0$ (blue dashed curve). (B) Bed elevation $z_{b}$ versus $x$ for surveyed bed elevations near $y=0$ (squares, plotted for $|y|<2 \mathrm{~m}$ ) and for the Gaussian fit at $y=0$ (dashed blue curve). (C) Bed elevation $z_{b}$ versus $y$ for surveyed bed elevations near $x=0$ (squares, plotted for $|x|<2 \mathrm{~m}$ ) and for the Gaussian fit at $x=$ 0 (dashed red curve). The depth of the hole relative to ambient bed elevation $(H=2.4 \pm$ $0.2 \mathrm{~m})$ and the cross- and alongshore standard deviations $\left(\sigma_{x}=3.0 \pm 0.3 \mathrm{~m}, \sigma_{y}=3.5 \pm\right.$ $0.4 \mathrm{~m}$ ) from the Gaussian fit ( $95 \%$ confidence intervals on the fit parameters are reported) are shown with arrows. 

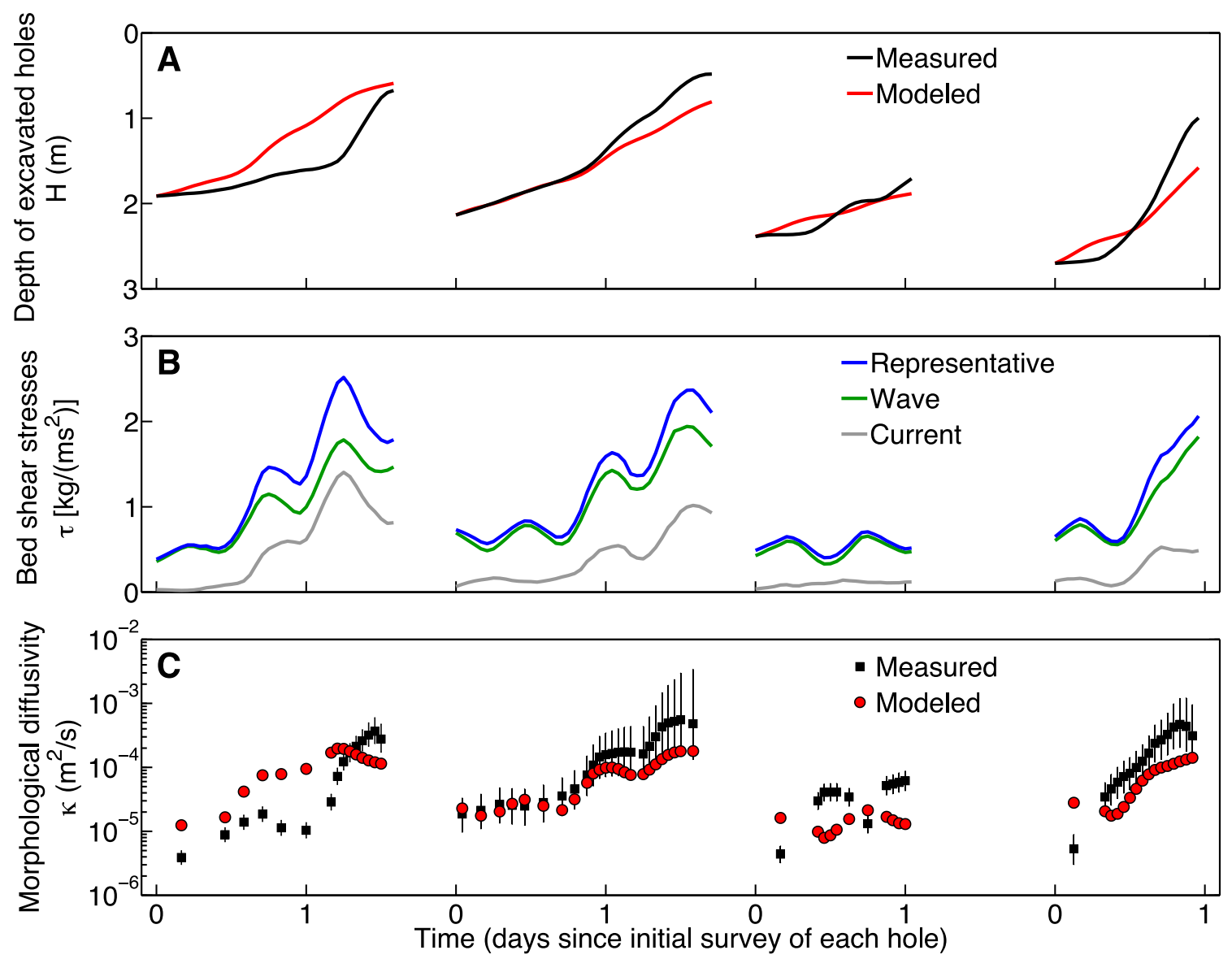

Figure 2.3. (A) Depth of excavated holes (m), (B) bed shear stresses $\left[\mathrm{kg} /\left(\mathrm{ms}^{2}\right)\right]$, and (C) morphological diffusivity $\left(\mathrm{m}^{2} / \mathrm{s}\right)$ versus time (days since initial survey of each hole). The measured depth of the excavated holes (black curves in A) was used with Gaussian fits to initial surveys (Figure 2.2) to infer a morphological diffusivity (black squares in C, error bars are $95 \%$ confidence intervals based on initial survey fits) each time the hole filled by a measurable amount $(0.05 \mathrm{~m}$, one-half the profiler bin size). A bedload morphological diffusivity theory (Equation 2.6) with $A=12$ [Soulsby and Damgaard, 2005] was used with the representative shear stress estimate [blue curves in $\mathrm{B}$, derived from the wave(green curves) and current- (grey curves) associated stresses] to model the time evolution of the morphological diffusivity (red curves in C) for the same time windows as for the data. The modeled coefficient was used to predict the hole depth evolution (red circles in A, model initial condition is the Gaussian fit to each initial survey).

\subsection{Theoretical morphological diffusivity}

Sediment in the surf zone is transported as bedload (in which grains roll, slide, or saltate near the bed) and suspended load (in which grains move in the water column). Based on the ratio of the turbulent vertical velocity fluctuations to the sediment fall velocity 
[Gonzalez-Rodriguez and Madsen, 2011] sediment transport was dominated by bedload for the field conditions considered here. The volumetric bedload transport $\boldsymbol{Q}$ can be determined from an along-bed force balance on a sediment grain in the presence of waves, currents, and a sloping bed [Bagnold, 1966; Bailard, 1981; Trowbridge and Young, 1989; Fredsøe and Deigaard, 1992; Nielsen, 1992; Kovacs and Parker, 1994; Soulsby, 1997; Soulsby and Damgaard, 2005; Amoudry and Souza, 2011], and can be expressed as the sum of a component of transport in the instantaneous flow direction (owing to fluid drag on a flat bed, referred to as "flat-bed transport" $\boldsymbol{Q}_{\mathbf{0}}$ ) and a component downslope (owing to the presence of a sloping bed, referred to as "downslope transport" $\left.Q_{s}\right)$.

Most bedload formulations relate the transport to a power of the bed shear stress [Amoudry and Souza, 2011]. Thus, a bedload transport relationship [Meyer-Peter and Müller, 1948; Soulsby and Damgaard, 2005] modified for the presence of a sloping bed [Bagnold, 1966; Bailard, 1981; Kovacs and Parker, 1994] is given by:

$$
\boldsymbol{Q}=\boldsymbol{Q}_{\mathbf{0}}+\boldsymbol{Q}_{\boldsymbol{S}}=\frac{A}{\rho^{3 / 2}(s-1) g} \tau^{1 / 2}\left(\tau-\tau_{c r}\right)\left[\frac{\tau}{\tau}-\frac{\nabla z_{b}}{\tan \phi}\right]
$$

where $\rho=1025 \mathrm{~kg} / \mathrm{m}^{3}$ is the density of seawater, $s=2.57$ is the ratio of the density of sediment (quartz) to the density of seawater, $g$ is the gravitational constant, $A$ is a dimensionless coefficient [Soulsby and Damgaard, 2005], $\tau$ is the magnitude of the bed shear stress, $\tau_{c r} \approx 0.17 \mathrm{~kg} /\left(\mathrm{ms}^{2}\right)$ [Shields, 1936] is a critical shear stress for initiation of motion ( $\boldsymbol{Q}=0$ for $\left.\tau \leq \tau_{c r}\right), \nabla z_{b}$ is the gradient of the bed level, and $\phi=32^{\circ}$ is the angle of repose. The unit vector $\left[\frac{\tau}{\tau}\right]$ is oriented in the instantaneous flow direction, and the vector $\left[-\frac{\nabla z_{b}}{\tan \phi}\right]$ is directed downslope. The form of Equation 2.1 relies on the assumption that the bed slope is much smaller than the angle of repose $\left(\left|\frac{\nabla z_{b}}{\tan \phi}\right| \ll 1\right)$, which is only weakly satisfied for some of the steepest slopes of the excavated holes $\left(0.05<\left|\frac{\nabla z_{b}}{\tan \phi}\right|<\right.$ 0.50). However, Equation 2.1 is used widely and is expected to describe the first-order effects of the downslope transport. In addition, the critical shear stress is expected to vary with the bed slope, and the downslope transport may depend on the angle between the 
bed gradient and the flow direction [Kovacs and Parker, 1994]. These higher-order effects are neglected here.

Usually, nearshore morphology changes on timescales of storms or seasons, much longer than the period of surface gravity waves (about $10 \mathrm{~s}$ ). Thus, often sediment transport and bed-level predictions are integrated over wave cycles, and approximations for the waveaveraged transport are used to avoid computationally expensive numerical integrations [Soulsby and Damgaard, 2005]. The total near-bed shear stress vector is approximately the sum of the shear stress from the mean current in the presence of waves $\boldsymbol{\tau}_{\boldsymbol{m}}$ and the time-dependent shear stress vector $\boldsymbol{\tau}_{\boldsymbol{w}}$ associated with a representative wave [Grant and Madsen, 1986; Madsen, 1994]. For (oscillatory) flat-bed transport owing to nearly sinusoidal waves perpendicular to a mean flow, the wave-averaged transport is in the direction of the mean current, and goes as $\tau_{w}^{1 / 2} \tau_{m}$ [Soulsby and Damgaard, 2005], where $\tau_{m}$ is the magnitude of the mean shear stress vector and $\tau_{w}$ is the amplitude of the oscillating wave shear stress vector. In contrast, the downslope transport is unidirectional (downslope), and thus the transport does not average to zero for sinusoidal waves, and the net transport is better parameterized using a representative wave-current bed shear stress magnitude, $\tau_{r}=\max \left(\left|\boldsymbol{\tau}_{\boldsymbol{m}}+\boldsymbol{\tau}_{\boldsymbol{w}}\right|\right)$. Therefore, for the field conditions presented here, the wave-averaged flat-bed transport and downslope transport are expressed approximately as (numerical experiments show that errors are small):

$$
\begin{gathered}
\left\langle\boldsymbol{Q}_{\mathbf{0}}\right\rangle \approx \frac{A}{\rho^{3 / 2}(s-1) g} \tau_{w}^{1 / 2} \tau_{m}\left[\frac{\tau_{m}}{\tau_{m}}\right] \\
\left\langle\boldsymbol{Q}_{\boldsymbol{S}}\right\rangle \approx \frac{A}{\rho^{3 / 2}(s-1) g} \tau_{r}^{1 / 2}\left(\tau_{r}-\tau_{c r}\right)\left[-\frac{\nabla z_{b}}{\tan \phi}\right]
\end{gathered}
$$

where $\langle\cdot\rangle$ indicates an average over a wave cycle, $\frac{1}{2 \pi} \int_{0}^{2 \pi} \cdot d\left(\omega_{r} t\right)$ and $\left[\frac{\tau_{m}}{\tau_{m}}\right]$ is a unit vector oriented in the mean flow direction. The expression in Equation 2.2 [Soulsby and Damgaard, 2005] requires that $\tau_{w} \gg \tau_{m}$ and $\tau \gg \tau_{c r}$, consistent with the average field conditions considered here. For these field conditions, Equation 2.3 may be simplified further by noting that $\tau_{r}^{1 / 2}\left(\tau_{r}-\tau_{c r}\right) \approx \tau_{w}^{3 / 2}$, but the form above shows better agreement with a wider range of field conditions. 
Mass conservation equates temporal changes in bed elevation (erosion or accretion) with spatial gradients (divergences or convergences) of horizontal sediment transport:

$$
\frac{\partial z_{b}}{\partial t}+\frac{1}{(1-n)} \nabla \cdot\langle\boldsymbol{Q}\rangle=0
$$

where $z_{b}$ is the elevation of the bed and $n=0.3$ is the sediment porosity. Substituting Equation 2.1 into Equation 2.4 and applying the approximation in Equation 2.3 yields:

$$
\begin{aligned}
& \frac{\partial z_{b}}{\partial t}=-\frac{1}{(1-n)} \nabla \cdot\left\langle\boldsymbol{Q}_{\mathbf{0}}\right\rangle+\nabla \cdot\left(\kappa \nabla z_{b}\right) \\
& \kappa=\frac{1}{(1-n)} \frac{A}{\rho^{3 / 2}(s-1) g} \frac{1}{\tan \phi} \tau_{r}^{1 / 2}\left(\tau_{r}-\tau_{c r}\right)
\end{aligned}
$$

The downslope transport (Equation 2.3) results in a diffusive term in the mass conservation equation (Equations 2.4 and 2.5), and the coefficient $\kappa$ (Equation 2.6) is referred to as the morphological diffusivity. The morphological diffusivity may vary temporally as the representative shear stress changes in response to changing incident wave conditions (e.g., passage of storms) and water depths (e.g., tidal fluctuations) and spatially as the stress changes in response to bathymetrically induced circulation patterns (e.g., divergence of a mean flow over a channel). Both terms in Equation 2.5 may be important for the evolution of nearshore bathymetric features. For example, the offshore migration of sandbars during storms primarily is the result of offshore flowing currents that are maximum near the crest of the bar (leading to divergences in $\boldsymbol{Q}_{\mathbf{0}}$ ) [Thornton et al., 1996; Gallagher et al., 1998], but the downslope transport $\boldsymbol{Q}_{\boldsymbol{S}}$ may be an important control on the bar height and slope, which impact the bar migration speed [Trowbridge and Young, 1989].

\subsection{Methods}

\subsubsection{Inferring a morphological diffusivity from evolving bathymetry}

The evolution of the excavated holes is expected to be dominated by the diffusive term (related to the downslope transport $\boldsymbol{Q}_{\boldsymbol{S}}$ ) for several reasons. Although the instantaneous downslope transport $\boldsymbol{Q}_{\boldsymbol{S}}$ is (according to Equation 2.1) smaller than the instantaneous flatbed transport $\boldsymbol{Q}_{\mathbf{0}}$, the wave-averaged downslope transport may be larger than the waveaveraged flat-bed transport. In particular, the wave-averaged flat-bed transport (Equation 2.2 ) is small for sinusoidal oscillatory waves and small mean flows $\left(\tau_{m}<\tau_{w}\right.$, Figure 
2.3B). Although wave orbital velocities in the surf zone are skewed and asymmetric, for the conditions here they do not transport significant amounts of sediment over the relatively short periods during which the holes filled. Conservation of sediment (Equation 2.5) predicts that flat-bed transport owing to a diverging mean flow would lead to migration of the holes in the mean flow direction [van de Kreeke et al., 2002]. However, the holes were not observed to migrate, implying bed evolution owing to diverging mean flows was small. The holes had steeply sloping sides, while the bed-slope was small outside of the holes and at the hole centers, leading to large spatial gradients in the downslope flux. The downslope transport (Equation 2.3) scales with the combined wave and current shear stress magnitude $\tau_{r}$, which (by definition) is larger than either $\tau_{w}$ or $\tau_{m}$ (Figure 2.3B). Thus, it is expected that the downslope term dominates the hole evolution [the second term on the right hand side of (Equation 2.5) usually is larger than the first term], and the bathymetric change in time is approximated by:

$$
\frac{\partial z_{b}}{\partial t} \approx \nabla \cdot\left(\kappa \nabla z_{b}\right)
$$

This balance and the measured bathymetric evolution can be used to find the diffusivity that best explains the evolution of the seafloor, similar to inverting tracer dispersion to infer hydrodynamic diffusivities [Ledwell et al., 1998; Clark et al., 2010].

For an approximately Gaussian bathymetry (Figure 2.2) evolving according to (Equation 2.7), the bathymetry remains a Gaussian at all times, and the morphological diffusivity can be expressed as an analytical function of the hole depth and width. An elliptical Gaussian hole has the form:

$$
z_{b}(x, y, t)=-H(t) \exp \left[-\left(\frac{x^{2}}{2 \sigma_{x}^{2}(t)}+\frac{y^{2}}{2 \sigma_{y}^{2}(t)}\right)\right]+z_{a m b}
$$

where $H(t)$ is the maximum hole depth, $z_{a m b}$ is the ambient bed elevation, and $\sigma_{x}(t)$ and $\sigma_{y}(t)$ are the standard deviations of the Gaussian shape in the cross-shore $(x)$ and alongshore (y), respectively. If the hole evolves diffusively (Equation 2.7), the depth and standard deviations at two times $t_{1}$ and $t_{2}$ are related by:

$$
H\left(t_{2}\right)=H\left(t_{1}\right)\left[\left(1+\frac{2 \kappa \Delta t}{\sigma_{x}^{2}\left(t_{1}\right)}\right)^{-1 / 2}\left(1+\frac{2 \kappa \Delta t}{\sigma_{y}^{2}\left(t_{1}\right)}\right)^{-1 / 2}\right]
$$




$$
\begin{aligned}
& \sigma_{x}\left(t_{2}\right)=\sigma_{x}\left(t_{1}\right)\left(1+\frac{2 \kappa \Delta t}{\sigma_{x}^{2}\left(t_{1}\right)}\right)^{1 / 2} \\
& \sigma_{y}\left(t_{2}\right)=\sigma_{y}\left(t_{1}\right)\left(1+\frac{2 \kappa \Delta t}{\sigma_{y}^{2}\left(t_{1}\right)}\right)^{1 / 2}
\end{aligned}
$$

where $\Delta t=t_{2}-t_{1}$. If the morphological diffusivity $\kappa$ varies between times $t_{1}$ and $t_{2}$ (e.g., owing to changing incident wave conditions) and over the spatial domain (e.g., owing to flows diverging over the hole), the value of $\kappa$ in (Equation 2.9) may be approximated using the average value in space and time. Numerical experiments verify that this approximation leads to small errors in $\kappa$ that are negligible relative to other sources of observational uncertainty.

For each hole, the depth at the center $H(t)$ (Figure 2.3A) is known at all times from the altimeter at the hole center (triangle in Figure 2.2), and the standard deviations at an initial time (arrows in Figure 2.2) are estimated by fitting Equation 2.8 to the initial survey (black squares in Figure 2.2). Thus, the diffusivity can be inferred by solving Equation 2.9A for $\kappa$ between times $t_{1}$ and $t_{2}$ when the depth changed by $0.05 \mathrm{~m}$ (half of the altimeter bin size, approximately the smallest measurable depth change). The standard deviations (Equation 2.8) were updated from the initial value using Equations 2.9B and 2.9C. The estimates of morphological diffusivity (black squares in Figure 2.3C) are similar if a different fraction or multiple of the bin size is used, or if a uniform time step is chosen. The error bars on these observationally inferred diffusivity estimates (Figure 2.3C) are the range of $\kappa$ given the $95 \%$ confidence intervals on the hole depth and standard deviations. The confidence intervals on the initial conditions are based on the confidence intervals for a nonlinear regression fit of an elliptical Gaussian to the initial survey of each hole. The confidence intervals on the hole depths are based on the uncertainty associated with the depth relative to the ambient bed elevation (from the initial fit to Equation 2.8, e.g., see Figure 2.2). The confidence interval on the initial standard deviations is found from the Gaussian fit (Figure 2.2), and the confidence intervals at subsequent time steps are found by updating the standard deviations (using Equations $2.9 \mathrm{~B}$ and $2.9 \mathrm{C}$ ) with the range of inferred $\kappa$ from the previous time step. 


\subsubsection{Bed shear stress estimates}

Observations from the 4 to 6 sensors nearest the cross-shore position of the hole centers (circles in Figure 2.2A) were used to estimate hourly wave, current, and representative (magnitude of the vector sum of the wave- and current-associated terms) near-bed shear stresses in the holes (Figure 2.3B) with a spectral wave-current bottom boundary layer approach [Grant and Madsen, 1986; Madsen, 1994]. The rms representative near-bed wave-orbital (from hourly wave-spectra, for frequencies $<0.25 \mathrm{~Hz}$ ), and hourly mean velocities were used in the estimates. The shear stresses from the individual sensors were averaged, and a 7-hr running mean was applied to the estimates. The roughness height $k_{n}=11 d_{50}$ is an average mobile-bed roughness based on best fits to observations from a previous field study at this site [Hsu et al., 2006]. This roughness value is expected to be appropriate for the environment of the excavated holes, although inner-surfzone roughness values for typical grain sizes $\left(0.2<d_{50}<0.5 \mathrm{~mm}\right)$ range from $k_{n}=d_{50}$ to $k_{n}=35 d_{50}$, and sometimes vary with the shear velocity [Ribberink, 1998; DohmenJanssen et al., 2001; Nielsen, 2006; Hsu and Raubenheimer, 2006; Gonzalez-Rodriguez and Madsen, 2011]. Variation of the choice of roughness within this wide range leads to changes in the estimate of the shear stresses by up to an order of magnitude, and is a major source of uncertainty in this analysis.

The near-bed shear stresses are expected to vary substantially from the shallow sides to the deep center of the hole, as wave near-bed velocities may decrease over the deeper part of the hole, leading to smaller wave shear stresses. In addition, mean currents may slow as they flow over the deeper water in the holes, also leading to smaller stresses. Separation effects also may be important, but are not considered here. To account for the deeper water in the holes, the average shear stresses in the hole (Figure 2.3B) were approximated by multiplying the representative shear stresses estimated at the sensors on the shallow sides of the holes by the ratio of the water depth on the shallow side to the water depth at one half of the maximum hole depth (ratios ranged from 0.5 to 0.9 ) raised to the three-halves power. Results for the representative shear stress in the holes are similar to those using approaches that treat wave near-bed velocity evolution (wave stress reduced by the ratio of water depths to the three-halves power, green curves in Figure 
2.3B) and flow divergence (mean stress reduced by the ratio of the water depths squared, grey curves in Figure 2.3B) separately.

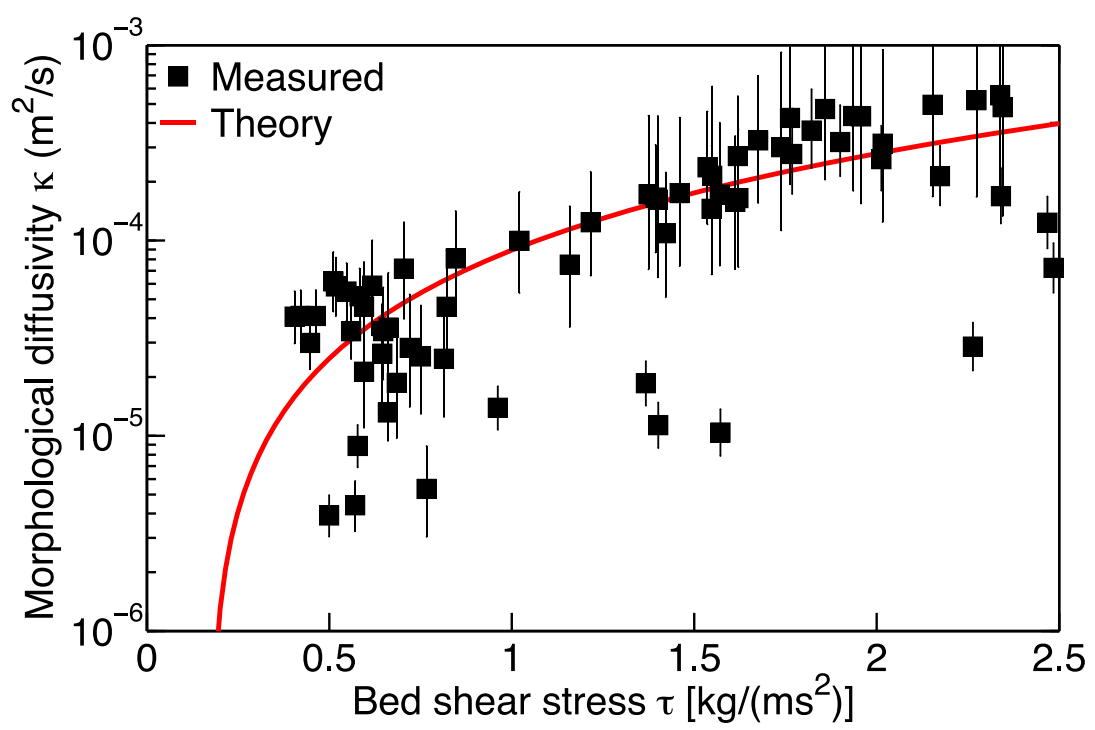

Figure 2.4. Morphological diffusivity $\left(\mathrm{m}^{2} / \mathrm{s}\right)$ versus representative shear stress $\left[\mathrm{kg} /\left(\mathrm{ms}^{2}\right)\right]$ for measurements (black squares, error bars are $95 \%$ confidence intervals, also see Figure 2.3C) and for a fit of the observed values to a bedload transport theory (Equation 2.6, with a best fit $A=24$, giving $r=0.73$ ) (red curve).

\subsection{Results and discussion}

The average representative shear stress estimates (blue curves in Figure 2.3B) were used in Equation 2.6 with $A=12$ [Soulsby and Damgaard, 2005] to model theoretical bedload morphological diffusivities (red circles in Figure 2.3C) for the same time windows used for the observationally inferred diffusivities (black squares in Figure 2.3C). The modeled morphological diffusivity is correlated with the morphological diffusivity inferred from data (compare red circles with black squares in Figure 2.3C). In addition, the time series of modeled diffusivities were used to predict the evolution (beginning with the initial Gaussian fit) of the depth of the holes (red curves in Figure 2.3A). The modeled diffusivity skillfully predicts the observed change in the seafloor elevation in the center of the holes as they fill (compare red with black curves in Figure 2.3A). Both observed and modeled diffusion coefficients are of order $10^{-5}$ to $10^{-3} \mathrm{~m}^{2} / \mathrm{s}$ (Figure $2.3 \mathrm{C}$ ), implying diffusive evolution time scales of hours to weeks for features with length scales of order $10 \mathrm{~m}$. The holes filled most rapidly (and the measured and modeled diffusivities were 
largest) when shear stresses were larger. For example (see Figure 2.3), Hurricane Danielle passed offshore beginning near day 1 of the first hole, a Nor'easter produced large offshore waves near day 0.5-1.5 of the second hole, and Hurricane Igor passed offshore beginning near day 0.5 for the fourth hole. The observationally inferred diffusivities (black squares in Figure 2.3C and Figure 2.4) are consistent with bedload transport theory (Equation 2.6) in which the diffusivity is proportional to the three-halves power of the shear stress (red curve in Figure 2.4). The representative shear stress (x-axis in Figure 2.4) was averaged over the same time windows as the observed diffusivities, and the data were fit to the theoretical relationship (Equation 2.6) (red curve in Figure 2.4 ), where $A$ is the fit parameter, yielding $A=24$ (correlation $r=0.73$ ).

While the observations are consistent with the bedload transport theory, there is some disagreement between the measured and modeled diffusivities and between the coefficient $A$ fit to the observations $(A=24)$ and used in theory [e.g., $A=12$, derived in Soulsby and Damgaard, 2005; see Amoudry and Souza, 2011 for a review]. The correlations for fits of the observed diffusivities to the theoretical relationship (Equation 2.6) are similar for a wide range of roughness heights (used to estimate the shear stress), while the coefficient $A$ varies substantially. For $k_{n}=d_{50}, r=0.70$ and $\mathrm{A}=65$. For $k_{n}=$ $11 d_{50}, r=0.73$ and $\mathrm{A}=24$. For $k_{n}=35 d_{50}, r=0.74$ and $\mathrm{A}=14$. The diffusivity in (6) varies approximately as $\kappa \propto \tau_{r}^{3 / 2}$ (the correlation does not change significantly when $\tau_{c r}$ is set to 0 , but $\tau_{c r}$ is retained in Equation 2.6 for better agreement with diffusivities observed at low shear stresses). However, the diffusivity may vary with a different power of the shear stress, e.g., at high shear stresses when suspended load may be significant and a higher-power dependence is expected [Bailard, 1981], or for other theoretical relationships that predict a lower shear stress dependence [Chen et al., 2010]. For the diffusivities inferred here, the correlation for the relationship $\kappa \propto \tau_{r}^{B}$ is maximum near $B$ $=3 / 2(r=0.73)$ and decreases to approximately $80 \%$ of the maximum at $B=1 / 2(r=$ $0.57)$ and $B=3(r=0.59)$, suggesting that the observations are consistent with Equation 2.6 and that more of the variance is explained by $B=3 / 2$ than by lower or higher powers. In addition, there are errors in the modeled morphological diffusivity associated with the choice of a constant roughness height (variations in the roughness height with changes in 
the shear stress were not considered), with the shear stress variation with depth across the hole, and with neglected possible separation effects. The inferred morphological diffusivity also has errors associated with the bathymetric sampling, deviations from the Gaussian approximation, and changes in the ambient bed elevation (accretion or erosion of the surrounding seafloor).

In some instances, particularly when the mean shear stress is large and spatially variable or if wave orbital velocities are highly asymmetrical, the divergence of the flat-bed transport may become important. For example, trenches have been observed to migrate owing to diverging tidal currents [van de Kreeke et al., 2002], sandbars migrate offshore during storms owing to diverging "undertow" currents [Thornton et al., 1996; Gallagher et al., 1998], and the onshore migration of sandbars between storms may be driven by asymmetrical wave orbital velocities [Elgar et al., 2001; Hoefel and Elgar, 2003]. Here, however, migration of the holes [which could lead to an overestimate of the diffusivity if the center (deepest part) of the hole moved away from the altimeter] was not observed by divers or in surveys. Unlike larger-scale features (e.g., 50-m wide, 100-m long rip channels) that may migrate or change shape owing to feedback between spatially varying waves, currents, and bathymetry, the 10-m diameter holes did not appear to impact the surrounding circulation in a way that led to large-scale morphological change. Instead, the results here suggest that for these steep, relatively small-scale features, downslope sediment transport is the dominant process in the hole evolution.

Despite uncertainty in the bed level and shear stress observations, the morphological diffusivity inferred from the excavated holes is consistent with a bedload transport theory in which the diffusivity scales with the bed shear stress to the three halves power. The observations of infilling excavated holes provide the first opportunity to infer a morphological diffusivity in the surf zone, and suggest that for bathymetric features with large and changing slopes, downslope gravity-driven bedload sediment transport is important to morphological evolution. 


\subsection{Acknowledgments}

Data are available via e-mail to the corresponding author.

We thank the PVLAB field team and the staff of the US Army Corps of Engineers Field Research Facility, Duck, NC for excellent field support, and in particular Brian Scarborough for excavating ordinance-laden sediments in the surf without getting the backhoe too wet and without blowing up anything (or anyone). Funding was provided by the Assistant Secretary of Defense for Research and Engineering, a National Defense Science and Engineering Graduate Fellowship, a National Science Foundation Graduate Research Fellowship, and the Office of Naval Research. The authors thank two anonymous reviewers for their helpful comments in improving this paper.

The Editor thanks two anonymous reviewers for their assistance in evaluating this paper. 


\subsection{References}

Amoudry, L. O., and A. J. Souza (2011), Deterministic coastal morphological and sediment transport modeling: A review and discussion, Rev. Geophys., 49, RG2002, doi:10.1029/2010RG000341.

Aubrey, D. G. (1979), Seasonal patterns of onshore/offshore sediment movement, $J$. Geophys. Res., 84(C10), 6347-6354, doi:10.1029/JC084iC10p06347.

Bagnold, R. A. (1966), An approach to the sediment transport problem from general physics, U.S. Geol. Surv. Prof. Paper, 422, 231-291.

Bailard, J. A. (1981), An energetics total load sediment transport model for a plane sloping beach, J. Geophys. Res., 86, 10938-10954, doi:10.1029/JC086iC11p10938.

Caballeria, M., G. Coco, A. Falqués, and D. Huntley (2002), Self-organization mechanisms for the formation of nearshore crescentic and transverse sand bars, $J$. Fluid Mech., 465, 379-410. doi:10.1017/S002211200200112X.

Calvete, D., N. Dodd, A. Falqués, and S. van Leeuwen (2005), Morphological development of rip channel systems: Normal and near-normal wave incidence, $J$. Geophys. Res., 110, C10006, doi:10.1029/2004JC002803.

Chen, X., J. Ma, and S. Dey (2010), Sediment transport on arbitrary slopes: Simplified model, J. Hydraul. Eng., 136(5), 311-317, doi:10.1061/(ASCE)HY.19437900.0000175 .

Clark, D. B., F. Feddersen, and R. T. Guza (2010), Cross-shore surfzone tracer dispersion in an alongshore current, J. Geophys. Res., 115, C10035, doi:10.1029/2009JC005683.

Dean, R. (1991), Equilibrium beach profiles: Characteristics and applications, J. Coastal Res., 7, 53-84.

Dohmen-Janssen, C., W. Hassan, and J. Ribberink (2001), Mobile-bed effects in oscillatory sheet flow, J. Geophys. Res., 106(C11), 27103-27115, doi:10.1029/2000JC000513.

Douglass, S. L. (1995), Estimating landward migration of nearshore constructed sand mounds, J. Waterway, Port, Coastal, Ocean Eng., 121, 247-250.

Elgar, S., E. L. Gallagher, and R. T. Guza, (2001), Nearshore sandbar migration, J. Geophys. Res., 106, 11,623-11,627, doi:10.1029/2000JC000389.

Falqués, A., G. Coco, and D. A. Huntley (2000), A mechanism for the generation of wave-driven rhythmic patterns in the surf zone, J. Geophys. Res., 105(C10), 24071-24088. 
Feng, Z., A. Reniers, B. K. Haus, and H. M. Solo-Gabriele (2013), Modeling sedimentrelated enterococci loading, transport, and inactivation at an embayed nonpoint source beach, Water Resour. Res., 49(2), 693-712, doi:10.1029/2012WR012432.

Fredsøe, J., and R. Deigaard (1992), Mechanics of Coastal Sediment Transport, Adv. Ser. on Ocean Eng., vol. 3. World Scientific, Singapore.

Gallagher, E., S. Elgar, and R. Guza (1998), Observations of sand bar evolution on a natural beach, J. Geophys. Res., 103, 3203-3215, doi:10.1029/97JC02765.

Garnier, R., D. Calvete, A. Falqués, and M. Caballeria (2006), Generation and nonlinear evolution of shore-oblique/transverse sand bars, J. Fluid Mech., 567, 327-360.

Garnier, R., D. Calvete, A. Falqués, and N. Dodd (2008), Modelling the formation and the long-term behavior of rip channel systems from the deformation of a longshore bar, J. Geophys. Res., 113(C7), doi:10.1029/2007JC004632.

Garnier, R., A. Falqués, D. Calvete, J. Thiébot, and F. Ribas (2013), A mechanism for sandbar straightening by oblique wave incidence, Geophys. Res. Lett., 40, 1-5.

Gonzalez-Rodriguez, D., and O. S. Madsen (2011), Boundary-layer hydrodynamics and bedload sediment transport in oscillating water tunnels, J. Fluid. Mech., 667, 4884.

Grant, W. D., and O. S. Madsen (1986), The continental-shelf bottom boundary layer, Ann. Rev. Fluid Mech., 18(1), 265-305.

Henderson, S., J. Allen, and P. Newberger (2004), Nearshore sandbar migration predicted by an eddy-diffusive boundary layer model, J. Geophys. Res., 109, C06024, doi:10.1029/2003JC002137.

Hoefel, F., and S. Elgar (2003), Wave-induced sediment transport and sandbar migration, Science, 299, 1885-1887, doi:10.1126/science.1081448.

Hsu, T.-J., and B. Raubenheimer (2006), A numerical and field study on inner-surf and swash sediment transport, Cont. Shelf Res., 26(5), 589-598. doi:10.1016/j.csr.2006.02.004.

Hsu, T.-J., S. Elgar, and R. Guza (2006), Wave-induced sediment transport and onshore sandbar migration, Coastal Eng., 53, 817-824, doi:10.1016/j.coastaleng.2006.04.003.

Jumars, P. A., and A. R. Nowell (1984), Fluid and sediment dynamic effects on marine benthic community structure, Am. Zool., 24(1), 45-55.

Kovacs, A., and G. Parker (1994), A new vectorial bedload formulation and its application to the time evolution of straight river channels, J. Fluid Mech., 267, $153-183$. 
Ledwell, J., A. Watson, and S. Law (1998), Mixing of a tracer in the pycnocline, $J$. Geophys. Res., 103, 21499-21529, doi:10.1029/98JC01738.

MacMahan, J., E. Thornton, A. Reniers, T. Stanton, and G. Symonds (2008), Low-energy rip currents associated with small bathymetric variations, Mar. Geol., 255, 156164.

Madsen, O. S. (1994), Spectral wave-current bottom boundary layer flows, Proc. Int'l. Conf. Coastal Eng. 1(24), doi:10.9753/icce.v24.

Meyer-Peter, E., and R. Müller (1948), Formulas for bed-load transport, in Proc. Second Meeting International Association Hydraulic Structures Research, pp. 39-64, IAHR, Stockholm, Sweden.

Moulton, M., S. Elgar, and B. Raubenheimer (2014), Improving the time resolution of surfzone bathymetry using in situ altimeters, Ocean Dyn., 64(5), 755-770, doi:10.1007/s10236-014-0715-8.

Nielsen, P. (1992), Coastal Bottom Boundary Layers and Sediment Transport, Adv. Seri. on Ocean Eng., vol. 4. World Scientific, Singapore.

Nielsen, P. (2006), Sheet flow sediment transport under waves with acceleration skewness and boundary layer streaming, Coastal Eng., 53(9), 749-758.

Plant N., R. Holman, and M. Freilich (1999), A simple model for interannual sandbar behavior, J. Geophys. Res., 104, 15755-15776, doi:10.1029/1999JC900112.

Ribberink, J. (1998), Bed-load transport for steady flows and unsteady oscillatory flows, Coastal Eng., 34(1-2), 59-82.

Ruessink B., I. van Enckevork, K. Kingston, and M. Davidson (2000), Analysis of observed two- and three-dimensional nearshore bar behavior, Marine Geol., 169, $161-183$.

Shields, A. (1936), Application of similarity principles and turbulence research to bedload movement (translation of original German by W. P. Ott and J. C. van Uchelen, California Inst. Tech.), Mitteilungen der Preussischen Versuchsanstalt für Wasserbau und Schiffbau.

Soulsby, R. (1997), Dynamics of Marine Sands: A Manual for Practical Applications, Thomas Telford, London, UK.

Soulsby, R. L., and J. S. Damgaard (2005), Bedload sediment transport in coastal waters, Coastal Eng., 52(8), 673-689, doi:10.1016/j.coastaleng.2005.04.003.

Thornton, E., R. Humiston, and W. Birkemeier (1996), Bar/trough generation on a natural beach, J. Geophys. Res., 101(C5), 12097-12110, doi:10.1029/96JC00209. 
Trowbridge, J., and D. Young (1989), Sand transport by unbroken water-waves under sheet flow conditions, J. Geophys. Res., 94(C8), 10971-10991.

van de Kreeke, J., S. Hoogewoning, and M. Verlaan (2002), An analytical model for the morphodynamics of a trench in the presence of tidal currents, Cont. Shelf Res., 22(11-13), 1811-1820, doi:10.1016/S0278-4343(02)00039-0.

van Enckevort, I., and B. Ruessink (2003), Video observations of nearshore bar behaviour. Part 2: Alongshore non-uniform variability, Cont. Shelf Res., 23, 513532. 


\title{
Chapter 3
}

\section{Improving the time resolution of surfzone bathymetry using in situ altimeters ${ }^{1}$}

\begin{abstract}
Surfzone bathymetry often is resolved poorly in time because watercraft surveys cannot be performed when waves are large, and remote sensing techniques have limited vertical accuracy. However, accurate high-frequency bathymetric information at fixed locations can be obtained from altimeters that sample nearly continuously, even during storms. A method is developed to generate temporally and spatially dense maps of evolving surfzone bathymetry by updating infrequent spatially dense watercraft surveys with the bathymetric change measured by a spatially sparse array of nearly continuously sampling altimeters. The update method is applied to observations of the evolution of shoreperpendicular rip current channels (dredged in Duck, NC, 2012) and shore-parallel sandbars (observed in Duck, NC, 1994). The updated maps are compared with maps made by temporally interpolating the watercraft surveys, and with maps made by spatially interpolating the altimeter measurements at any given time. Updated maps of the surfzone rip channels and sandbars are more accurate than maps obtained by using either only watercraft surveys or only the altimeter measurements. Hourly altimeter-updated bathymetric estimates of five rip channels show rapid migration and infill events not resolved by watercraft surveys alone. For a two-month observational record of sandbars, altimeter-updated maps every 6 hours between nearly daily surveys improve the time resolution of rapid bar-migration events.
\end{abstract}

\footnotetext{
${ }^{1}$ This chapter is the accepted version of the following article: Moulton, M., S. Elgar, and B. Raubenheimer (2014), Improving the time resolution of surfzone bathymetry using in situ altimeters, Ocean Dynamics, 64(5), 755-770. The final publication is available at Springer via http://dx.doi.org/10.1007/s10236-014-0715-8. Used with permission as granted in the original copyright agreement.
} 


\subsection{Introduction}

Surfzone bathymetry controls wave shoaling, refraction, and breaking, and consequently affects wave-driven setup, nearshore currents, and the transport of nutrients, biota, and sediment. On energetic sandy coastlines, the seafloor can evolve dramatically within several hours. Cusps and channels associated with rip currents [Chen et al., 1999; Haller et al., 2002; MacMahan et al., 2006; Austin et al., 2010; Dalrymple et al., 2011; and many others] migrate and flatten quickly in the presence of wave-driven alongshore flows [Falqués et al., 2000; van Enckevort and Ruessink, 2003; Garnier et al., 2013], and sandbars migrate rapidly offshore during storms [Thornton et al., 1996; Gallagher et al., 1998a; Hsu et al., 2006; and many others]. Nearshore hydrodynamic model results are sensitive to bathymetry [Plant et al., 2002; Plant et al., 2009], and often the largest model errors are associated with poor temporal resolution of bathymetric changes [Wilson et al., 2010]. Obtaining surfzone bathymetry with sufficient spatial and temporal sampling for developing, testing, and improving models, especially during energetic conditions, is challenging.

Watercraft with surveying equipment are used to map the surfzone seafloor with high spatial resolution [Birkemeier and Mason, 1984; MacMahan, 2001; Dugan et al., 2001; Lippmann and Smith, 2008], but these techniques usually are restricted to calm conditions preceding and following storms, and thus the temporal evolution of the largest bathymetric changes is not resolved well. During times when waves and bubbles prevent watercraft surveys, observations of evolving bathymetry may be obtained by remote sensing techniques [Holman and Haller, 2013]. By taking advantage of the depthdependence of wave speed and dissipation [van Dongeren et al., 2008; Holman et al., 2013] and by assimilating in situ observations [Wilson et al., 2010; Birrien et al., 2013], video observations may be used to estimate bathymetry at low cost and with reasonable vertical accuracy (roughly $0.5 \mathrm{~m}$ ) [Holman and Haller, 2013], which has allowed for long-term monitoring of changes in the position of nearshore sand bars and rip current channels [Lippmann and Holman, 1989; Holman et al., 1993; Holland et al., 1997; Ruessink et al., 2000; van Enckevort et al., 2004; Holman et al., 2006; Gallop et al., 2011; and many others]. However, remotely sensed bathymetric inversion techniques 
usually are limited to timescales of several days or longer and to spatial scales of $10 \mathrm{~m}$ or greater [van Dongeren et al., 2008; Holman et al., 2013], and for some studies video observations may not be available or may not provide sufficient vertical accuracy.

In contrast, in situ altimeters provide accurate, nearly continuous estimates of the distance between the sensor and the seafloor [Gallagher et al., 1996; Gallagher et al., 1998a; Gallagher et al., 1998b]. Usually, altimeters are deployed at a limited number of locations, and thus may not resolve the spatial structure of the seafloor evolution, while watercraft surveys offer good spatial resolution, but at a limited number of times. Combining the two data sets should produce higher temporal resolution maps of the seafloor than obtained with infrequent spatially dense watercraft surveys, and higher spatial resolution maps than obtained with spatially sparse altimeters. Data with irregular sampling and errors may be combined with interpolation and mapping techniques [Ooyama, 1987; Plant et al., 2002] and data assimilation methods [van Dongeren et al., 2008; Holman et al., 2013; Wilson et al., 2010; Birrien et al., 2013]. Here, a method is presented that seeks an accurate estimate of a spatially smoothed bathymetry by updating spatially dense watercraft surveys with temporally continuous, spatially sparse altimeter estimates of seafloor elevation change. The method is tested for two datasets that span a wide range of variability in the surf zone, including observations of migrating and filling shore-perpendicular rip channels dredged on a sandy ocean beach near Duck, NC in 2012, and observations of a migrating shore-parallel sandbar near Duck, NC in 1994. The methods used for measuring (Section 3.2) and mapping (Section 3.3) surfzone bathymetry are described, and are tested and applied for the rip channel (Section 3.4) and sandbar (Section 3.5) datasets, and the results are discussed and summarized (Section 3.6).

\subsection{Direct estimation of seafloor location}

\subsubsection{Vehicle surveys}

Small personal watercraft can navigate effectively in shallow water under moderate waves, and when equipped with GPS and bottom-finding sonar can be used to map surfzone bathymetry [MacMahan, 2001; Dugan et al., 2001; Lippmann and Smith, 2008]. 
A jetski (waverunner) was used in the 2012 Duck, NC experiment discussed in Section 3.4. Typically, watercraft surveys are performed along cross- and alongshore tracks, with spacing between tracks and sample density along tracks dependent on the experimental design and survey system. The horizontal accuracy of differential GPS systems is about 0.25 to $0.50 \mathrm{~m}$. The vertical accuracy from individual bed-level estimates from acoustic pings is about 0.05 to $0.10 \mathrm{~m}$ (this includes $0.02-0.04 \mathrm{~m}$ errors in GPS vertical estimates, and 0.03-0.06 m errors in the estimate of the distance from the transducer to the bed, but does not include the effects of short-horizontal-scale features such as wave-orbital ripples and megaripples). Watercraft provide estimates of the seafloor location over a wide area in a relatively short time, but often are less effective in the surf zone because the approximately $10 \mathrm{~km} / \mathrm{hr}$ speed precludes averaging (at any one location) of many acoustic returns, some of which can be obscured by breaking-wave induced bubbles.

In contrast with acoustic systems that are degraded by bubbles, amphibious vehicles can be used to map the seafloor even in an active surf zone. For the 1994 Duck, NC experiment described in Section 3.5, the CRAB, a tall three-wheeled vehicle that is tracked with a laser survey system [Birkemeier and Mason, 1984] was used to map the seafloor. The CRAB operates from above the high-tide line to 8-m water depth in waves up to $2 \mathrm{~m}$ high, travels at up to $4 \mathrm{~km} / \mathrm{hr}$, has vertical accuracy of 0.03 to $0.10 \mathrm{~m}$, and has a horizontal resolution of roughly $8 \mathrm{~m}$ (the spacing between the wheels) [Birkemeier and Mason, 1984].

\subsubsection{Fixed Altimeters}

Fixed acoustic devices (altimeters) also may be used to find the seafloor [Gallagher et al., 1996]. Altimeters can be deployed during calm conditions, and continue to sample during large wave events when watercraft cannot operate. Moreover, by sampling relatively rapidly at one location, the acoustic returns from a fixed altimeter can be used to find the seafloor even if bubbles obscure the signal most of the time or if the transducer is coming in and out of the water in wave troughs at low tide. Altimeters have been used to investigate sandbar evolution [Gallagher et al., 1998a; Elgar et al., 2001; Hoefel and Elgar, 2003; Henderson et al., 2004; Hsu et al., 2006; and many others], 
bottom roughness [Feddersen et al., 2003; Gallagher et al., 2005], and bedforms [Gallagher et al., 1998b]. Although fixed altimeters can find the seafloor in the surf zone, it is difficult to deploy and maintain more than a few dozen instruments (resulting in limited spatial resolution) for more than a few months. Altimeter estimates of the seafloor location can be biased owing to survey errors in the vertical elevation of the acoustic transducers $(0.04-0.10 \mathrm{~m})$. In addition, there are randomly distributed errors owing to the finite bin size of the acoustic returns and to the algorithm used to detect the bottom in a time series of noisy acoustic returns.

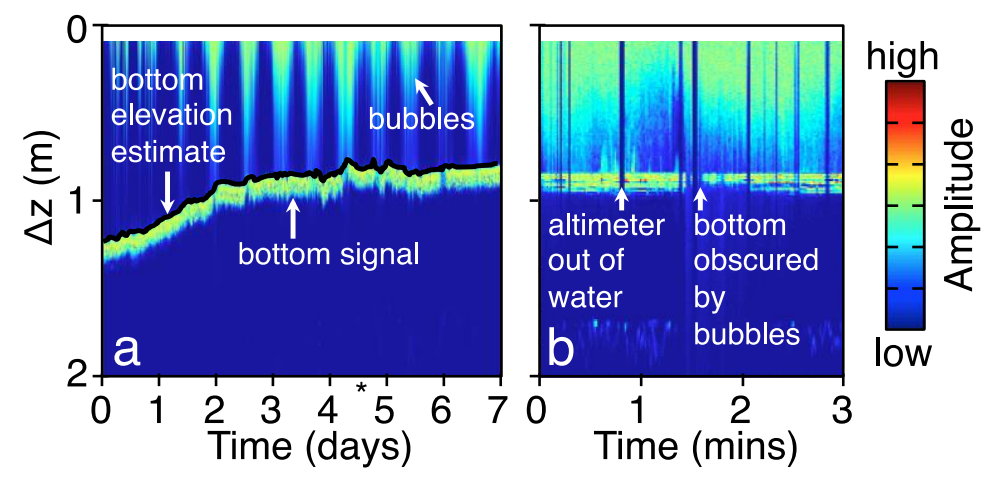

Figure 3.1. Amplitude of acoustic returns from the WHOI altimeter (color scale on right) as a function of depth below the altimeter $(\Delta z)$ and time for (a) 7 days (black curve is seafloor location) and (b) 3 minutes of data. The $*$ on the time axis of (a) (between time $=$ 4 and time $=5$ days) corresponds to the time of the time series in (b).

In the 2012 Duck, NC experiment, single-beam acoustic altimeters recently developed at the Woods Hole Oceanographic Institution (WHOI altimeter, $1 \mathrm{MHz}$ beam, $2 \mathrm{~Hz}$ echo amplitude averaged to $1 \mathrm{~min}, 0.01 \mathrm{~m}$ vertical bins) were used to monitor changes in the surfzone seafloor. During a performance test, a WHOI altimeter deployed on a pipe in the surf zone found the distance from the transducer to the bed (Figure 3.1) with roughly 0.05 $\mathrm{m}$ accuracy even in the presence of bubbles in a saturated surf zone (offshore significant wave height of $2.5 \mathrm{~m}$, surfzone wave height of $1.5 \mathrm{~m}$ ). Older versions of the altimeters (used in the 1994 Duck, NC experiment) performed well during large storms with offshore wave heights greater than $4.0 \mathrm{~m}$ [Gallagher et al., 1996; Gallagher et al., 1998a]. 
The backscatter strength from acoustic Doppler current profilers (ADCP) also may be used to find the seafloor. For example, a Nortek Aquadopp (three $2 \mathrm{MHz}$ beams, oneminute-average echo amplitude in $0.10 \mathrm{~m}$ bins averaged over the three beams) sampling in a saturated surf zone (during the 2012, Duck NC experiment) usually found the bottom within one bin [Moulton et al., 2013], although the bottom signal was weaker and less robust to bubbles than the signal from the faster-sampling WHOI Altimeter.

\subsection{Bathymetric mapping methods}

\subsubsection{Spatially dense watercraft surveys}

The time to complete a watercraft survey is short relative to the timescale of morphological evolution, and thus the bed-level estimates are treated as a snapshot of the bathymetry at time $t_{S}$, where $t_{S}$ is the time of the middle of the survey. At each survey time $t_{S}$, there is a spatially dense and irregularly sampled set of bed-level observations. The observations can be interpolated to form an estimate of the bathymetry $Z_{S}\left(x, y, t_{S}\right)$ at a set of regularly spaced spatial coordinates $(x, y)$. If multiple surveys are available, the time evolution of the bathymetry could be estimated by interpolating in both space and time to form at estimate of the bathymetry $Z_{S}(x, y, t)$ at a set of times $t$. Properties (e.g., smoothness, agreement with observations) of the mapped bathymetry $Z_{S}$ may be controlled by the choice of interpolation weights in space and time (see 3.7 Appendix).

For the watercraft survey data presented here, spatial interpolation weights are chosen with a scale-controlled objective mapping method [Ooyama, 1987; Plant et al., 1999] to account for unresolved features such as ripples and megaripples. The interpolation weights are found assuming a Gaussian covariance function with scales $L_{x}$ (in the crossshore) and $L_{y}$ (in the alongshore), a spatially and temporally uniform variance $V_{S}$ (the average variance estimated from all observations), and an observation error $\epsilon_{O}$. The observation error $\epsilon_{O}$ includes the measurement error in the bed level estimated by each acoustic return, plus the root-mean-square (rms) amplitude of features with length scales less than $L_{x}$ and $L_{y}$ (see 3.7 Appendix). For dense sampling (many observations within a radius $L_{x}$ or $L_{y}$ ), computation time may be reduced by binning the observations prior to 
mapping, where the error for each binned value is estimated assuming each bottom return is an independent bathymetric estimate. A mean beach slope (computed from all observations) is removed from the observations before mapping, and added back after mapping, such that the estimate approaches the mean profile far from observations (see 3.7 Appendix). The resulting maps are a smooth estimate of the bathymetry resolving scales greater than or equal to $L_{x}$ and $L_{y}$. A map of the estimated errors $\epsilon_{S}\left(x, y, t_{S}\right)$ is computed for each watercraft survey map (see 3.7 Appendix). The bathymetry at an arbitrary time $Z_{S}(x, y, t)$ can be estimated by linearly interpolating (inverse separation weighting, see 3.7 Appendix) between two surveys.

\subsubsection{Temporally dense altimeter bed levels}

Altimeters sample nearly continuously, providing temporally dense estimates of the seafloor location. At each altimeter location $\left(x_{A}, y_{A}\right)$, where $x_{A}$ and $y_{A}$ are the cross- and alongshore coordinates of the altimeter, there is an estimate of the bed level at a set of times. Interpolation is used to compute an estimate of the bathymetry $Z_{A}(x, y, t)$ on a regular grid $(x, y)$ at a set of times $t$, and properties of the bathymetric estimate are controlled by the choice of the interpolation weights, which are found with a scalecontrolled objective mapping method. To reduce computation time, the spatiotemporal interpolation is separated into two steps by assuming space-time separability of the covariance (effectively ignoring small and poorly constrained space-time interactions in the covariance between the widely separated altimeters) [Genton, 2007]. First, the altimeter bed levels are interpolated in time to yield $Z_{T}\left(x_{A}, y_{A}, t\right)$. The interpolation is performed assuming a Gaussian temporal covariance with timescale $T$, a spatially and temporally uniform variance $V_{T}$ (the average variance estimated from all observations, equal to $V_{S}$ ), and measurement rms error $\epsilon_{r m s}$ (the error in the estimate of the distance from the transducer to the bed plus the rms amplitude of unresolved scales). A linear trend is removed from the time series prior to interpolating, and added back after interpolating. If the timescale $T$ is chosen to be larger than the time between bed-level estimates and larger than the period of migrating bedforms, the temporal interpolation step leads to smoothed time series with rms error $\epsilon_{T}\left(x_{A}, y_{A}, t\right)<\epsilon_{r m s}$ owing to averaging over random measurement errors and migrating ripples. A bias error $\epsilon_{\text {bias }}$ 
(associated with measurements of the vertical elevation of the transducer) is added to the error estimate for the interpolated time series. Next, at each time, the time-interpolated bed-level estimates are interpolated in space assuming a Gaussian spatial covariance with scales $L_{x}$ and $L_{y}$, a spatially and temporally uniform variance $V_{A}$ (equal to $V_{S}$ ), and a measurement error $\epsilon_{T}\left(x_{A}, y_{A}, t\right)+\epsilon_{\text {bias }}$. A mean beach slope (computed from all observations) is removed from the observations before interpolation, and added back after interpolation, such that the estimate approaches the mean profile far from observations (see 3.7 Appendix). Ideally, altimeter arrays are designed such that sensors are spaced more densely than one half of the decorrelation scale of the features of interest, but logistical difficulties often lead to undersampling, and thus there are regions far from altimeters where insufficient bathymetric information is available (and interpolation weights approach zero). The spatial interpolation yields a set of maps $Z_{A}(x, y, t)$ and an error estimate $\epsilon_{A}(x, y, t)$.

\subsubsection{Update method for combining all observations}

At the times of surveys, it is expected that the spatially interpolated watercraft surveys are the best estimate of the bathymetry, because the maps made from the spatially dense survey data have smaller errors than the interpolated altimeter data. In between the survey times, the temporally interpolated surveys are a good estimate of bathymetry that changes roughly constantly in time. However, nearshore bathymetric evolution can be highly variable in time, including rapid and large changes during storms when watercraft surveying is not possible. The altimeter maps resolve variable (and rapid) rates of change, but have larger vertical errors than the survey maps, which have no bias and average bedlevel estimates over a small area. Alternatively, watercraft survey and altimeter bed-level estimates can be combined to create a single set of maps with known accuracy. One approach is to use space-time objective mapping [Bretherton et al., 1976; Ooyama, 1987; Rybicki and Press, 1992; Plant et al., 1999; Plant et al., 2002] of all the bed-level estimates. Here, an alternative approach is presented that "updates" infrequent watercraft surveys with altimeter data. The spatial pattern of seafloor change is estimated using altimeter data, and added to the mapped watercraft surveys to yield an updated bathymetric estimate at another time. Unlike space-time objective mapping, the maps 
made using the update method are equal to the spatially mapped surveys at the survey times, and by using the bed-level change estimated by altimeters, rather than the bed level itself, bias errors in the altimeter bed-level estimates are removed.

To implement the update method, first the bed-level change $C_{A}$ at each time $t$ before or after each survey time $t_{S}$ is estimated from the time-mapped altimeter time series:

$$
C_{A}\left(x_{A}, y_{A}, t_{S}, t\right)=Z_{A}\left(x_{A}, y_{A}, t\right)-Z_{A}\left(x_{A}, y_{A}, t_{S}\right) \quad \text { (Equation 3.1) }
$$

The error in the change signal $\epsilon_{C A}\left(x_{A}, y_{A}, t\right)$ is assumed to be equal to the error in the mapped time series, $\epsilon_{C A}\left(x_{A}, y_{A}, t\right)=\epsilon_{T}\left(x_{A}, y_{A}, t\right)$. Next, at each time, the change estimates are mapped in space assuming a Gaussian covariance with length scales $L_{x}$ and $L_{y}$, a spatially uniform variance $V_{C}$ [estimated from the change $C_{A}\left(x_{A}, y_{A}, t_{S}, t\right)$ between $t_{S}$ and $\left.t\right]$, and an observation error $\epsilon_{C A}$. No mean or trend is removed from $C_{A}\left(x_{A}, y_{A}, t_{S}, t\right)$ prior to mapping, so that the change signal estimate approaches zero far from observations. This process yields a gridded estimate of the change $C\left(x, y, t_{S}, t\right)$ since each survey with estimated errors $\epsilon_{C}\left(x, y, t_{S}, t\right)$.

Each mapped spatially dense survey is "updated" to other times by adding the mapped change:

$$
Z_{U}\left(x, y, t_{S}, t\right)=Z_{S}\left(x, y, t_{S}\right)+C\left(x, y, t_{S}, t\right)
$$

The error of the updated map is estimated as a sum of the errors of the survey and the change signal:

$$
\epsilon_{U}\left(x, y, t_{S}, t\right)=\epsilon_{S}\left(x, y, t_{S}\right)+\epsilon_{C}\left(x, y, t_{S}, t\right)
$$

The method described in Equation 3.2 "updates" a spatially dense survey either forward or backward in time to form an estimate of the bathymetry at another time. This method is referred to as the forward-backward update method.

When multiple dense surveys are available, a weighted-update method may be used. The bathymetry at each time $Z_{U W}(x, y, t)$ is computed as a weighted sum of the maps updated from each survey:

$$
Z_{U W}(x, y, t)=\sum_{t_{S}} W\left[Z_{S}\left(x, y, t_{S}\right)+C\left(x, y, t_{S}, t\right)\right]
$$


where $W$ are the weights. The errors are estimated as a weighted sum of the errors of the updated maps:

$$
\epsilon_{U W}(x, y, t)=\sum_{t_{S}} W\left[\epsilon_{S}\left(x, y, t_{S}\right)+\epsilon_{C}\left(x, y, t_{S}, t\right)\right] \quad \text { (Equation 3.5) }
$$

The weights chosen here are proportional to the time separation between the time of interest $t$ and the survey times $t_{S}$, with the weights for the surveys immediately preceding and following the time $t$ summing to one, and all other surveys weighted zero. For this choice of inverse distance weighting, the bathymetric estimate at survey times is equal to $Z_{S}\left(x, y, t_{S}\right)$. Between survey times, the bed-level estimate approaches the mapped altimeter bed-level estimate at time $t$ plus a weighted offset between the mapped altimeter bed-level estimates and the surveys at the nearest survey times (note that $\left.C\left(x, y, t_{S}, t\right) \approx Z_{A}(x, y, t)-Z_{A}\left(x, y, t_{S}\right)\right)$. The bathymetric estimate far (several times $L_{x}$ or $L_{y}$ ) from altimeters approaches a weighted sum of the surveys (note that the mapped $C\left(x, y, t_{S}, t\right)$ approaches zero far from the altimeters $)$.

\subsubsection{Method assessment}

In addition to comparing the estimated interpolation errors, the methods are tested by comparing the mapped estimates with an independent estimate of the true bathymetry. A mapped survey at a particular survey time is set aside as independent "ground truth" for the methods attempting to reconstruct the bathymetry at that time. Comparisons are made only in the region for which the surveys have errors below a specified threshold (in regions with poor survey coverage, the mapped survey may not be an accurate representation of the true bathymetry). At each time, the differences (at the set of spatial mapping coordinates) between the true bathymetry and a mapped bathymetric estimate are referred to as the "reconstruction residuals," and the rms residuals are referred to as the "reconstruction errors" $\epsilon_{R}$. The average reconstruction error over all comparisons is denoted $\overline{\epsilon_{R}}$. For the forward-backward update method (Equation 3.2), only one watercraft survey is used with the altimeters to estimate the bathymetry, and all other surveys are used as ground truth. For the weighted update method (Equation 3.4), as well as for temporally interpolating between two dense surveys, the ground truth survey is one that was obtained between two other surveys that are used to reconstruct the bathymetry at any time between them. Thus, any combination of three surveys can be used to test the 
weighted-update and the temporal-interpolation methods. The first and last surveys are used to estimate the bathymetry at the time of the middle survey, which is the ground truth.

\subsection{Rip channel bathymetric estimates}

\subsubsection{Overview of field observations and mapping of dredged rip channels}

The propellers from a Vietnam-era landing craft were used to dredge large shoreperpendicular channels in 1- to 3-m water depth on a long straight Atlantic Ocean beach at the US Army Corps of Engineers Field Research Facility near Duck, NC, USA. Five channels were dredged in July and August 2012 (Figure 3.2 shows two of the five channels). Pressure sensors colocated with current meters (both sampled at $2 \mathrm{~Hz}$ ) and current profilers (1-minute averages) were deployed near the bed in and outside of the channels (Figure 3.2), and bathymetric evolution was recorded by a watercraft survey system and altimeters. The channels were on average 2-m deep, 30-m wide in the alongshore, and 50-m long in the cross-shore. The ambient bathymetry was either a terrace (e.g., Figure 3.2c,d,e,f) or a small sandbar (0.5-1 m trough to crest) (e.g., Figure $3.2 \mathrm{a}, \mathrm{b}$ on the south side of the channel), and the average tidal range was $1 \mathrm{~m}$. Bedforms observed by divers and documented in detail for previous studies at this site included small wave ripples and larger-scale megaripples with heights of order 0.1-0.5 m (rms amplitude $\sim 0.1 \mathrm{~m}$ ), horizontal length scales of order 1-10 $\mathrm{m}$, and propagation speeds of 0.3-1.2 m/hr [Gallagher et al., 1998b; Gallagher et al., 2005]. Significant wave heights [4 times the standard deviation (std dev) of sea-surface-elevation fluctuations in the frequency $(f)$ band $0.05<f<0.30 \mathrm{~Hz}$ ] just offshore of the channels ranged from 0.5 to $1.5 \mathrm{~m}$ and wave directions [Kuik et al., 1988] ranged from approximately -35 to +35 degrees relative to shore normal. Both rip current circulation patterns $(0.1$ to $1.0 \mathrm{~m} / \mathrm{s}$ hour-averaged jet speeds) and alongshore flows over the channels $(0.1$ to $1.0 \mathrm{~m} / \mathrm{s}$ houraveraged speeds) were observed, and the bathymetry tended to evolve rapidly in response to the larger waves and stronger flows [Moulton et al., 2013].

Surveys were performed daily with a personal watercraft (waverunner) except when waves were too large for safe operations. The 24 personal watercraft surveys for the 5 
channel experiments (3 surveys each for the 2 channels shown in Figure 3.2, and 6 surveys each for the other 3 channels) spanned roughly $200 \mathrm{~m}$ in the alongshore (centered at the channels), and extended from the mean shoreline (surveys usually were performed at high tide) to about 100 to $200 \mathrm{~m}$ offshore [Moulton et al., 2013]. The 1- to 3-hr long surveys were conducted along cross- and alongshore oriented tracks, each separated by approximately $5 \mathrm{~m}$ with a sample every $0.1 \mathrm{~m}$ along each track.

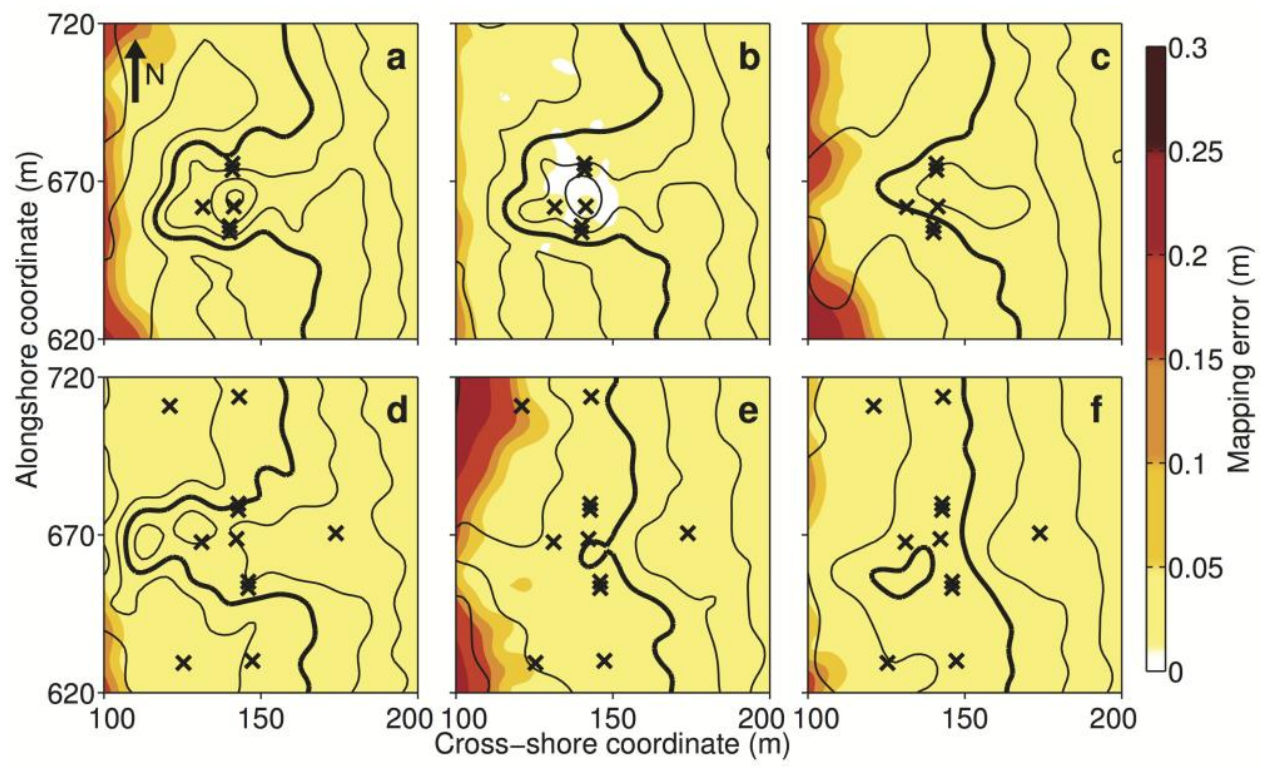

Figure 3.2. Contours of mapped water depth (relative to mean sea level, black curves every $0.5 \mathrm{~m}$ in depth, the thick curves are $-1.5 \mathrm{~m}$ ) and estimated interpolation errors (colors, scale on right) from watercraft surveys for channels dredged on 18 July (top row: a, b, c) and 24 July 2012 (bottom row: d, e, f) as a function of cross- and alongshore coordinate, with the shoreline on the left side of each panel and north toward the top. The survey times for the first dredged channel are (a) 18 July 18:00 EDT (shortly after dredging), (b) 20 July 10:00, and (c) 23 July 12:00. The survey times for the second dredged channel are (d) 24 July 12:00 (shortly after dredging), (e) 26 July 14:00, and (f) 27 July 15:00. Crosses show positions of altimeters, which were colocated with a pressure gauge and a current meter or current profiler. Three other dredged channels (not shown) had arrays similar to the channel dredged on 24 July (d, e, f). For all survey maps the errors usually are $0.01-0.05 \mathrm{~cm}$, except near the shoreline where the density of survey tracks (not shown) was reduced and errors are as great at $0.3 \mathrm{~m}$.

To study the coupled evolution of the channels and flows, the survey data were mapped (Figure 3.2) to a 2-m spatial grid $(x, y)$ spanning $100 \mathrm{~m}$ in the alongshore (centered at the channels) and $100 \mathrm{~m}$ in the cross shore (approximately from the mean shoreline to $3-\mathrm{m}$ 
water depth). The surveys were mapped as a deviation from an average linear beach slope for each channel location (average slopes found from a fit to all observations for each channel location ranged from 0.019 to 0.025 ). To speed the computations, raw survey data were averaged over $2 \times 2 \mathrm{~m}$ bins prior to mapping. The error in each bin is estimated as the sample error divided by the square root of the number of observations in the bin. The binned data were mapped using scale-controlled objective mapping with $L_{x}=L_{y}=$ $9 \mathrm{~m}, V_{S}=0.08 \mathrm{~m}^{2}$, and an observation error (prior to binning) of $\epsilon_{O}=0.20 \mathrm{~m}$. The decorrelation scales are found from Gaussian fits to the autocovariance of cross- and alongshore bathymetric profiles, and on average were $5 \mathrm{~m}$ in the cross-shore ( $\operatorname{std} \mathrm{dev}=2$ $\mathrm{m}$ ) and $6 \mathrm{~m}$ in the alongshore (std dev $=2 \mathrm{~m}$ ). Across the deepest channel cross-sections, the alongshore decorrelation scale is on average $9 \mathrm{~m}(\operatorname{std} \operatorname{dev}=2 \mathrm{~m})$. Here, $L_{x}=L_{y}=9$ $\mathrm{m}$ are used in the mapping to resolve the rip channels and smooth over smaller features (megaripple wavelengths may be 1-10 m). The variance $V_{S}$ is the average variance of the deviations of smooth bathymetric estimates from the mean beach slope (estimated using all observations). The observation error $\epsilon_{O}$ was chosen to account for vertical errors in the bed location $(0.10 \mathrm{~m})$ and for the amplitude of unresolved features $(0.10 \mathrm{~m} \mathrm{rms}$ bedform amplitude). The result is 24 bathymetric estimates (at the survey times) $Z_{S}\left(x, y, t_{S}\right)$ (Figure 3.2, contours) and a corresponding set of error estimates $\epsilon_{S}\left(x, y, t_{S}\right)$ (Figure 3.2, colors). The errors for the surveys are small $(\sim 0.02 \mathrm{~m})$ except near the shoreline where survey tracks are sparse or absent. An estimate of the bathymetry between survey times on a 1-hour time $(t)$ grid $\left[Z_{S}(x, y, t)\right]$ spanning the observational record was found using the temporal-inverse-distance weighting described in Section 3.1. The error in $Z_{S}(x, y, t)$ is expected to be equal to $\epsilon_{S}\left(x, y, t_{S}\right)$ at the survey times and increase quadratically with increasing time separation from surveys, and thus to become larger than the signal variance when more than one decorrelation time scale away from any survey [e.g., Mastroianni and Milovanović, 2008], but no formal error estimate is made here.

Estimates of the seafloor elevation were obtained every minute from an array of altimeters (as few as 3 and as many as 14 sensors) with roughly 5 to $30 \mathrm{~m}$ spacing centered at the channel (arrays for two channels are shown in Figure 3.2, the 3 channels 
not shown had 10-14 altimeters in an array similar to that shown in Figure 3.2d,e,f). The arrays were designed to resolve the flows and bathymetry in the rip channels [expected to have scales of $\mathrm{O}(10 \mathrm{~m})$ in the cross- and alongshore directions] and on the adjacent crossshore terrace and bar structure [expected to have scales of $\mathrm{O}(10 \mathrm{~m})$ in the cross-shore and scales of $\mathrm{O}(50 \mathrm{~m})$ or longer in the alongshore far from the channels]. Sensors were spaced most densely across the channels, where the flows and bathymetry were expected to vary most rapidly in space and time. Two types of acoustic altimeters were deployed. At most locations, the bed level was estimated with the single-beam acoustic altimeters recently developed at WHOI, and at a few locations the bed elevation was estimated using a downward-looking Nortek Aquadopp profiler mounted above the seafloor. The altimeter time series are mapped in time to the 1-hour grid $t$ with a scale-controlled objective mapping method with $T=6$ hours, $V_{T}=0.08 \mathrm{~m}^{2}$ (the average variance estimated from all observations), and measurement rms error $\epsilon_{r m s}=0.10 \mathrm{~m}$ (assumed the same for both types of altimeters). The timescale $T$ was chosen to resolve the fastest migration events, and is large enough to average over several periods of most migrating bedforms [although some bedforms may take as long as 36 hours to pass under each altimeter (Gallagher et al. 2005)]. The temporal mapping step led to smoothed time series with rms error $\epsilon_{T} \sim 0.013 \mathrm{~m}<\epsilon_{r m s}$. This error may be an underestimate if there are large megaripples (the analysis assumes that the observation errors are correlated on scales smaller than $T$, which is not the case for long, slow-moving bedforms). A bias error (error in the mean, owing to GPS and hand-measurement errors) $\epsilon_{\text {bias }}=0.10 \mathrm{~m}$ is added to the error estimate for each mapped altimeter time series. The time-mapped bed-level estimates are mapped in space (using the same grid as the mapped surveys) as a deviation from a linear beach slope (same as the slope removed in the mapped surveys) assuming a Gaussian spatial covariance with scales $L_{x}=L_{y}=9 \mathrm{~m}, V_{A}=0.08 \mathrm{~m}^{2}$, and measurement error $\left[\epsilon_{T}+\epsilon_{\text {bias }}\right] \sim 0.11 \mathrm{~m}$. The resulting maps $Z_{A}(x, y, t)$ have estimated errors $\epsilon_{A}(x, y, t)$ ranging from $\sim 0.1 \mathrm{~m}$ near the altimeter locations to $\sim 0.3 \mathrm{~m}$ far from the altimeters.

The survey and altimeter data are combined using the weighted-update method described in Section 3.3, yielding gridded ( $2 \mathrm{~m}, 1 \mathrm{hr})$ estimates of the bathymetry $Z_{U W}(x, y, t)$ and 
the associated error $\epsilon_{U W}(x, y, t)$. The weighted-update maps have errors that are equal to the survey errors at survey times $\epsilon_{U W}\left(x, y, t_{S}\right)=\epsilon_{S}\left(x, y, t_{S}\right)$, and are smallest near the altimeter locations at all other times. The size of the errors in the updated maps increases with time since a watercraft survey, and is scaled by the variance of the change since the nearest surveys. To test the update method, all possible forward-backward update maps $Z_{U}\left(x, y, t_{S}, t\right)$ (and the corresponding error estimate $\epsilon_{U}\left(x, y, t_{S}, t\right)$ ) (Equation 3.2, using each survey) and all testable weighted-update maps (Equation 3.4, using the first and third survey for all possible sets of three surveys) are computed. For comparison with the weighted-update maps, all testable time-interpolated surveys are computed.

\subsubsection{Assessment of rip channel maps}

The accuracy of maps made with watercraft surveys alone (Sect. 3.2), altimeters alone (Sect. 3.3), and surveys updated with altimeter-estimated change (Sect. 3.4) is assessed for the 24 watercraft surveys ( 3 surveys for each of 2 channels, and 6 surveys each for the other 3 channels) of evolving rip channels. First, the forward-backward updated maps are assessed and compared with the altimeter maps. Next, the weighted-update maps are assessed and compared with the forward-backward updated maps, the altimeter maps, and time-interpolation of surveys. The errors are computed in the region for which survey errors are smaller than $0.05 \mathrm{~m}$ (regions near the shoreline with large survey errors are excluded).

There are 51 pairs (and thus 102 test cases by going forward or backward in time) of temporally separated watercraft surveys, where one survey in the pair is used with Equation 3.2 to estimate the bathymetry at the time of the other survey, which is used as ground truth to test the estimate. In addition, bathymetry estimated from altimeter bed levels at the time of the ground truth survey was compared with the ground truth. The forward-backward updated maps have smaller average reconstruction errors $\left(\overline{\epsilon_{R, U}}=0.14\right.$ $\mathrm{m})$ than the altimeter maps $\left(\overline{\epsilon_{R, A}}=0.18 \mathrm{~m}\right)$. The average rms difference between the pairs of spatially dense surveys is $0.15 \mathrm{~m}$. 
There are 62 sets of three temporally separated watercraft surveys, where the first and third survey are used to estimate the bathymetry at the time of the second survey (the ground truth), using inverse-time weighting of the watercraft surveys or by updating with altimeter information either forward in time from the first survey ("forward updated map"), backward in time from the third survey ("backward updated map"), or a weighted combination (Equation 3.4). In addition, at the time of the second survey, an altimeterbased estimate of the bathymetry was compared with the second survey. The weightedupdate maps have average reconstruction errors $\left(\overline{\epsilon_{R, U W}}=0.08 \mathrm{~m}\right)$ that are smaller than errors in the forward and backward updated maps $\left(\overline{\epsilon_{R, U}}=0.12 \mathrm{~m}\right)$, the altimeterinterpolation maps $\left(\overline{\epsilon_{R, A}}=0.16 \mathrm{~m}\right)$, and temporal interpolation between surveys $\left(\overline{\epsilon_{R, S}}=\right.$ $0.09 \mathrm{~m}$ ). The average rms difference between final and initial spatially dense surveys is $0.19 \mathrm{~m}$.

As an example, the bathymetry surveyed on 26 July (Figure 3.3a) is estimated from a survey 2 days earlier (24 July 12:00, Figure 3.2d) and a survey 1 day later (27 July 15:00, Figure 3.2f) using the weighted-update (Equation 3.4) (Figure 3.3b) and altimeterinterpolation (Figure 3.3c) methods. The weighted-update map has smaller errors (Figure $3.3 \mathrm{~b}$, colors) than the altimeter-interpolation map (Figure 3.3c, colors). The rms change between the 24 and 27 July surveys was $0.29 \mathrm{~m}$ (Figure 3.3d). The average residuals (difference from the ground truth survey) for the updated map (Figure $3.3 \mathrm{e}$ ) $[0.11 \mathrm{~m}$, similar to the average estimated errors $(0.14 \mathrm{~m})$ for the updated map] are smaller than the average residuals for the altimeter map (Figure 3.3f) $[0.21 \mathrm{~m}$, similar to the average estimated errors $(0.26 \mathrm{~m})$ for the altimeter map]. The spatial pattern of the residuals (Figure 3.3e,f, colors) is not consistent with the error estimate (Figure 3.3b,c, colors), likely because the bathymetry varies more rapidly in time (Figure 3.3d) and space (Figure 3.3a, compare relatively uniform shoals with the channel) near the channels and the shoreline than elsewhere, in contrast with the assumption of a uniform signal variance. The mapping methods and error estimates may be improved by estimating a non-uniform spatial variance (larger at the channel position). However, the channels migrate, and thus a non-uniform spatial variance that is accurate at one time may be a poor estimate at another time. 


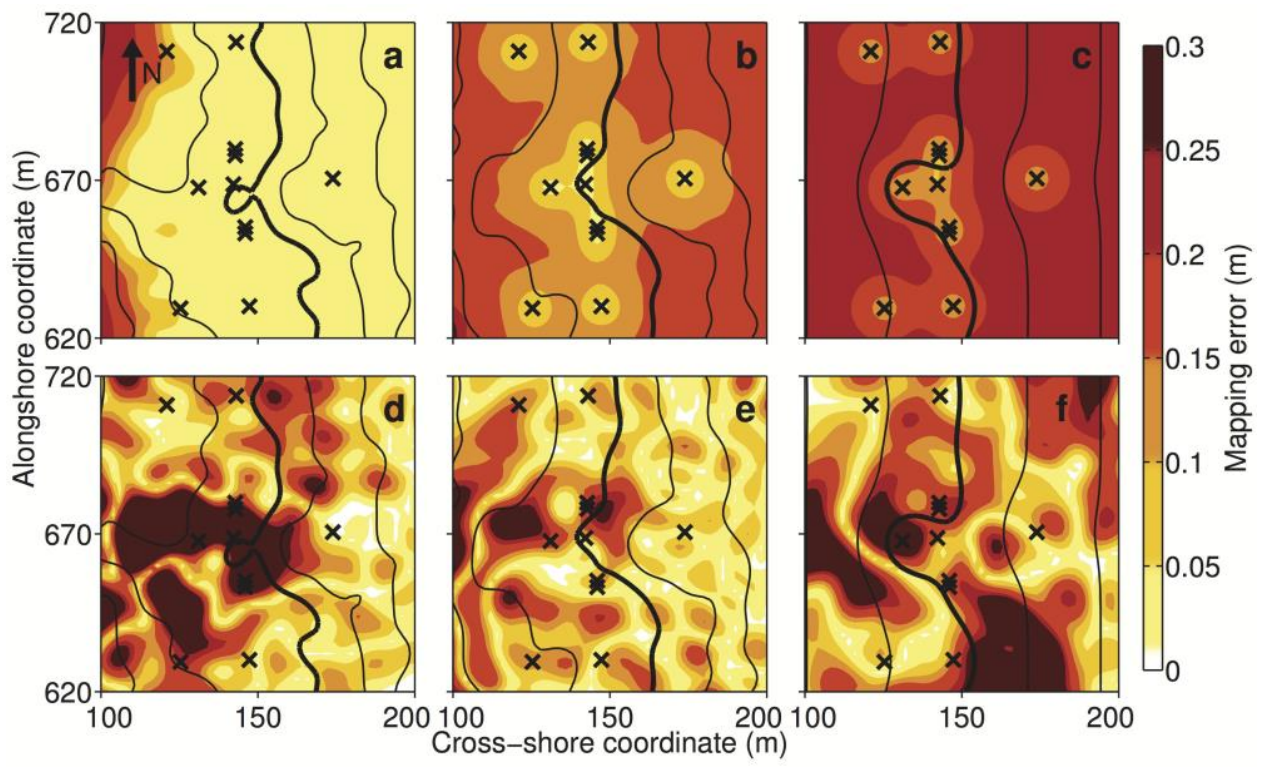

Figure 3.3. Contours of mapped water depth (relative to mean sea level, black curves every $0.5 \mathrm{~m}$ in depth, the thick contours are $-1.5 \mathrm{~m}$ ) and errors (colors, scale on right) on 26 July 14:00 for (a) a mapped watercraft survey, (b) a weighted-update map (surveys at 24 July 12:00 and 27 July 15:00 are used to form the estimate, see Figure 3.2d,f), and (c) an altimeter map. (d) The mapped watercraft survey on 26 July 14:00 (black contours) and the magnitude of change between the surveys on 24 July 12:00 and 27 July 15:00, and (e and $\mathrm{f}$ ) contours of water depth (black contours) and magnitude of residuals with the survey on 26 July 14:00 using (e) a weighted-update map and (f) an altimeter map. All maps are a function of cross- and alongshore coordinate, with the shoreline on the left side of each panel. Crosses show positions of altimeters.

To study the evolution of the channels with higher temporal resolution, channel crosssections (depth versus alongshore coordinate) are extracted from the two-dimensional maps (at the cross-shore coordinate nearest the densest cross-channel altimeter spacing) for each of the mapping methods, resulting in an estimate of the channel cross-section every hour for each channel and each method. The cross-sectional profiles may have different error statistics than the two-dimensional maps, because the sensor-spacing is denser on average, and the bathymetry may vary more rapidly in space and time for the cross-section of a deep section of the channel than for the full two-dimensional domain. Similar to the two-dimensional maps, the accuracy of the one-dimensional cross-section estimates was compared for time-interpolation of surveys, mapping of altimeter data, and the forward-backward and weighted-update methods. 
For the 51 pairs of temporally separated watercraft surveys (102 comparisons), the forward-backward updated maps have slightly smaller average reconstruction errors $\left(\overline{\epsilon_{R, U}}=0.17 \mathrm{~m}\right)$ than the altimeter maps $\left(\overline{\epsilon_{R, A}}=0.18 \mathrm{~m}\right)$. The average rms difference between final and initial spatially dense surveys is $0.20 \mathrm{~m}$. For the 62 sets of three temporally separated watercraft surveys, the weighted-update maps have average reconstruction errors $\left(\overline{\epsilon_{R, U W}}=0.10 \mathrm{~m}\right)$ that are smaller than the forward and backward updated maps $\left(\overline{\epsilon_{R, U}}=0.15\right)$, the altimeter maps $\left(\overline{\epsilon_{R, A}}=0.15 \mathrm{~m}\right)$, and the weighted surveys $\overline{\epsilon_{R, S}}=0.11 \mathrm{~m}$ ). The average rms difference between pairs of spatially dense surveys is $0.24 \mathrm{~m}$.

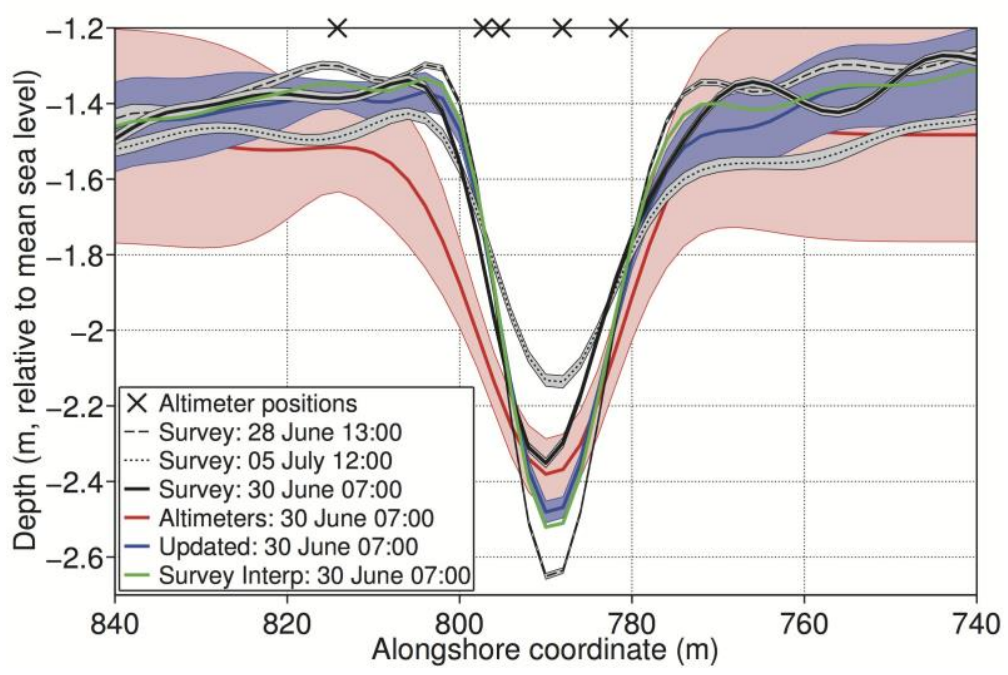

Figure 3.4. Depth of seafloor across the channel versus alongshore coordinate from watercraft surveys on 28 June 13:00 (black dashed curve), 30 June 07:00 (ground truth, solid black curve), and 5 July 12:00 (dotted black curve), and estimated for 30 June 07:00 using the weighted-update (blue curve), altimeter-interpolation (red curve), and timeinterpolation of the 28 June and 5 July surveys (green curve). Shaded areas are 1 std dev errors for the estimated bathymetries. Crosses show alongshore positions of altimeters.

The three methods (weighted-update, altimeter-interpolation, and time-interpolation of dense surveys) are used to reconstruct the bathymetry on 30 June (Figure 3.4). The survey on 30 June (Figure 3.4, solid black) has small errors (Figure 3.4, grey shading around black curve), and thus is a good representation of the true bathymetry. The surveys completed 28 June (Figure 3.4, dashed black curve) and 5 July (Figure 3.4, dotted black curve) are used with altimeter change estimates in the weighted-update 
method (Equation 3.4) to produce estimates of the bathymetry (Figure 3.4, blue curve) and associated errors (Figure 3.4, blue shading). Altimeter interpolation also is used to estimate the bathymetry on 30 June (Figure 3.4, red curve) and associated errors (Figure 3.4, red shading). Interpolating between the surveys on 28 June and 5 July (Figure 3.4, green curve) is similar to the weighted-update method (Figure 3.4, blue curve). The rms reconstruction error (rms difference with the survey on $30 \mathrm{June}$ ) for the weighted-update map is $0.07 \mathrm{~m}$ (similar to the average estimated error $0.08 \mathrm{~m}$ ), for the altimeter maps is $0.15 \mathrm{~m}$ (similar to the average estimated error $0.22 \mathrm{~m}$ ), and for the time-interpolation of surveys is $0.07 \mathrm{~m}$. The rms difference between the surveys on 28 June and 5 July is 0.21 $\mathrm{m}$.

\subsubsection{Application of update method to rip channel cross-section evolution}

The cross-sections of the hourly updated maps can be used to investigate the temporal evolution of the channels between the spatially dense surveys. For the channel dredged on 18 July, dense surveys show that the channel filled and moved northward (toward larger alongshore coordinate) between 20 and 23 July (Figure 3.2, compare panels b and c). However, these surveys do not resolve the higher-frequency temporal changes caused by the relatively large waves and rip current that were observed during the several days between dense surveys. In the absence of additional information, it must be assumed the bathymetry evolved uniformly between the times of the dense surveys. In contrast, the cross sections estimated by updating dense surveys with changes observed by the altimeters (Figure 3.5, grey curves are every 3 hours) indicate that the rates of channel infill and migration (Figure 3.6) varied non-uniformly in time. Gaussian fits to hourly updated cross sections are used as a proxy to determine the channel position (Figure 3.6a, usually within one grid cell of the location of the minimum of the profile) and channel depth (Figure 3.6b), and (not shown) channel width and ambient bed elevation. Confidence intervals (grey shading in Figure 3.6) are found from the distribution of parameters from a series of fits to 300 curves generated by summing the updated maps with random errors drawn from a Gaussian distribution with std dev given by the estimated mapping rms error. 


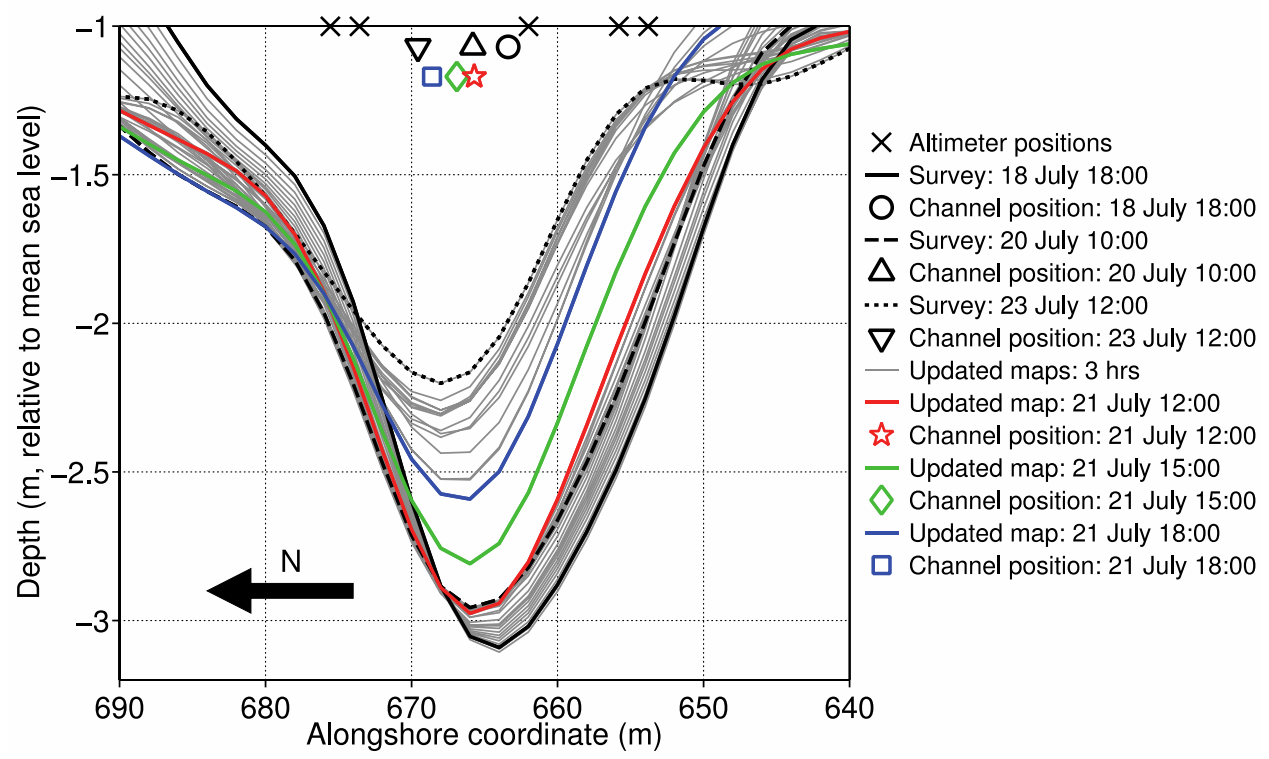

Figure 3.5. Depth of the seafloor across the channel versus alongshore coordinate. The solid black curve is the cross-section from the watercraft survey on 18 July 18:00, the dashed black curve is from the survey on 20 July 10:00, and the dotted black curve is from the survey on 23 July 12:00. Grey, red, green, and blue curves are cross sections using the weighted-update method every 3 hours between 18 July 18:00 and 23 July 12:00. The channel fills and migrates northward most rapidly on 21 July from 12:00 (red curve), through 15:00 (green curve), and until 18:00 (blue curve). Crosses at depth $=-1$ $\mathrm{m}$ are alongshore positions of altimeters, and the other symbols below the crosses are the alongshore position of the channel (estimated by fit to a Gaussian) for surveys (circle and triangles) and updated maps for 21 July 12:00 (red star), 15:00 (green diamond), and 18:00 (blue square).

Flows in the rip channel fluctuated with the tidal elevation, with the highest flows occurring near low tide when wave breaking was strongest on the shallow sides. When the channel center moved north of the mid-way point between the center and the northern sensor (Figure 3.6a, 21-23 July), the maximum measured offshore-directed flow (not shown) also moved north, from near the center of the channel $(y=662 \mathrm{~m})$ on 21 July to the northern edge of the channel $(\mathrm{y}=674 \mathrm{~m})$ [Moulton et al., 2013]. The channel filled by almost $1 \mathrm{~m}$ during the 27 hours that the channel center migrated north (from $21 \mathrm{July}$ 12:00 until 22 July 15:00, Figures 3.5 and 3.6). Significant wave heights just offshore of the channel were between 0.5 and $1.0 \mathrm{~m}$, and wave directions were within $15^{\circ}$ of shore normal between 21 July 15:00 and 22 July 06:00, but were more obliquely incident (roughly $35^{\circ}$ from the south) during the previous and following 24 hours. The channel 
may have migrated owing to alongshore divergences in sediment transport by alongshore flows over the channel, and the coupled morphologic and hydrodynamic changes will be the subject of a future study.
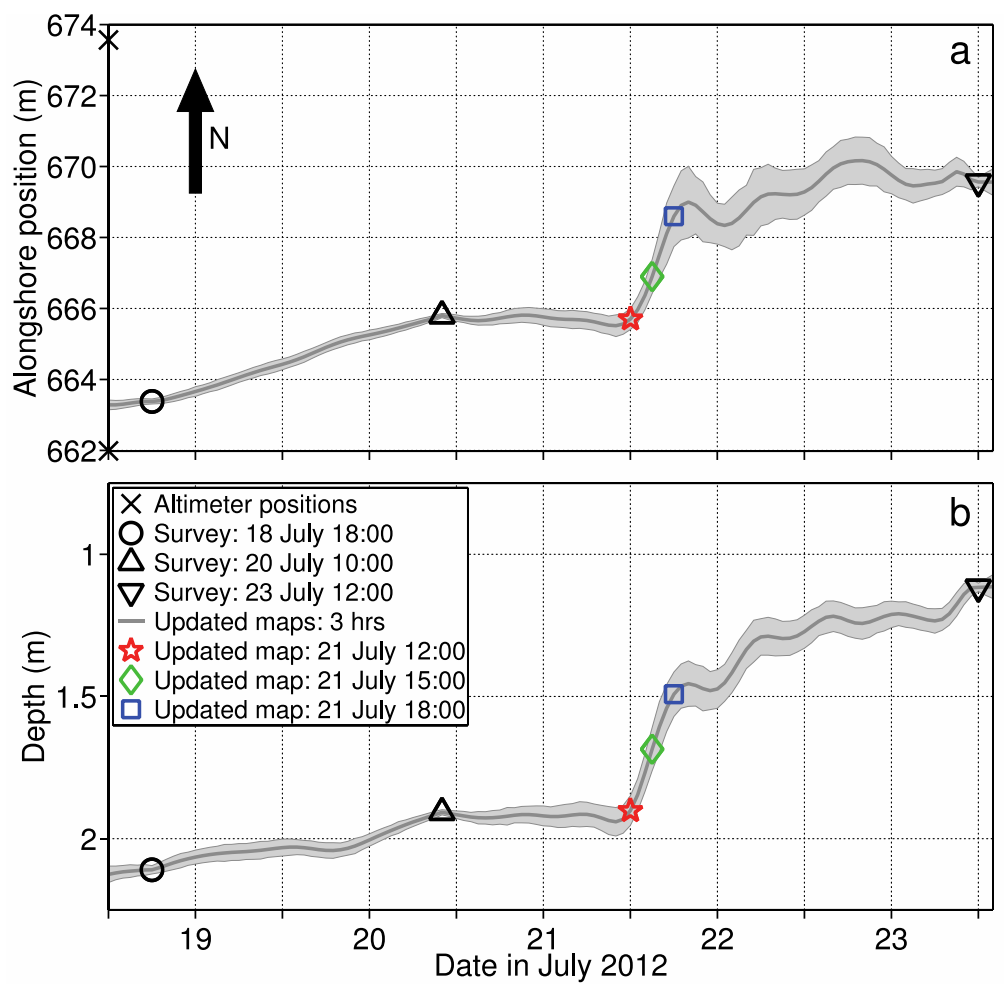

Figure 3.6. (a) Alongshore position of the channel center and (b) channel depth based on altimeter-updated cross sections (curves with shaded 95\% confidence interval) and watercraft surveys (circles and triangles) versus time (date in July, labeled tick marks at 00:00). Crosses on the $y$-axis in (a) show alongshore positions $(y=662$ and $y=674 \mathrm{~m})$ of the two nearest altimeters. The most rapid change in the channel (infill and northward migration, found from Gaussian fits, also see Figure 3.5) occurred beginning 21 July from approximately 12:00 (red star), through 15:00 (green diamond), until 18:00 (blue square).

\subsection{Sandbar profile estimates}

\subsubsection{Overview of field observations and mapping of natural sandbars}

To investigate sandbar migration, 24 spatially dense cross-shore bathymetry profiles were obtained with the CRAB survey system [Birkemeier and Mason, 1984] between 25 August and 26 October 1994 at Duck, NC [Thornton et al., 1996; Gallagher et al., 1998a; Birkemeier et al., 2001; and many others]. The surveys extended from above the high tide 
line to roughly 4-m water depth (Figure 3.7), with a sample approximately every $1 \mathrm{~m}$ along the cross-shore track. In addition, bed levels were estimated every 3 hours at 10 locations (crosses in Figure 3.7) along the transect with altimeters (similar to the WHOI Altimeters described in Sect. 2.2) [Gallagher et al., 1996; Gallagher et al., 1998a]. The altimeters were colocated with pressure and velocity sensors. The sensor locations were chosen based on estimates of the cross-shore variability of the nearshore processes investigated. Offshore significant wave heights ranged from 0.5 to $4.0 \mathrm{~m}$. The sandbar was 30 to $80 \mathrm{~m}$ wide, 0.5 to $1 \mathrm{~m}$ high, and migrated both onshore (e.g., Figure 3.7, between 7 and 30 September) and offshore (e.g., Figure 3.7, between 25 August and 7 September). The crest of the sandbar migrated more than $100 \mathrm{~m}$ in the cross-shore, between 1.5- and 2.5-m water depths (Figure 3.7). Bedforms included small wave-orbital ripples and megaripples with heights of order 0.1-0.5 $\mathrm{m}$ ( $\mathrm{rms}$ amplitude $\sim 0.1 \mathrm{~m}$ ), horizontal length scales of order 1-10 m, and propagation speeds of $0.3-1.2 \mathrm{~m} / \mathrm{hr}$ [Gallagher et al., 1998; Gallagher et al., 2005].

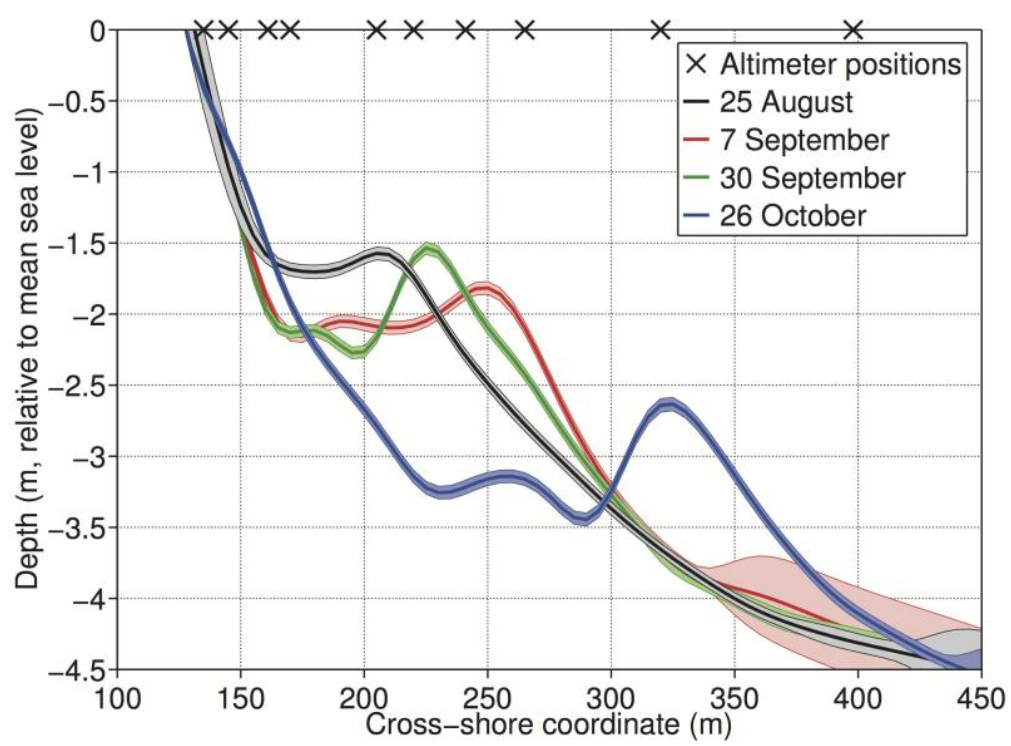

Figure 3.7. Depth of the seafloor (relative to mean sea level) versus cross-shore coordinate for spatially dense CRAB surveys (curves with shaded one std dev error estimates) for 25 August (black), 7 September (red), 30 September (green), and 26 October (blue) 1994. Crosses at depth $=0 \mathrm{~m}$ are cross-shore positions of altimeters.

The 24 CRAB surveys are mapped as a deviation from a smoothed mean profile (Plant et al. 1999) to a 5-m spatial grid $x$ spanning $350 \mathrm{~m}$ in the cross shore from $x=100 \mathrm{~m}$ to 
$x=450 \mathrm{~m}$. The data were mapped using scale-controlled objective mapping with $L_{x}=$ $17 \mathrm{~m}, V_{S}=0.10 \mathrm{~m}^{2}$, and an observation error of $\epsilon_{O}=0.20 \mathrm{~m}$. For cross-shore profiles, the alongshore coordinate $y$ is fixed. The decorrelation scales of the sandbars are found from Gaussian fits to the autocovariance of the bathymetric profiles, and on average were $17 \mathrm{~m}$ (std dev $7 \mathrm{~m}$ ), a scale that resolves the sandbar, while averaging over smaller features. The variance $V_{S}$ is the average variance of the deviations of smooth bathymetric estimates from the smoothed mean profile (estimated using all observations). The observation error $\epsilon_{O}$ was chosen to account for vertical errors in the bed location $(0.10 \mathrm{~m})$ and the amplitude of unresolved features $(0.10 \mathrm{~m}$ rms bedform amplitude). The result is 24 bathymetric estimates (at the survey times) $Z_{S}\left(x, t_{S}\right)$ (e.g., Figure 3.7, curves) and a corresponding set of error estimates $\epsilon_{S}\left(x, t_{S}\right)$ (e.g., Figure 3.7, shaded error bars). The errors $\left[\epsilon_{S}\left(x, t_{S}\right)\right]$ for the surveys are small $(\sim 0.05 \mathrm{~m}$, Figure 3.7$)$, except for a few cases when survey tracks did not fill the mapping domain and the estimate approaches the mean profile. In those cases the error is as large as, or larger than the signal variance (e.g., Figure 3.7, red shading near the most offshore $50 \mathrm{~m}$ of the 7 September survey). Bathymetry on a 6-hour time grid $t$ between survey times $\left[Z_{S}(x, t)\right]$ was estimated using the inverse-temporal weighting described in Section 3.1. The error in $Z_{S}(x, t)$ is expected to be equal to $\epsilon_{S}\left(x, t_{S}\right)$ at the survey times and to increase with increasing time separation from surveys [Mastroianni and Milovanović, 2008], but no formal error estimate is made here.

The altimeter time series are mapped to the 6-hour grid $t$ with a scale-controlled objective mapping method with $T=6$ hours, $V_{T}=0.10 \mathrm{~m}^{2}$ (the average variance estimated from all observations), and measurement rms error $\epsilon_{r m s}=0.10 \mathrm{~m}$. The timescale $T$ is short enough to resolve the fastest migration events, and is large enough to average over migrating bedforms. The temporal mapping step led to smoothed time series with smaller rms error $\epsilon_{T} \sim 0.03 \mathrm{~m}$. A bias error (error in the mean, owing to survey-equipment and hand-measurement errors) $\epsilon_{\text {bias }}=0.10 \mathrm{~m}$ is added to the error estimate for each mapped altimeter time series. The time-mapped bed-level estimates are mapped in space (using the same grid as the mapped surveys) as a deviation from a smoothed mean profile (same as the profile removed in the mapped surveys) assuming a Gaussian spatial covariance 
with scales $L_{x}=17 \mathrm{~m}, V_{A}=0.10 \mathrm{~m}^{2}$, and measurement error $\left[\epsilon_{T}+\epsilon_{\text {bias }}\right] \sim 0.13 \mathrm{~m}$. The resulting maps $Z_{A}(x, t)$ have estimated errors $\epsilon_{A}(x, t)$ ranging from $\sim 0.1 \mathrm{~m}$ near the altimeter locations to $\sim 0.3 \mathrm{~m}$ far from the altimeters.

The survey and altimeter data are combined using the weighted-update method, yielding gridded ( $5 \mathrm{~m}, 6 \mathrm{hrs}$ ) estimates of the bathymetry $Z_{U W}(x, t)$ and associated errors $\epsilon_{U W}(x, t)$. To test the update method, all possible forward-backward update maps $Z_{U}\left(x, t_{S}, t\right)$ [and the corresponding error estimate $\epsilon_{U}\left(x, t_{S}, t\right)$ ], weighted-update maps $Z_{U W}(x, t)$ (Equation 3.4) [and the corresponding error estimate $\left.\epsilon_{U W}(x, t)\right]$, and timeinterpolated surveys are computed.

\subsubsection{Assessment of sandbar profile maps}

The accuracy of the sandbar profile estimates made with CRAB surveys alone, altimeters alone, and surveys updated with altimeter-estimated change is assessed using selected CRAB surveys as independent ground truth. Forward-backward updated maps are assessed and compared with the altimeter maps, and weighted-update maps are assessed and compared with the forward-backward updated maps, the altimeter maps, and timeinterpolation of surveys. The errors are computed in the region for which survey errors are smaller than $0.10 \mathrm{~m}$.

For the 276 pairs of temporally separated watercraft surveys, the forward-backward updated maps have approximately the same average reconstruction errors $\left(\overline{\epsilon_{R, U}}=0.16\right.$ $\mathrm{m})$ as the altimeter maps $\left(\overline{\epsilon_{R, A}}=0.16 \mathrm{~m}\right)$. The average rms difference between final and initial spatially dense surveys is $0.38 \mathrm{~m}$. For the 2024 sets of three temporally separated $\mathrm{CRAB}$ surveys, the weighted-update maps have average reconstruction errors $\left(\overline{\epsilon_{R, U W}}=\right.$ $0.12 \mathrm{~m})$ that are smaller than the forward and backward updated maps $\left(\overline{\epsilon_{R, U}}=0.14\right)$, the altimeter maps $\left(\overline{\epsilon_{R, A}}=0.14 \mathrm{~m}\right)$, and the temporally weighted surveys $\left.\overline{\epsilon_{R, S}}=0.21 \mathrm{~m}\right)$. The average rms difference between final and initial spatially dense surveys is $0.43 \mathrm{~m}$.

The weighted-update and altimeter-interpolation methods, along with the time interpolation of surveys, are used to reconstruct the bathymetry on 30 September (Figure 
3.8). The survey on 30 September has small errors (Figure 3.8, solid black curve and grey shading), and thus is a good representation of the true bathymetry. The surveys completed at 21 September (Figure 3.8, dashed black curve) and 4 October (Figure 3.8, dotted black curve) are used with altimeter change estimates in the weighted-update method to produce estimates of the bathymetry (Figure 3.8, blue curve) and associated errors (Figure 3.8, blue shading). The time-interpolated survey estimate using the 30 September and 4 October surveys also is shown (Figure 3.8, green curve), and altimeter interpolation also is used to estimate the bathymetry on 30 September (Figure 3.8, red curve) and associated errors (Figure 3.8, red shading). The rms reconstruction error (rms difference with the survey on 26 September) for the weighted-update map is $0.08 \mathrm{~m}$ [smaller than the average estimated interpolation error (Equation 3.A7) $0.25 \mathrm{~m}$ ], for the altimeter maps is $0.12 \mathrm{~m}$ (smaller than the average estimated error $0.21 \mathrm{~m}$ ), and for the time-interpolation of surveys is $0.13 \mathrm{~m}$. The rms difference between the surveys on 21 and 30 September is $0.16 \mathrm{~m}$, and between the surveys on 30 September and 4 October is $0.14 \mathrm{~m}$.

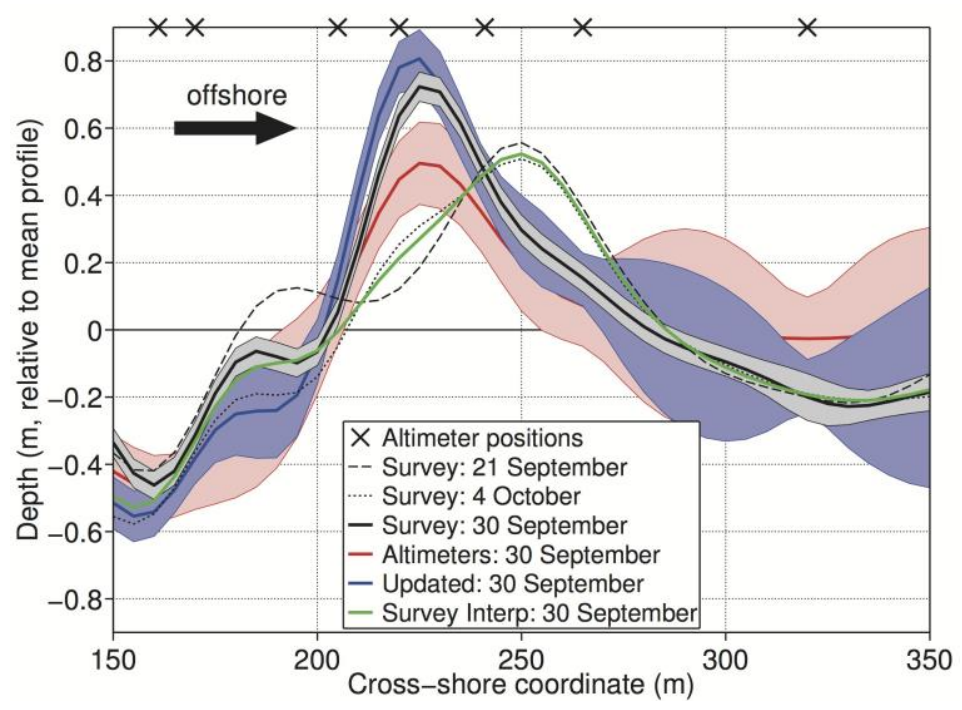

Figure 3.8. Depth of the seafloor (relative to a smoothed mean profile that is removed from each map) versus cross-shore coordinate from CRAB surveys on 21 September (dashed black curve), 30 September (ground truth, solid black curve), and 4 October (dotted black curve), and estimated for 30 September using the weighted-update (solid blue curve), altimeter-interpolation (red solid curve), and time-interpolation of the 21 September and 4 October CRAB surveys (green solid curve) methods. Shaded areas are 1 std dev error estimates (errors for 21 September and 4 October are similar to the grey shading shown for 30 September) and the estimated bathymetries. Crosses show crossshore positions of altimeters. 


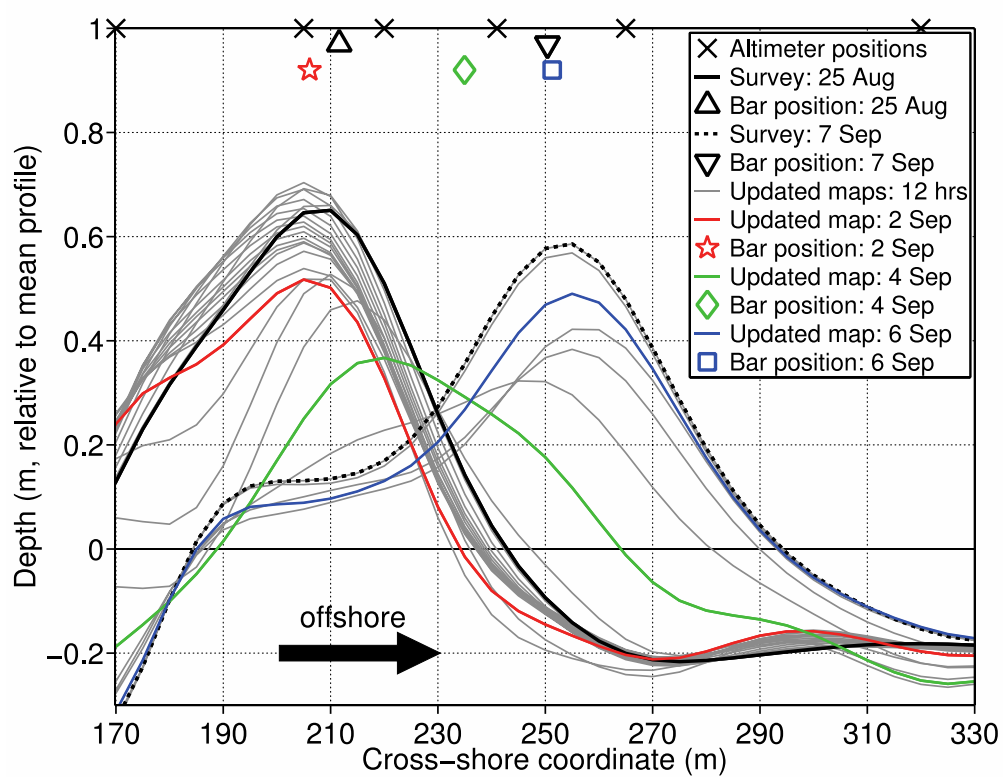

Figure 3.9. Depth of seafloor (relative to a smoothed mean profile that is removed from each map) across the sandbar versus cross-shore coordinate (the shoreline is near crossshore coordinate $100 \mathrm{~m}$ ). The solid black curve is the initial watercraft survey on 25 August 1994, and the dotted black curve is the survey on 7 September. Grey, red, green, and blue curves are cross-shore profiles using the weighted-update method every 12 hours between 25 August and 7 September. The sandbar migrated most rapidly on 2 September (red curve), through 4 September (green curve), and until 6 September (blue curve). Crosses at depth $=1 \mathrm{~m}$ are cross-shore positions of altimeters, and the symbols below the crosses are the bar crest position (estimated by a fit to a linear slope plus a Gaussian) for surveys on 25 August (upward triangle) and 7 September (downward triangle) and updated maps for 2 (red star), 4 (green diamond), and 6 September (blue square).

\subsubsection{Application to sandbar migration}

The weighted-update maps improve the temporal resolution of the evolving cross-shore profile, both during rapid bar migration events and during times when conditions precluded CRAB surveys (often simultaneous with rapid bar migration) (Figure 3.9). Gaussian fits (summed with a linear beach profile) to six-hour updated profiles are used as a proxy to determine the sandbar crest position (usually within one or two grid cells of the location of the maximum of a detrended profile, Figures 3.9 and 3.10). Confidence intervals (grey shading in Figure 3.10) are found from the distribution of parameters from a series of fits to 300 curves generated by summing the updated maps with random errors drawn from a Gaussian distribution with std dev given by the estimated mapping rms error. Infrequent dense surveys show the sandbar migrated about $40 \mathrm{~m}$ offshore between 
25 August and 7 September (triangles in Figures 3.9 and 3.10). Interpolating between the CRAB surveys assumes the migration was constant in time. However, the updated maps suggest that the offshore migration occurred rapidly between 2 and 6 September (Figure 3.10) during a nor'easter storm ( $3 \mathrm{~m}$ significant wave height in $8 \mathrm{~m}$ depth) [Gallagher et al., 1998a], and was preceded by more than one week of slow onshore migration (Figure 3.10, 25 August to 2 September). Similarly, during a second nor'easter (14 to 17 October, $4 \mathrm{~m}$ significant wave height in $8 \mathrm{~m}$ depth) [Gallagher et al., 1998a] the updated maps suggest more rapid migration on 15 October than would be inferred from interpolation of the CRAB surveys on 14 and 18 October (Figure 3.10). Between 15 and 17 October large waves precluded $C R A B$ surveys of the sandbar.

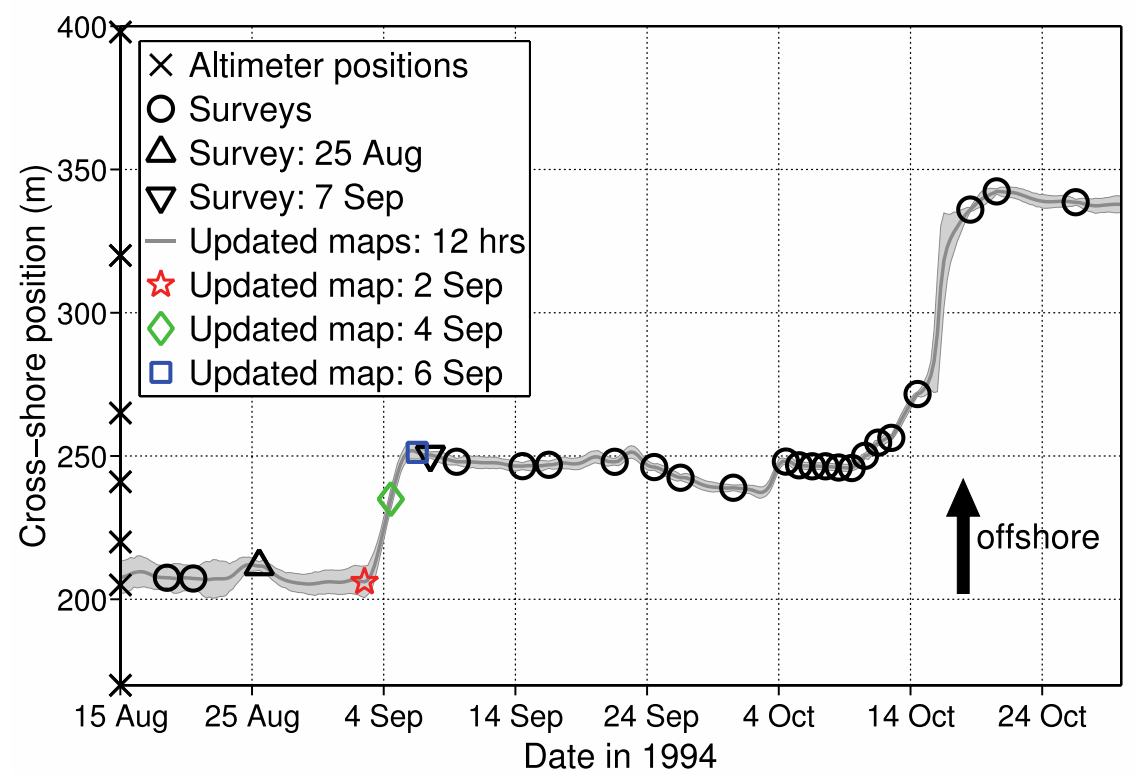

Figure 3.10. (a) Cross-shore position of the sandbar crest based on altimeter-updated profiles every 3 hours (grey curve with shaded $95 \%$ confidence interval) and on spatially dense CRAB surveys (black circles and triangles) versus time. The shoreline is near cross-shore position $100 \mathrm{~m}$. Crosses along the y-axis are cross-shore positions of the altimeters. A rapid bar migration event (also see Figure 3.9) occurred from 2 to 6 September, between the surveys on 25 August (upward-pointing triangle) and 7 September (downward triangle). The bar cross-shore position moved rapidly starting on 2 September (red star), through 4 September (green diamond), until 6 September (blue square). 


\subsection{Discussion and summary}

Interpolating in time between two spatially dense surveys produces accurate maps of the seafloor assuming the bathymetry changes uniformly in time (for some of the rip channels and some of the bar migration events, e.g., compare green with blue curves in Figure 3.4). However, surfzone bathymetry often evolves rapidly and non-uniformly when large waves, strong currents, and breaking wave-generated bubbles preclude spatially dense bathymetric surveys (e.g., with watercraft), and temporal interpolation is not accurate [e.g., the migration of the channel (July 21.5 in Figure 3.6) and the sandbar (2 to 6 September in Figure 3.10) in big waves]. In contrast, fixed altimeters can estimate bed levels in the presence of large waves and many bubbles. An array of altimeters sampling continuously can be used to make spatially interpolated bed-level maps at any given time, and may resolve the spatial structure of the bathymetry with reasonable accuracy if altimeter spacing is smaller than the spatial decorrelation scales of the features of interest. However, altimeter spacing can be relatively sparse and the altimeter bed-level estimates can be biased. Here, bed-level estimates from spatially dense, but infrequent surveys were combined with accretion and erosion estimates from spatially sparse, but nearly continuously sampling altimeters to form a bathymetric estimate that is more accurate than either temporally interpolating between two dense surveys or spatially interpolating between the fixed altimeters e.g., Figures 3.6 and 3.10). In studies for which the bathymetric estimate does not need to be independent of hydrodynamic measurements, additional improvements may be made by assimilating hydrodynamic measurements [Wilson et al., 2010; Birrien et al., 2013] along with altimeter bed levels or change signals.

The accuracy of the mapped altimeter change (and therefore of the updated maps) and of the mapped altimeter bed levels is sensitive to the trend removed from the observations prior to mapping (and subsequently added back to the mapped estimate), owing to the tendency of objectively mapped estimates to approach zero far from information [Rybicki and Press, 1992; also see 3.7 Appendix]. This tendency can be exploited to improve accuracy where there is insufficient information. Here, the mapped altimeter bed levels far from instrument locations approached a mean beach slope (for the rip channels) or a 
smoothed mean profile (for the sandbars). The mean slope and smoothed mean profile were found using the dense survey data, so the altimeter bed-level estimates are not strictly independent of the dense surveys. For the maps of bed-level change from altimeters used in the update method, no mean or trend was removed, and thus the estimated change is zero far from altimeters. There are alternatives that may be more appropriate in other applications, such as allowing the change signal estimate far from sensors to approach the average change.

Although interpolation weights estimated assuming spatially uniform and temporally constant Gaussian covariance functions produced relatively accurate seafloor maps, the patterns of the estimated mapping errors and the errors found in the reconstruction tests did not agree, perhaps because the bathymetry evolves more rapidly and with larger amplitude near the shore and when waves are large. Choosing spatially and temporally variable covariance functions may produce more accurate bathymetric and error estimates. Further investigation of the sensitivity of the estimated and reconstruction errors to the covariance estimates is needed to guide the selection of interpolation weights.

Here, the observations of changes in bed level at the locations of fixed altimeters were mapped and added to maps made from occasional spatially dense surveys. When multiple dense surveys were available, updated maps made from each survey were combined in a weighted average. For evolving dredged channels and natural sandbars in the surf zone, the updated maps are a better estimate of the bathymetry than maps made by spatially interpolating altimeter estimates of the bed level or by temporally interpolating dense surveys.

\subsection{Appendix. Interpolation and mapping of irregularly sampled observations}

Often, a set of bed-level observations $z\left(x_{j}, y_{j}, t_{j}\right)$, where $x_{j}$ and $y_{j}$ are the cross- and alongshore coordinates of the $j$ th observation made at time $t_{j}$, are mapped using linear interpolation to a regular spatial $\left(x_{i}, y_{i}\right)$ and temporal $\left(t_{i}\right)$ grid: 


$$
Z\left(x_{i}, y_{i}, t_{i}\right)=\sum_{j} W_{i j} z\left(x_{j}, y_{j}, t_{j}\right)
$$

where $Z$ is the linearly interpolated bed-level elevation estimate at a set of "mapping coordinates" $\left(x_{i}, y_{i}, t_{i}\right)$ and $W_{i j}$ is the weight of the $j$ th observation at the $i$ th mapping coordinate.

One common choice of interpolation weights is inverse separation weighting, e.g., in time:

$$
W_{i j}=A\left|t_{i}-t_{j}\right|^{-1}
$$

The factor $A$ (which may be a function of the observation and mapping coordinates) is sometimes set such that the only observations with nonzero weights are those immediately preceding and following the mapping coordinate, and may be normalized by the sum of the weights such that weights at each mapping coordinate sum to one.

Other mapping methods take advantage of knowledge of the signal covariance to seek an estimate of the bathymetry that minimizes the root-mean-square (rms) difference between the true and the mapped bathymetry [Bretherton et al., 1976]. Optimal weights are:

$$
W_{i j}=\sum_{j^{\prime}}\left[P_{j^{\prime} j}\right]^{-1} R_{j^{\prime} i}
$$

where $P_{j^{\prime} j}$ is the covariance between observed elevations at locations with indices $j^{\prime}$ and $j$, $R_{j \prime i}$ is the covariance between observed and mapped elevations, and [ ] $]^{-1}$ is the matrix inverse. This method is referred to as objective mapping or optimal interpolation. Often a Gaussian model for the covariance is used for mapping either in space or in time, e.g., in one dimension:

$$
R_{m n}=V \exp \left(-\frac{\left(p_{m}-p_{n}\right)^{2}}{2 L^{2}}\right)
$$

where $V$ is the estimated signal variance, $p$ is the spatial or time coordinate, $m$ and $n$ are arbitrary indices, and $L$ is a decorrelation length or time scale. The covariance between all observed elevations is:

$$
P_{j^{\prime} j}=R_{j^{\prime} j}+\epsilon_{O}^{2}\left(x_{j}, y_{j}, t_{j}\right) \delta_{j^{\prime} j}
$$


where $\epsilon_{O}\left(x_{j}, y_{j}, t_{j}\right)$ is the rms observational error associated with the $j$ th observation. It is assumed that observation errors are uncorrelated with errors at other locations and times (the delta function $\delta_{j^{\prime} j}=0$ if $j^{\prime} \neq j$, and $\delta_{j^{\prime} j}=1$ if $j^{\prime}=j$ ).

Often a mean or trend $M$ is removed before mapping and then added back in after mapping (this can be considered a scale separation):

$$
Z\left(x_{i}, y_{i}, t_{i}\right)=\sum_{j} W_{i j}\left[z\left(x_{j}, y_{j}, t_{j}\right)-M\right]+M
$$

The function $M$ may be an estimate of the true signal mean, a linear trend, a higher-order trend, or an ensemble-averaged estimate of a mean state. The choice becomes particularly important for data that are under-sampled because far from observations the interpolation weights tend to approach zero, and thus the bathymetric estimate approaches $M[R y b i c k i$ and Press, 1992].

The estimated interpolation error is:

$$
\epsilon\left(x_{i}, y_{i}, t_{i}\right)=V-\sum_{j} W_{i j} R_{i j}
$$

If there are small-scale features (e.g., ripples, megaripples, cusps) that are not resolved by the surveys (e.g., there is aliasing owing to undersampling) or are not desired in the estimate of the bathymetry (e.g., considered noise), weights may be derived to minimize the rms difference between the mapped bathymetry and a filtered (e.g., smoothed) true bathymetry [Ooyama, 1987; Plant et al., 1999]. When seeking the optimal estimate of smoothed bathymetry, smoothed covariance functions of the true bathymetry [Ooyama, 1987] are used. Here, the covariance function is assumed to be a Gaussian (Equation 3.A5) with the scale $L$ set to the smoothing scale (a resolvable scale of interest) and the signal variance $V$ set to the estimated variance of the smoothed bathymetry. In the presence of unresolved scales, $\epsilon_{O}$ should include both the rms measurement error and an rms estimate of the error associated with unresolved scales (e.g., the rms amplitude of bedforms). The results are optimal only if the covariance function is chosen correctly (e.g., a spatially variable covariance function could be used), but more detailed information about the true bathymetry would be needed to improve the covariance function estimate, and it is expected that the interpolation errors are not highly sensitive to errors in the choice of covariance function [Rybicki and Press, 1992]. 


\subsection{Acknowledgements}

The US Army Corps of Engineers Field Research Facility (Duck, NC, USA) provided excellent logistical support for both the 1994 and 2012 datasets. We thank Brian Scarborough and Jason Pipes for driving the landing craft and making depressions in the surfzone seafloor, and Jesse McNinch and the FRF team for their generous hospitality. We also thank Bill Boyd, David Clark, Danik Forsman, Dana Giffen, Levi Gorrell, Jeff Hansen, Julia Hopkins, Sean Kilgallin, Christen Rivera-Erick, Jenna Walker, Anna Wargula, Regina Yopak, and Seth Zippel for their tenacity in the field. Peter Traykovski and Fred Jaffre designed and built the WHOI altimeters. Falk Feddersen, Edith Gallagher, Robert Guza, Thomas Herbers, the Scripps Center for Coastal Studies field crew, and many others helped gather the Duck94 data. This work was funded by the Office of the Assistant Secretary of Defense for Research and Engineering, a National Defense Science and Engineering Graduate Fellowship, A National Science Foundation Graduate Research Fellowship, the National Science Foundation, and the Office of Naval Research. 


\subsection{References}

Austin, M., T. Scott, Jenna Brown, Jeff Brown, J. MacMahan, G. Masselink, and P. Russell (2010), Temporal observations of rip current circulation on a macro-tidal beach, Cont. Shelf. Res., 30, 1149-1165, doi:10.1016/j.csr.2010.03.005.

Birkemeier, W. A., and C. Mason (1984), The CRAB: A unique nearshore surveying vehicle, J. Surv. Eng., 110(1), 1-7, doi:10.1061/(ASCE)0733-9453(1984)110:1(1).

Birkemeier, W. A., C. Long, and K. Hathaway (2001), DELILAH, DUCK94 \& SandyDuck: Three Nearshore Field Experiments, Proc. Coast. Eng., ASCE, 1(25), 4052-4065, doi:10.9753/icce.v25.

Birrien, F., B. Castelle, V. Marieu, and B. Dubarbier (2013), On a data-model assimilation method to inverse wave-dominated beach bathymetry using heterogeneous video-derived observations, Ocean Eng., 73, 126-138, doi:10.1016/j.oceaneng.2013.08.002.

Bretherton, F. P., R. E. Davis, and C. B. Fandry (1976), A technique for objective analysis and design of oceanographic experiments applied to MODE-73, DeepSea Res., 23, 559-582, doi:10.1016/0011-7471(76)90001-2.

Chen, Q., R. Dalrymple, J. Kirby, A. Kennedy, and M. Haller (1999), Boussinesq modeling of a rip current system, J. Geophys. Res., 104(C9), 20617-20637, doi: 10.1029/1999JC900154.

Dalrymple, R., J. MacMahan, A. Reniers, and V. Nelko (2011), Rip Currents. Ann. Rev. Fluid. Mech., 43, 551-581, doi:10.1146/annurev-fluid-122109-160733.

Dugan, J., W. Morris, K. Vierra, C. Piotrowski, G. Farruggia, and D. Campion (2001), Jetski-based nearshore bathymetric and current survey system, J. Coast. Res., 17(4), 900-908.

Elgar, S., E. L. Gallagher, and R. T. Guza (2001), Nearshore sandbar migration, J. Geophys. Res., 106, 11623-11627, doi:10.1029/2000jc000389.

Falqués, A., G. Coco, and D. A. Huntley (2000), A mechanism for the generation of wave-driven rhythmic patterns in the surf zone, J. Geophys. Res., 105(C10), 24071-24088, doi:10.1029/2000JC900100.

Feddersen, F., E. L., Gallagher, R. T. Guza, and S. Elgar (2003), The drag coefficient, bottom roughness, and wave breaking in the nearshore, Coast. Eng., 48, 189-195, doi:10.1016/s0378-3839(03)00026-7.

Gallagher, E., W. Boyd, S. Elgar, R. Guza, and B. Woodward (1996), Performance of a sonar altimeter in the nearshore, Mar. Geol., 133, 241-248, doi:10.1016/00253227(96)00018-7. 
Gallagher, E., S. Elgar, and R. Guza (1998a), Observations of sand bar evolution on a natural beach, J. Geophys. Res., 103, 3203-3215, doi:10.1029/97JC02765.

Gallagher, E., S. Elgar, and E. Thornton (1998b), Megaripple migration in a natural surfzone, Nature, 394, 3203-3215, doi:10.1038/28139.

Gallagher, E. L., S. Elgar, R. T. Guza, and E. B. Thornton (2005), Estimating nearshore bedform amplitudes with altimeters, Mar. Geol., 216(1), 51-57, doi:10.1016/j.margeo.2005.01.005.

Gallop, S. L., K. R. Bryan, G. Coco, and S. A. Stephens (2011), Storm-driven changes in rip channel patterns on an embayed beach, Geomorph., 127, 179-188, doi:10.1016/j.geomorph.2010.12.014.

Garnier, R., A. Falqués, D. Calvete, J. Thiebot, and F. Ribas (2013), A mechanism for sandbar straightening by oblique wave incidence, Geophys. Res. Lett., 40(11), 2726-2730, doi:10.1002/grl.50464.

Genton, M. G. (2007), Separable approximations of space-time covariance matrices, Environmetrics, 18(7), 681-695, doi:10.1002/env.854.

Haller, M. C., R. A. Dalrymple, and I. A. Svendsen (2002), Experimental study of nearshore dynamics on a barred beach with rip channels, J. Geophys. Res., 107(C6), doi:10.1029/2001JC000955.

Henderson, S., J. Allen, and P. Newberger (2004), Nearshore sandbar migration predicted by an eddy-diffusive boundary layer model, J. Geophys. Res., 109, doi:10.1029/2003JC002137.

Hoefel, F., and S. Elgar (2003), Wave-induced sediment transport and sandbar migration, Science, 299, 1885-1887, doi:10.1126/science.1081448.

Holland, K. T., R. A. Holman, T. C. Lippmann, J. Stanley, and N. Plant (1997), Practical use of video imagery in nearshore oceanographic field studies, IEEE J. Oc. Eng., 22, 81-92, doi:10.1109/48.557542.

Holman, R. A., A. H. Sallenger, T. C. Lippmann, and J. W. Haines (1993), The application of video image processing to the study of nearshore processes, Oceanogr., 6, 78-85, doi:10.5670/oceanog.1993.02.

Holman, R. A., G. Symonds, E. B. Thornton, and R. Ranasinghe (2006), Rip spacing and persistence on an embayed beach, J. Geophys. Res., 111, C01006, doi:10.1029/2005JC002965.

Holman, R. A., M. C. Haller (2013), Remote Sensing of the Nearshore, Ann. Rev. of Mar. Sci., 5(1), 95-113, doi:10.1146/annurev-marine-121211-172408. 
Holman, R., N. Plant, and T. Holland (2013), cBathy: A robust algorithm for estimating nearshore bathymetry, J. Geophys. Res., 118, 2595-2609. doi:10.1002/jgrc.20199.

Hsu. T.-J., S. Elgar, and R. Guza (2006), Wave-induced sediment transport and onshore sandbar migration, Coast. Eng., 53, 817-824, doi:10.1016/j.coastaleng.2006.04.003.

Kuik, A., G. van Vledder, L. Holthuijsen (1988), A method for the routine analysis of pitch-and-roll buoy wave data, J. Phys. Oceanogr., 18, 1020-1034, doi:10.1175/1520-0485(1988)018<1020:AMFTRA $>2.0 . C O ; 2$.

Lippmann, T., and R. Holman (1989), Quantification of sand-bar morphology: a video technique based on wave dissipation, J. Geophys. Res., 94(C1), 995-1011, doi:10.1029/JC094iC01p00995.

Lippmann, T., and G. Smith (2008), Shallow surveying in hazardous waters, Shallow Water Surv. Conf., Durham, NH, USA.

MacMahan, J. (2001), Hydrographic surveying from personal watercraft, J. Surv. Eng., 127(1), 12-24, doi:10.1061/(ASCE)0733-9453(2001)127:1(12)

MacMahan, J. H., E. B. Thornton, and A. J. H. M. Reniers (2006), Rip current review, Coast. Eng., 53(2-3), 191-208, doi:10.1016/j.coastaleng.2005.10.009.

Mastroianni, G., and G. V. Milovanović (2008), Interpolation Processes: Basic Theory and Applications, Springer, Berlin, doi:10.1007/978-3-540-68349-0.

Moulton, M., S. Elgar, and B. Raubenheimer (2013), Structure and evolution of dredged rip channels, Proc. Coast. Dynam. '13, ASCE, Arcachon, Fr. 1263-1274.

Ooyama, K. V. (1987), Scale-Controlled Objective Analysis, Mon. Weather Rev., 115, 2479-2506, doi:10.1175/1520-0493(1987)115<2479:SCOA>2.0.CO;2.

Plant, N. G., R. A. Holman, and M. H. Freilich (1999), A simple model for interannual sandbar behavior, J. Geophys. Res., 104(C7), 15755-15776, doi:10.1029/1999JC900112.

Plant, N. G., K. T. Holland, and J. A. Puleo (2002), Analysis of the scale errors in nearshore bathymetric data, Mar. Geol., 191, 71-86, doi:10.1016/S00253227(02)00497-8.

Plant, N. G., K. Edwards, J. Kaihatu, J. Veeramony, L. Hsu, and K. Holland (2009), The effect of bathymetric filtering on nearshore process model results, Coast. Eng., 56, 484-493, doi:10.1016/j.coastaleng.2008.10.010.

Ruessink, B. G., I. M. J. van Enckevork, K. S. Kingston, and M. A. Davidson (2000), Analysis of observed two- and three-dimensional nearshore bar behavior, Mar. Geol., 169, 161-183, doi:10.1016/S0025-3227(00)00060-8. 
Rybicki, G. B., and W. H. Press (1992), Interpolation, realization, and reconstruction of noisy, irregularly sampled data, Astrophys. J., 398, 169-176.

Thornton, E., R. Humiston, and W. Birkemeier (1996), Bar/trough generation on a natural beach, J. Geophys. Res., 101(C5), 12097-12110, doi:10.1029/96JC00209.

van Dongeren, A., N. Plant, A. Cohen, D. Roelvink, M. C. Haller, and P. Catalán (2008), Beach Wizard: Nearshore bathymetry estimation through assimilation of model computations and remote observations, Coast. Eng., 55(12), 1016-1027, doi:10.1016/j.coastaleng.2008.04.011.

van Enckevort, I. M. J., and B. G. Ruessink (2003), Video observations of nearshore bar behaviour. Part 2: alongshore non-uniform variability, Cont. Shelf Res., 23, 513532, doi:10.1016/S0278-4343(02)00235-2.

van Enckevort, I. M. J., B. G. Ruessink, G. Coco, K. Suzuki, I. L. Turner, N. G. Plant, and R. A. Holman (2004), Observations of nearshore crescentic sandbars, $J$. Geophys. Res., 109, C06028, doi:10.1029/2003JC002214.

Wilson, G. W., H. T. Özkan-Haller, and R. A. Holman (2010), Data assimilation and bathymetric inversion in a two-dimensional horizontal surf zone model, $J$. Geophys. Res., 115, C12057, doi:10.1029/2010JC006286. 


\title{
Chapter 4:
}

\section{Rip currents and alongshore flows in dredged channels ${ }^{1}$}

\begin{abstract}
To investigate the response of nearshore flows to non-uniform bathymetry, five channels (on average 30-m wide and 1.5-m deep) were dredged across the surf zone at different times using the propellers of a landing craft, and the subsequent evolution of waves, currents, and morphology was observed for a range of incident wave conditions. In addition, flows were simulated with the COAWST modeling system initialized with the observed incident waves and rip channel bathymetry, and with an extended range of wave conditions and rip channel geometries. Model simulations of surfzone circulation, including alongshore, feeder, and rip currents are consistent with the observations. Depthaveraged model momentum balances suggest that pressure gradients, wave breaking accelerations, advection, and the horizontal vortex force are the dominant terms near deep channels. Balances for simulations with obliquely incident waves are similar to balances for shore-normal waves, but the patterns are the shifted downstream (in the direction of the alongshore flow) and are asymmetric about the channel. The observed and simulated maximum offshore-directed flow speeds are correlated with a parameter based on the incident wave height and angle, the water depths in the channel and on the sandbar crest, the ratio of wave height to water depth at breaking, and the alongshore flow speed (which can be approximated from wave properties and a drag coefficient).
\end{abstract}

\footnotetext{
${ }^{1}$ This manuscript has been prepared for submission to the Journal of Geophysical Research with authors M. Moulton, S. Elgar, and B. Raubenheimer.
} 


\subsection{Introduction}

Nearshore rip currents and alongshore flows are hazardous to swimmers and are important mechanisms for transporting sediments, pollutants, and larvae across the surf zone and along the shoreline. Wave breaking on alongshore-nonuniform beaches can drive rip current circulation patterns and spatial variations in breaking-wave-driven alongshore flows [Sonu, 1972; MacMahan et al., 2010; Garnier et al., 2013; Houser et al., 2013; Winter et al., 2014]. The alongshore gradients in wave breaking and setup that drive rip currents may be generated by local bathymetric variations [Bowen and Inman, 1969; Chen et al., 1999; Brander and Short, 2001; Haller et al., 2002; Haas et al., 2003; MacMahan et al., 2005, 2006, 2008; Bruneau et al., 2009; Austin et al., 2010, 2014; Dalrymple et al., 2011], offshore bathymetric variations [Long and Özkan-Haller, 2005], wave-wave interactions [Dalrymple, 1975; Peregrine, 1998; Buhler and Jacobson, 2001], or wave-current interactions [Dalrymple and Lozano, 1978]. In both field and laboratory studies the speed of rip currents near inhomogeneous bathymetry varies with incident wave properties, tidal elevation, and the geometry of the bathymetric depression [Brander and Short, 2001; Haller et al., 2002; Bruneau et al., 2009; Austin et al., 2010].

The presence of alongshore currents driven by breaking obliquely incident waves [Bowen, 1969; Longuet-Higgins, 1970; Thornton, 1970; Thornton and Guza, 1986; Guza et al., 1986; Feddersen et al., 1998; and many others] affects the speed and position of rip current jets and other offshore-directed flows [Wu and Liu, 1984; Svendsen et al., 2000; Kumar et al., 2011; Wilson et al., 2013]. When incident waves propagate over alongshore-variable bathymetry, spatial variations in breaking-wave-driven setup lead to non-uniformities in the alongshore flow and offshore-directed flows near bathymetric depressions [Sonu, 1972; Oltman-Shay et al., 1989; Svendsen and Putrevu, 1990; Putrevu et al., 1995; Sancho, 1998; Slinn et al., 2000; Apotsos et al., 2008a, Hansen et al., 2015]. Circulation patterns that include features of both alongshore flows and rip currents have been observed in field [Sonu, 1972; Aagard et al., 1997; MacMahan et al., 2010; Austin et al., 2010; Houser et al., 2013; Winter et al., 2014], laboratory [Haller et al., 2002; Borthwick and Foote, 2002], and modeling studies [Svendsen et al., 2000; Yu and Slinn, 2003; Kumar et al., 2011; Wilson et al., 2013; Garnier et al., 2013]. Drifter tracks from 
several field studies suggest that transitions from rip currents to alongshore flows occur with increasing wave angle and decreasing wave breaking [MacMahan et al., 2010; Austin et al., 2010; Houser et al., 2013], and can be modulated tidally [Winter et al., 2014]. In laboratory studies with fixed channeled beds, rip currents occur for shorenormal waves, whereas meandering alongshore flows occur for obliquely incident waves [Haller et al., 2002; Borthwick and Foote, 2002]. Models of circulation patterns in the presence of channels suggest that as the wave angle increases, rip currents are shifted downstream (in the direction of the alongshore current) and suppressed [Svendsen et al., 2000; Kumar et al., 2011; Wilson et al., 2013], and that closed circulation cells exist only for small wave angles ( $<5^{\circ}$ from shore normal) [Yu and Slinn, 2003].

Despite the importance of rip currents and other circulation patterns resulting from alongshore variations in surfzone bathymetry, there are few field observations of currents in and near deep channels. To investigate the response of nearshore flows to alongshorevariable bathymetry, five channels (on average 30-m wide and $1.5-\mathrm{m}$ deep) were dredged across the surf zone on the Outer Banks of $\mathrm{NC}$ at different times using the propellers of a landing craft (Figure 4.1A). The subsequent evolution of waves, currents, and morphology was observed for a range of incident wave conditions. In addition, flows were simulated with the COAWST modeling system [Warner et al., 2008, 2010] initialized with the observed incident waves and channel bathymetry, and for an extended range of wave conditions and channel geometries. The observations and simulations are used to quantify the dynamics of surfzone circulation near deep channels for a range of wave forcings, tidal elevations, and bathymetries. The relative roles of terms in depthaveraged momentum balances are considered for several wave-breaking regimes, and the dependence of the offshore-directed flow speed on wave properties and bathymetry is discussed. 


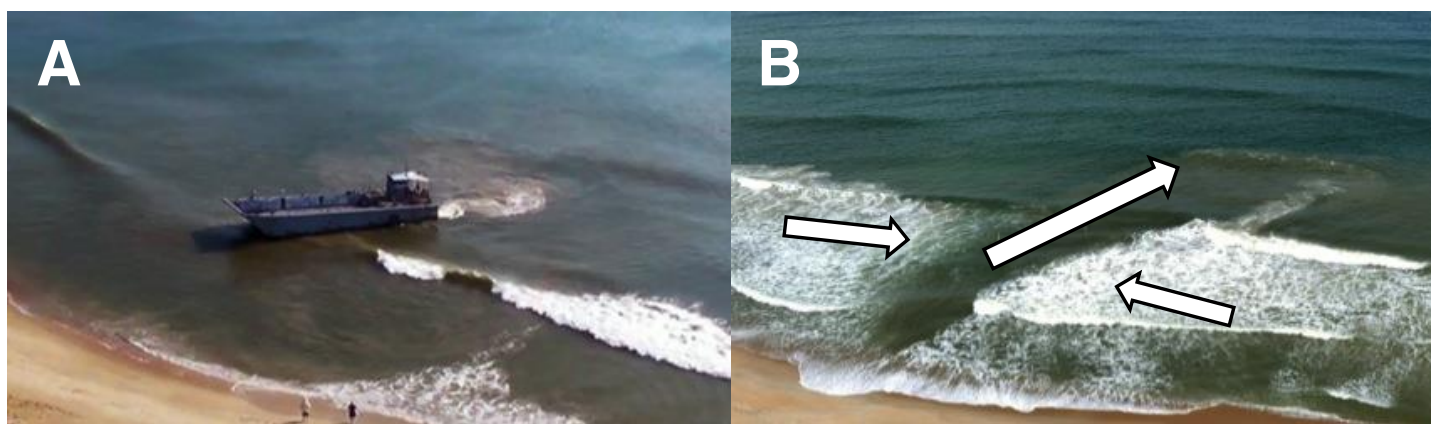

Figure 4.1. Photographs of (A) the landing craft excavating an approximately 2-m deep, 30-m wide (cross-shore), and 75-m long channel across the surf zone, and (B) breaking (white areas on the sides of the channel) and nonbreaking (dark areas) waves near a rip channel. The arrows indicate flow direction. Sediment (brown) and foam (white) carried offshore of the surf zone by the rip current are visible, especially to the right and offshore of the large rip-current arrow.

\subsection{Field observations}

Observations were collected near Duck, NC at the US Army Corps of Engineers Field Research Facility (FRF, http://frf.usace.army.mil/frf.shtml) in summer 2012. The 1-m diameter propellers on a Vietnam-era landing craft (Figure 4.1A) were used to excavate shore-perpendicular channels in 1- to 3-m water depth (Figure 4.2) by suspending huge quantities of sediment that were carried away by currents (Figure 4.1A). The dredging experiment was performed five times, creating channels of different sizes that were on average 1- to 2-m deep, 30-m wide in the alongshore, and 75-m long in the cross-shore. The channels were dredged across a terrace or across a small sandbar and nearshore trough (Figure 4.2) and evolved at varying rates [Moulton et al., 2014]. Tides, waves, and currents were measured with pressure sensors colocated with acoustic current meters and current profilers in and outside of the channels (Figure 4.2), and bathymetry was surveyed nearly continuously with in situ altimeters and daily (when conditions permitted) with a watercraft system. Offshore (incident) wave properties were estimated with a colocated pressure gage and current meter in $8.5-\mathrm{m}$ water depth [Hanson et al., 2009].

Observed flows included rip current jets (Figure 4.3A) flowing offshore through the channels and alongshore currents flowing across the channels (Figure 4.3B). Significant wave heights (4 times the standard deviation of sea-surface elevation fluctuations in the frequency band from 0.05 to $0.30 \mathrm{~Hz}$ ) in $8.5 \mathrm{~m}$ depth ranged from 0.3 to $1.5 \mathrm{~m}$, wave 
angles ranged from $0^{\circ}$ to $45^{\circ}$ relative to shore normal, and wave periods (centroid of the spectrum between 0.05 and $0.30 \mathrm{~Hz}$ ) ranged from 5 to $11 \mathrm{~s}$ (Figure 4.3E, F, G). Rip currents lasted from 2 to 36 hours and were stronger (1-hr means up to $1 \mathrm{~m} / \mathrm{s}$ ) for larger wave heights (Figure 4.3E), more normally incident wave directions (Figure 4.3F), and low tides (Figure 4.3C), consistent with other field studies [Brander and Short, 2001; Austin et al., 2010] and with rip current rescue statistics [Dusek and Seim, 2013]. Obliquely incident waves tended to produce alongshore flows and smaller offshoredirected flows, whereas nearly shore-normal waves produced rip currents. Sometimes, strong offshore-directed flows were observed in the presence of alongshore flows. Similar to laboratory measurements [Haas and Svendsen, 2002], the rip current jets were nearly depth-uniform in the channels, and some of the jets were stronger near the surface in the region offshore of the channel.
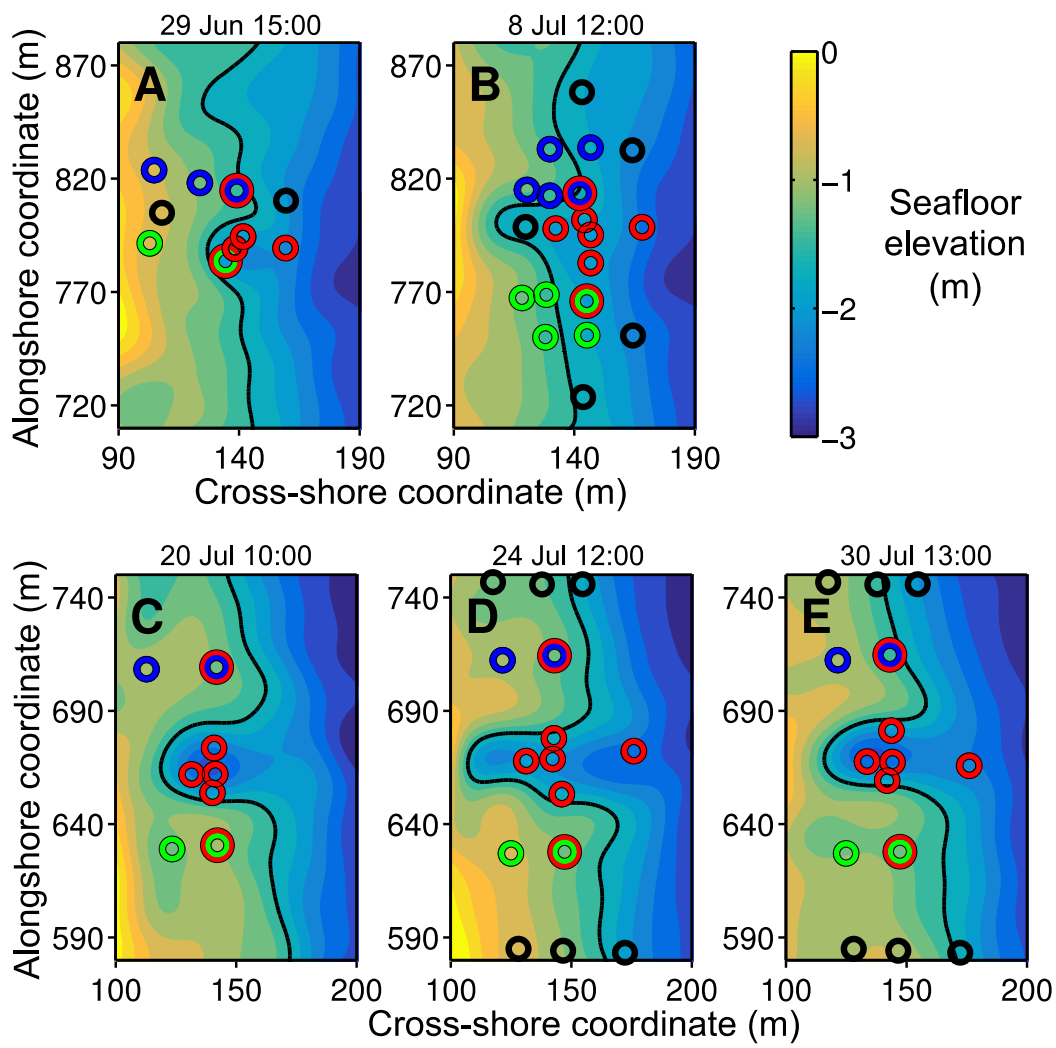

Figure 4.2. Bathymetry (relative to mean sea level, color contours, scale on right; solid black curve is $-1.5 \mathrm{~m}$ ) of five rip current channels dredged at different times in 2012 in Duck, NC versus cross- ( $x$-axis) alongshore ( $y$-axis) coordinate. Circles are locations of colocated current meters and profilers, pressure sensors, and altimeters. Red, green, and blue circles show the locations of observations plotted in Figure 4.3. 

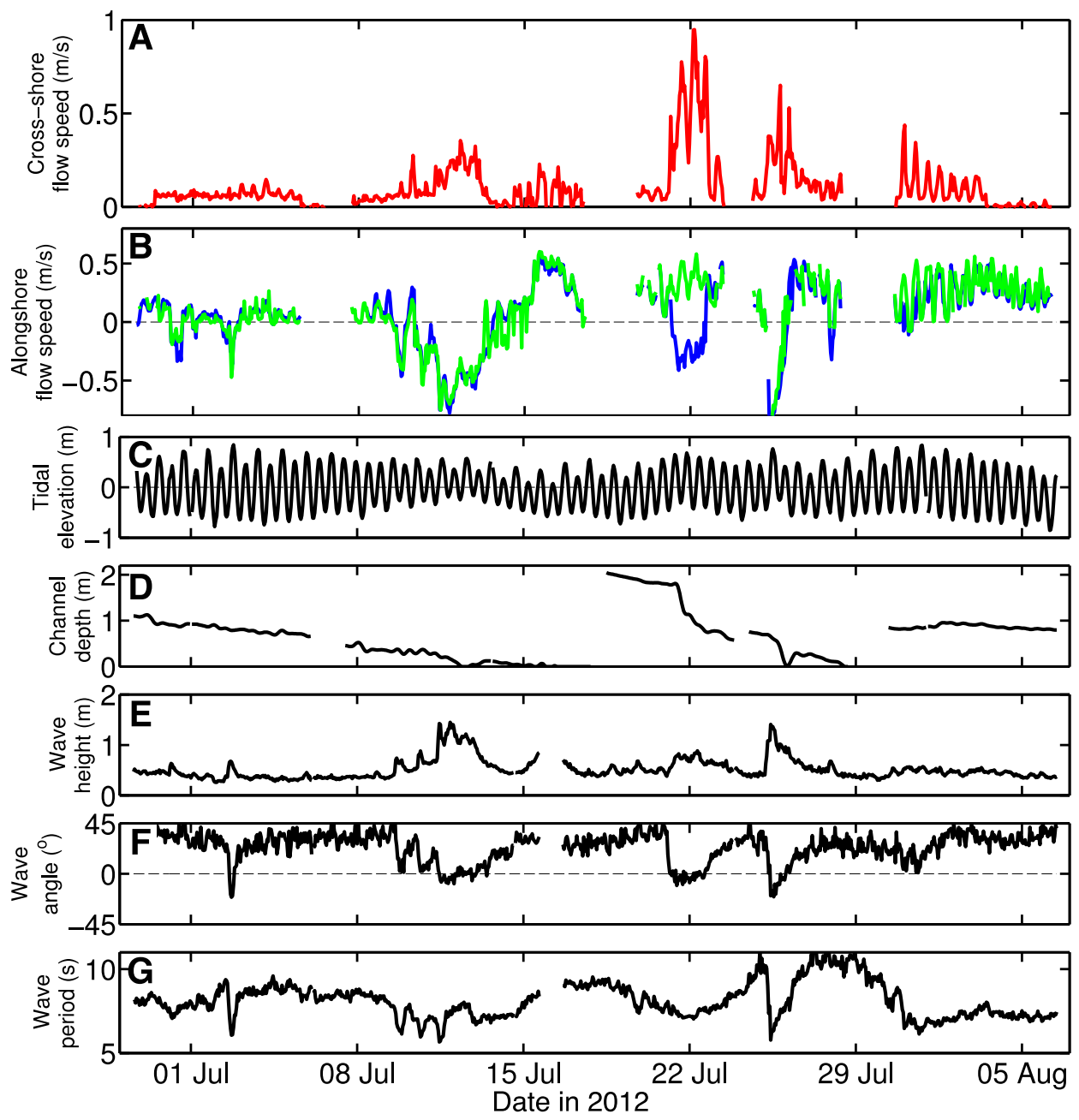

Figure 4.3. (A) Maximum 1-hr mean offshore-directed current speed observed at locations of red symbols in Figure 4.2, (B) maximum alongshore flow speeds (positive northward) estimated from observations at locations of blue and green symbols in Figure 4.2, (C) tidal elevation (NOAA gage in $6 \mathrm{~m}$ depth), (D) channel depth (difference between seafloor elevation near the channel center and on the sides of the channel), and incident (8.5 m depth) (E) significant wave height, $(F)$ energy-weighted wave direction (relative to shore-perpendicular, positive values are waves from the south), and (G) centroidal wave period versus time.

\subsection{Numerical simulations}

Nearshore circulation was simulated using COAWST [Warner et al., 2008, 2010], a fully three-dimensional coupled wave and current model that has skill simulating nearshore and surfzone observations [Kumar et al., 2011, 2012]. COAWST couples the wave model SWAN [Booij et al., 1999] with the ocean circulation model ROMS [Haidvogel et al., 2000], and also includes the option to couple to atmospheric forcing and sediment 
transport modules. SWAN is a spectral wave model that has skill predicting the wave field (heights, directions, periods) in complex nearshore environments [van der Westhuysen, 2010; Mulligan et al., 2010, Gorrell et al., 2011; Kumar et al., 2011, 2012; and many others]. The hydrodynamic model used here is based on the Rutgers University version [Haidvogel et al., 2000] of the Regional Ocean Modeling System (ROMS), a three-dimensional, free surface, topography following numerical model that solves the Reynolds-averaged Navier-Stokes equations [Shchepetkin and McWilliams, 2005, 2009; Haidvogel et al., 2008; Warner et al., 2008]. The ROMS module has been updated to include wave-current interactions based on the concept of a vortex force [McWilliams et al., 2004; Smith, 2006] that has been extended to the surf zone [Uchiyama et al., 2010; Warner et al., 2010]. Additional extensions for surfzone work [Kumar et al., 2011, 2012] include a scheme for wave-induced mixing via a surface boundary condition [Feddersen and Trowbridge, 2005], improved vertical structure of depth-limited wave-dissipation induced acceleration, and bottom streaming effects [Henderson et al., 2004]. The vortex force approach allows the three-dimensional circulation to be modeled, which is important for predicting surfzone currents.

Here, the model is used to simulate the hydrodynamic response for both the observed and synthetic bathymetry and wave forcing. Each simulation is run for a period of 3 hours to allow the flows to spin up and reach equilibrium, and the average of the final hour is used for the analysis. The model domain extends $4 \mathrm{~km}$ in the alongshore, centered on a single rip channel. In the cross-shore, the domain extends $\sim 800 \mathrm{~m}$ from the shoreline to 9-m water depth, with $2 \mathrm{~m}$ horizontal grid resolution and 10 layers in the vertical. The results are not sensitive to doubling or halving the grid resolution. Waves at the offshore boundary of the domain are described with a frequency-directional spectrum. The boundary conditions are closed at the shoreline and open at the offshore, north, and south boundaries. A Flather radiation condition is applied at the offshore boundary [Chapman, 1985; Flather, 1976] and gradient boundary conditions are applied at the other open boundaries. The ROMS model is run with a time step of $0.5 \mathrm{~s}$ and the coupling interval between ROMS and SWAN is $15 \mathrm{~s}$. The bottom stress is computed with a quadratic drag law with a standard value of the drag coefficient $C_{d}=0.0033$ [Feddersen et al., 2003] and 
the horizontal viscosity is set to $0.05 \mathrm{~m}^{2} / \mathrm{s}$ to account for sub-grid scale mixing. The results are not sensitive to doubling or halving the drag or viscosity. The turbulence closure scheme used is General Length Scale [GLS, $k-\varepsilon$, Warner et al., 2005].

Depth-limited wave breaking [Battjes and Janssen, 1978; Thornton and Guza, 1983; Raubenheimer et al., 1996; Apotsos et al., 2008b] is described by the ratio of the wave height to water depth at breaking, set to the default value of $\gamma_{b r}=0.73$. Wave rollers [Reniers et al., 2004] are simulated with a parameter $\alpha_{r}=0.5$ specifying that $50 \%$ of the wave energy dissipation goes to the roller (the rest goes to local dissipation) [Tajima and Madsen, 2006; Kumar et al., 2012]. The rip current speed varies by approximately $15 \%$ for changes in $\alpha_{r}$ from 0 to 1 .

To compare model simulations with observations every $3 \mathrm{hrs}$, the model is forced with hourly offshore wave spectra (wave gage at the offshore boundary, average depth $\sim 8.5 \mathrm{~m}$, and $x=915 \mathrm{~m}, y=935 \mathrm{~m}$ in the FRF Cartesian coordinate system), tidal elevations (NOAA tide gage, $\sim 6 \mathrm{~m}$ depth, $x=622 \mathrm{~m}, y=543 \mathrm{~m}$ ), and bathymetry. The bathymetry at each time is estimated using a method that combines observations from watercraft surveys (daily or weekly depending on conditions) with the hourly bed level estimates from in situ altimeters at up to a dozen locations [Moulton et al., 2014]. The bathymetric estimates are centered in the alongshore at the channel and extend $160 \mathrm{~m}$ in the alongshore direction and from the shoreline to approximately $3.5 \mathrm{~m}$ depth (Figure $4.2 \mathrm{C}$ ). The bathymetry elsewhere in the model domain is set to a constant average bathymetric profile for the region near the channel (average over several larger surveys from summer 2012).

Flows also were simulated for a wider range of wave conditions [represented by a JONSWAP spectrum, Hasselmann et al., 1973], tidal elevations, and rip channel depths than those observed. The JONSWAP spectral width $\left(\gamma_{J S}=1\right)$, peak period $(\mathrm{T}=7 \mathrm{~s})$, and directional spread $\left(36^{\circ}\right)$ were set as constants based on the average values from fits to observed spectra. The offshore wave height was varied from 0.05 to $2 \mathrm{~m}$ and the wave angle was varied from 0 to $45^{\circ}$. The depth-limited breaking parameter was set to $\gamma_{b r}=0.73$. For these synthetic simulations, the rip channel bathymetry consists of a planar 
beach summed with a Gaussian sandbar ( $1 \mathrm{~m}$ high, $32 \mathrm{~m}$ wide) interrupted by a Gaussian channel ( $20 \mathrm{~m}$ wide, 0.1 to $1 \mathrm{~m}$ depth). The results are not sensitive to doubling or halving the rip channel or bar widths.

\subsection{Model-data comparisons}

\subsubsection{Time series}

The model simulations are compared with observations for the range of conditions measured between 19 and $23 \mathrm{Jul}$ (Figures $4.2 \mathrm{C}$ and 4.4). The maximum offshore-directed flow speed (Figure 4.4A) and the maximum alongshore flow or feeder current speeds (Figure 4.4B) were estimated for the nearly continuous (except during the lowest tides) 1hr-averaged observations and for simulations run every $3 \mathrm{hr}$. For each set of 1-hraveraged observations, the maximum offshore-directed flow (Figures $4.3 \mathrm{~A}$ and $4.4 \mathrm{~A}$, curves) was estimated as the maximum of the cross-shore flows observed in the channel (red symbols in Figure 4.2). The maximum offshore-directed flow for the simulations (Figure 4.4A, squares) was chosen to be the maximum simulated offshore-directed flow in a region spanning the rip channel [96 $\mathrm{m}<x<166 \mathrm{~m}$ and $644<y<684(+/-20 \mathrm{~m}$ in the alongshore from channel center) in Figure $4.2 \mathrm{C}$ ]. The alongshore flows on the north and south sides of the channel are estimated by taking the minimum, maximum, and mean of the alongshore component of the flows between the shoreline and the bar crest on the north (blue symbols in Figure 4.2C, or simulated flows in the region $96 \mathrm{~m}<x<146 \mathrm{~m}$ and $664 \mathrm{~m}<y<694 \mathrm{~m}$ ) or south (green symbols in Figure 4.2, or simulated flows in the region $96 \mathrm{~m}<x<146 \mathrm{~m}$ and $634 \mathrm{~m}<y<664 \mathrm{~m}$ ) sides of the channel. At each time, the characteristic alongshore flow on each side of the channel is estimated as the maximum flow speed toward the channel, except for cases where the flow speed toward the channel does not exceed a small threshold $(v=0.1 \mathrm{~m} / \mathrm{s})$, chosen to exclude small recirculation cells of the alongshore current from this analysis. If there is no flow directed toward the channel or if flows toward the channel do not exceed the threshold, the characteristic flow on each side of the channel is estimated as the maximum flow in the direction of the alongshore current (defined as the sign of the mean alongshore component of the flow). 

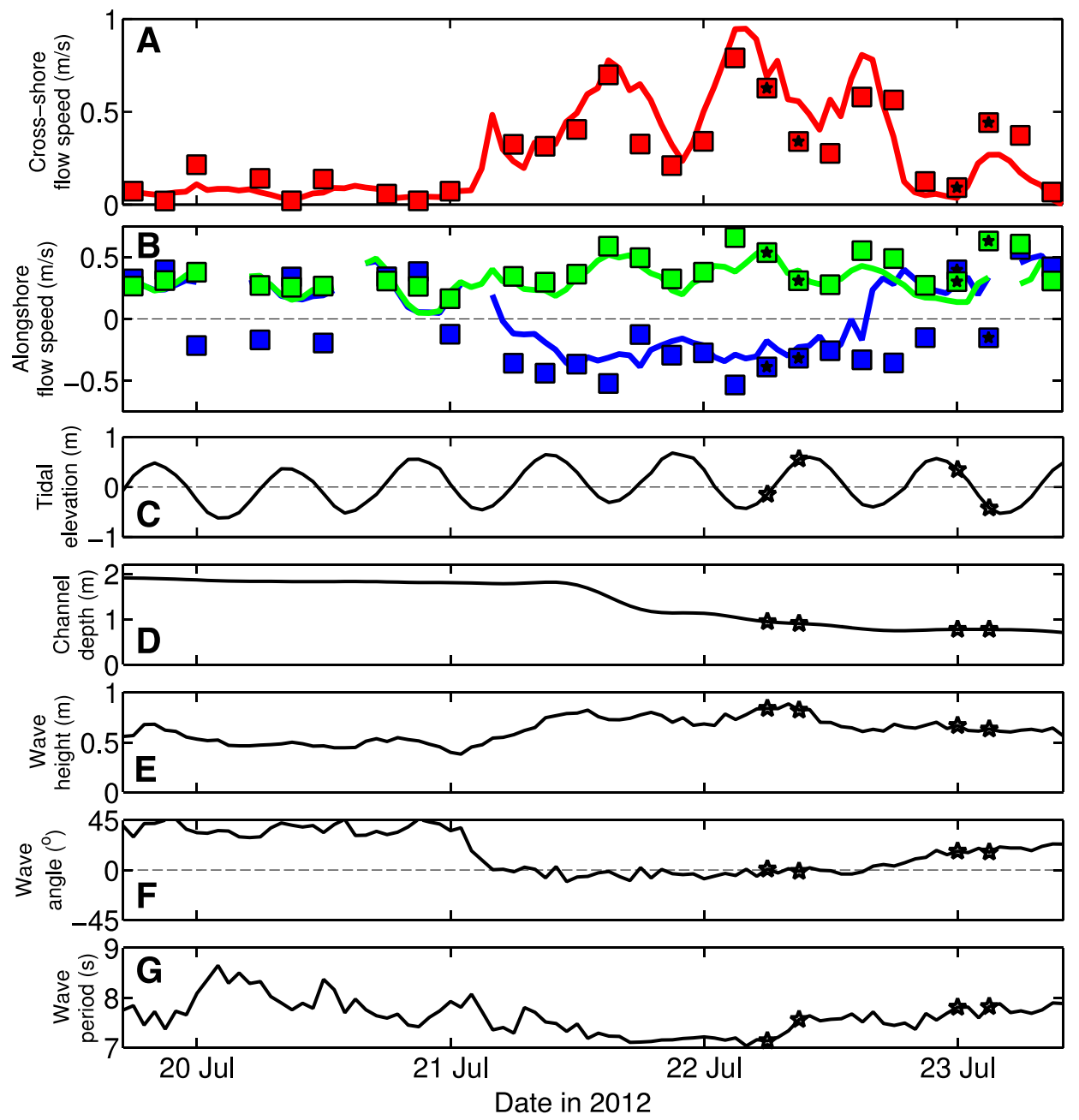

Figure 4.4. Observed (curves) and simulated (squares) properties versus date in 2012. (A) Observed (curve, maximum cross-shore speed observed at locations of red symbols in Figure 4.2C) and simulated (squares, maximum cross-shore speed observed near rip channel) 1-hr mean offshore-directed current speed from 20 to 23 Jul (Figure 4.3), (B) observed (curves, estimated from observations at locations of blue and green symbols in Figure 4.2C) and simulated (squares, estimated from simulated flows in regions on north and south side of the channel) alongshore flow speeds, (C) tidal elevation relative to mean sea level, (D) channel depth (difference between seafloor elevation near the channel center and on the sides of channel), and incident (8.5 m depth) (E) significant wave height, (F) energy-weighted wave direction (relative to shore-perpendicular, positive values are waves from the south), and (G) centroidal wave period versus time. Stars indicate times plotted in Figure 4.5.

For the experiment beginning on $19 \mathrm{Jul}$, the offshore component of the flow (Figure 4.4A) observed in the channel initially (before $21 \mathrm{Jul}$ ) was small, and on $21 \mathrm{Jul}$ increased to a $0.5-1.0 \mathrm{~m} / \mathrm{s}$ rip current that persisted for 36 hours, with the strongest currents at low tides (Figure 4.4C). The depth of the channel (Figure 4.4D) initially was $2 \mathrm{~m}$, and 
accreted by $1 \mathrm{~m}$ from $21 \mathrm{Jul}$ to $23 \mathrm{Jul}$. The offshore wave height (Figure 4.4E) increased from approximately 0.5 to $0.8 \mathrm{~m}$, and the wave direction (Figure $4.4 \mathrm{~F}$ ) changed from $45^{\circ}$ south of shore normal to nearly normally incident, coincident with the increase in the offshore-directed flow speed (Figure 4.4A). The large decrease in the rip current speed on 22 Jul 15:00 coincided with a rising tide (Figure 4.4C), decreasing wave height (Figure 4.4D), and an increase in the incident wave obliquity (Figure 4.4E).

The simulated offshore-directed flow speeds (Figure 4.4A, symbols) are similar to the observations [normalized (by the range of the observations) root-mean-square difference $=0.15$, with weak flows on $20 \mathrm{Jul}$, followed by a strong tidally modulated rip current. The simulated alongshore components of the flows on the north and south sides of the channel (Figure 4.4B, symbols) also are similar to the observations (normalized rootmean-square difference $=0.32$ on the north side, and 0.25 on the south side), with primarily alongshore flows (flows on the north and south sides of the channel in the same direction) on 20 and $23 \mathrm{Jul}$ when the wave angle was largest, and with feeder current patterns (flows on the north and south sides converging toward the channel) on 21 and 22 Jul when the wave angle was closer to shore-normal. At some times on 20 and 23 July, the simulated alongshore flow speeds (using the method described above) have opposite signs on either side of the channel (feeder currents), whereas the observed flows were in the same direction (alongshore flow). At these times the simulations had predominately northward-directed flows on each side of the channel (consistent with the observations), with small regions of converging flows near the shoreline that were detected by the algorithm for estimating alongshore flows, but may not have been resolved by the in situ sensors.

\subsubsection{Flow patterns}

The observed and simulated plan view circulation patterns are compared with each other (Figure 4.5) at several times (stars in Figure 4.4) that were chosen to encompass a range of conditions (Table 4.1). 


\begin{tabular}{|c|c|c|c|c|c|}
\hline $\begin{array}{c}\text { Date and } \\
\text { time in } \\
2012\end{array}$ & $\begin{array}{c}\text { Tidal } \\
\text { elevation } \\
\text { (NAVD-88) }\end{array}$ & $\begin{array}{c}\text { Channel } \\
\text { depth } \\
(\mathrm{m})\end{array}$ & $\begin{array}{c}\text { Significant } \\
\text { wave height } \\
(\mathrm{m})\end{array}$ & $\begin{array}{c}\text { Wave angle } \\
\left({ }^{\circ} \text { S of shore- }\right. \\
\text { normal })\end{array}$ & $\begin{array}{c}\text { Wave } \\
\text { period } \\
(\mathrm{s})\end{array}$ \\
\hline 22 Jul 06:00 & -0.15 & 0.94 & 0.84 & 1 & 7.1 \\
\hline 22 Jul 09:00 & 0.56 & 0.90 & 0.82 & -1 & 7.6 \\
\hline 23 Jul 00:00 & 0.35 & 0.78 & 0.67 & 17 & 7.8 \\
\hline 23 Jul 03:00 & -0.42 & 0.77 & 0.63 & 16 & 7.8 \\
\hline
\end{tabular}

Table 4.1. Tidal elevation, channel depth, significant wave height, energy-weighted wave direction, and period corresponding to the centroid of the sea-surface elevation spectrum for 4 dates.

On 22 Jul 06:00 (Figure 4.5A), waves were near shore normal, and the observed and simulated flows have a rip current circulation pattern, with alongshore feeder currents converging at an offshore-directed rip jet in the deep channel. The pattern is asymmetric in both the observations and the simulations, with a stronger feeder current on the south side of the channel than on the north side. In the simulations, the rip jet flows along the north side of the channel, and turns northward and flows along the coast offshore of the channel. On 22 Jul 09:00 (Figure 4.5B), the bathymetry and wave conditions are similar to the conditions on $22 \mathrm{Jul}$ 06:00 (Figure 4.5A), and the tidal elevation is $0.7 \mathrm{~m}$ higher. The observed and simulated rip jet is located near the south side of the channel, and turns southward and flows along the coast offshore of the channel. The alongshore flows on the south side of the channel change sign in the cross-shore as part of a circulation cell. Although the simulated rip current circulation pattern is shoreward of the observed pattern (Figure 4.5B), the simulated current speeds are similar to those observed (Figure 4.4A, B), and both are weaker than during low tide [compare Figure 4.5B (high tide) with 4.5A (low tide)].

Relative to the 22 Jul examples (Figure 4.5A, B), on 23 Jul 00:00 (Figure 4.5C) and 23 Jul 03:00 (Figure 4.5D), the wave height is smaller, the wave angle is more southerly, and the channel depth was $0.3 \mathrm{~m}$ shallower (Table 4.1, Figure 4.4). The tidal elevation for $23 \mathrm{Jul} \mathrm{00:00}$ is about $0.2 \mathrm{~m}$ lower than the other higher tide case (22 Jul 09:00), and the tidal elevation for $23 \mathrm{Jul}$ 03:00 is about $0.3 \mathrm{~m}$ lower than the other lower tide case (22 Jul 
06:00). The difference in tidal elevation between the two cases on $23 \mathrm{Jul}$ is approximately $0.8 \mathrm{~m}$, similar to the $0.7 \mathrm{~m}$ difference between the $22 \mathrm{Jul}$ cases. On $23 \mathrm{Jul}$ 00:00, the simulated and observed alongshore flows are weak and relatively alongshore uniform, with slightly onshore-directed flows south of the channel, slightly weaker flows in the channel, and slightly offshore-directed flows on the north side of the channel (Figure 4.5C). On $23 \mathrm{Jul}$ 03:00, the tidal elevation is nearly $0.8 \mathrm{~m}$ lower than at 00:00, and the alongshore flow is stronger and more variable (Figure 4.5D). The simulations and observations have strong offshore-directed flows shifted toward the downstream edge of the channel. The strongest simulated offshore-directed flow is downstream of the northernmost channel sensor, suggesting that the sparse fixed observations may not have resolved the largest flows in the circulation patterns. The observed flows on both sides of the channel are northward on $23 \mathrm{Jul}$ 03:00, similar to the simulations. The predominately northward-directed simulated flow patterns on 20 and 23 July sometimes included regions with southward-directed flows near the shoreline on the downstream side of the channel (Figure 4.5D, near $y=700 \mathrm{~m}$ ). These small-scale features sometimes were diagnosed as feeder currents by the algorithm used to estimate characteristic alongshore flows (Figure 4.4B) and were not resolved by the in situ sensors (Figure 4.5D).

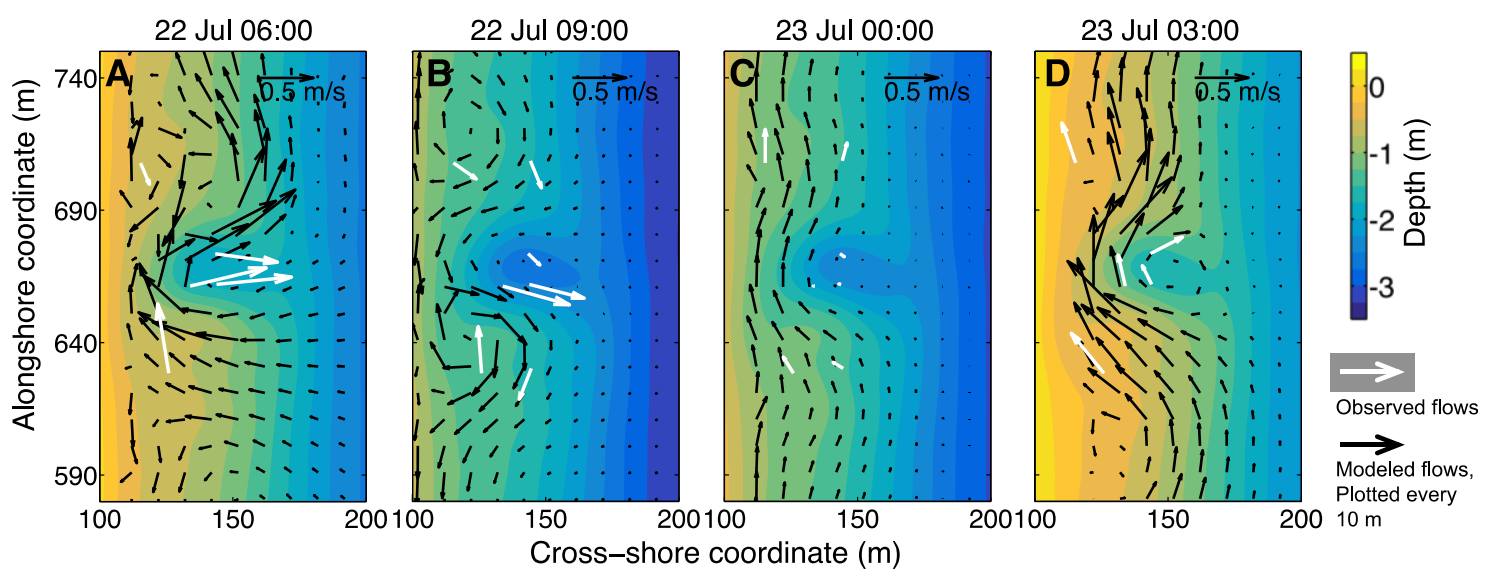

Figure 4.5. Bathymetry (relative to mean sea level, color contours, scale on the right) and observed (white arrows) and simulated (black arrows, plotted every $10 \mathrm{~m}$ ) 1-hr-averaged flows (scale arrow in each panel, upper right) versus cross- and alongshore coordinate. The observed flows on the sides of the channel are from current meters $\sim 0.8 \mathrm{~m}$ above the seafloor, and the observed flows in the channel are depth-averaged from current profilers. The current meters on the sides of the channel at cross-shore distance $\sim 140 \mathrm{~m}$ were dry at low tide, and thus observations from those sensors are not shown in A or D. The simulated flows from the 3D model are depth-averages. 


\subsection{Dynamics of flows in channels}

\subsubsection{Breaking-wave driven setup and flows}

The observed and simulated changes in the flow patterns and speeds (Figures 4.4 and 4.5) can be explained by considering the patterns of wave height and angle, wave dissipation, and breaking-wave driven setup. For an idealized rip channel bathymetry (Figure 4.6A) normally incident waves with offshore $H_{s i g}=0.8 \mathrm{~m}$ (Figure 4.6B) shoal and refract over the complex bathymetry and circulation (Figure 4.6A). Waves break in the shallow water on the sides of the channel, where the ratio of their height to the water depths reaches a threshold for breaking $\gamma_{b r}$ [Thornton and Guza, 1983; Raubenheimer et al., 1996; Apotsos et al., 2008a], but not in the deeper channel (Figure 4.6C). When waves break, their momentum flux is transferred to the water column, driving an increasing water level or setup [Longuet-Higgins and Stewart, 1964; Lentz and Raubenheimer, 1999; Raubenheimer et al., 2001, and many others] (Figure 4.6D, dashed contours). Consequently, the surfzone sea surface is higher on the shallow sides than within the depression, resulting in pressure gradients (Figure 4.6D, color contours) that drive the rip current circulation pattern (Figure 4.6A). There is a small setdown of the mean sea level (not shown) as waves shoal. For shore-normal incident waves and idealized bathymetry, the feeder currents are symmetric and the rip jet is centered in the channel (Figure 4.6A). A secondary circulation cell associated with breaking onshore of the channel is present near the shoreline, with flows directed away from the channel.

For the same idealized bathymetry, but with obliquely incident waves $\left(\theta=10^{\circ}\right)$ the patterns of wave transformation, dissipation, and setup (Figure 4.7) are similar to the shore-normal wave case (Figure 4.6), except that waves have an oblique angle at breaking (Figure 4.7B), leading to asymmetries about the channel in the patterns of the dissipation (Figure 4.7C) and sea-level (Figure 4.7D). The obliquely incident breaking waves drive an alongshore flow (Figure 4.7A). The spatial pattern of breaking-wavedriven setup (Figure 4.7D) accelerates and decelerates the alongshore flow near the channel, leading to a strong offshore-directed flow (rip jet) at the downstream edge of the channel. Similar to the shore-normal case, there are secondary circulation cells near the shoreline. 

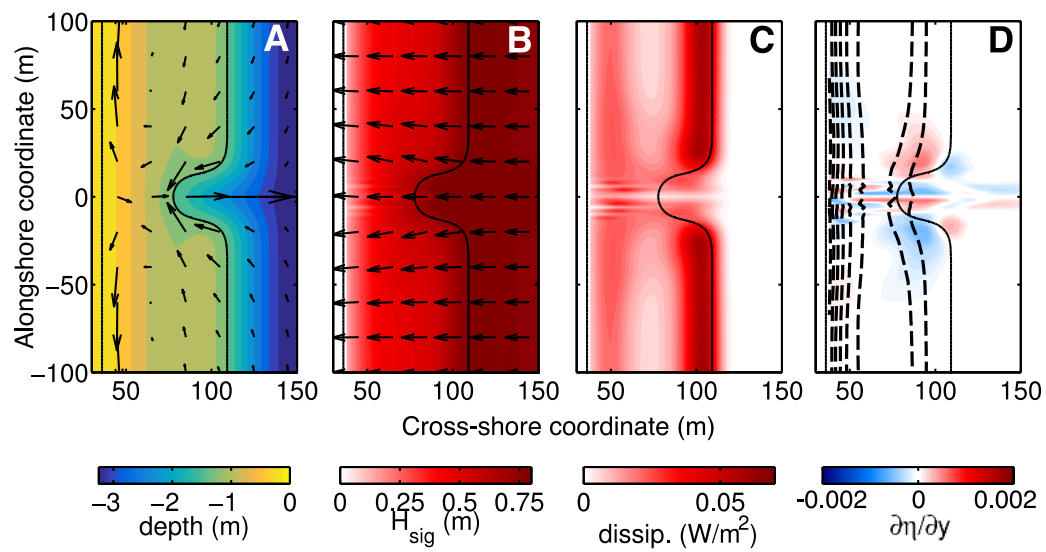

Figure 4.6. Simulation results for incident waves with offshore $H_{\text {sig }}=0.8 \mathrm{~m}$ and $\theta=0^{\circ}$ and a 1-m deep channel in a 1-m high bar with $\sim 0.9 \mathrm{~m}$ water depth on the bar crest. (A) Model bathymetry (relative to mean sea level, color contours) with black contours at -1.25 , and $0 \mathrm{~m}$ (shown in all panels) and depth-averaged flows (arrows plotted every 20 $\mathrm{m}$, maximum magnitude $=0.61 \mathrm{~m} / \mathrm{s}$ ), (B) wave height (color contours) and wave angle (direction of arrows), (C) wave dissipation (color contours), and (D) mean sea level $\eta$ (dashed contours every $0.01 \mathrm{~m}$ beginning at $0.01 \mathrm{~m}$ and increasing shoreward) and $\partial \eta / \partial y$ (color contours) as a function of cross- and alongshore coordinate.

The idealized examples (Figures 4.6 and 4.7) have wave heights and tidal elevations similar to those observed on 22 Jul 06:00 (Table 4.1, Figure 4.4). In the model simulation of 22 Jul 06:00 (Figure 4.8), the waves were nearly shore-normal, similar to the first idealized case (Figure 4.6). Unlike the shore-normal idealized case (Figure 4.6), the simulated rip jet on 22 Jul 06:00 was not centered on the channel (Figure 4.8A). The simulated patterns of flows, wave height and angle, wave dissipation, and sea level for 22 Jul 06:00 (Figure 4.8) are more similar to the idealized case with obliquely incident waves (Figure 4.7) than to the case with shore-normal waves (Figure 4.6), suggesting that the circulation response is sensitive to small deviations of the incident wave angle from shore-normal. In addition, irregularities in the bathymetry (e.g., differences in the water depths on the north and south shoals, and deviations of the orientation of the channel thalweg from shore normal) may lead to asymmetries in the flow pattern. The idealized case with the oblique wave angle has a rip current jet speed that is about $25 \%$ smaller than for the shore-normal case, likely because the onshore component of wave breaking acceleration that drives setup is smaller, and the presence of an alongshore flow suppresses the rip jet. Thus, the effect of the wave angle change is significant and large enough to explain the difference in the observed rip speed between $23 \mathrm{Jul}$ 03:00 and 22 
Jul 06:00, although the differences in wave height and tidal elevation likely also were important.
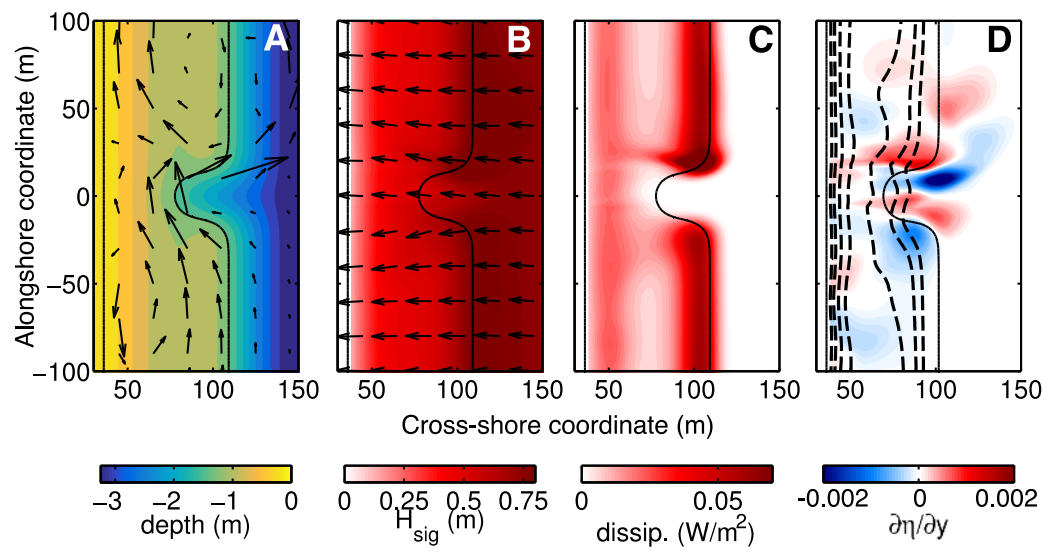

Figure 4.7. Simulation results for incident waves with offshore $H_{s i g}=0.8 \mathrm{~m}$ and $\theta=10^{\circ}$ and a 1-m deep channel in a 1-m high bar with $\sim 0.9 \mathrm{~m}$ water depth on the bar crest. (A) Model bathymetry (relative to mean sea level, color contours) with black contours at -1.25 , and $0 \mathrm{~m}$ (shown in all panels) and depth-averaged flows (arrows plotted every 20 $\mathrm{m}$, maximum magnitude $=0.58 \mathrm{~m} / \mathrm{s}$ ), (B) wave height (color contours) and wave angle (direction of arrows), (C) wave dissipation (color contours), and (D) mean sea level $\eta$ (dashed contours every $0.01 \mathrm{~m}$ beginning at $0.01 \mathrm{~m}$ and increasing shoreward) and $\partial \eta / \partial y$ (color contours) as a function of cross- and alongshore coordinate.
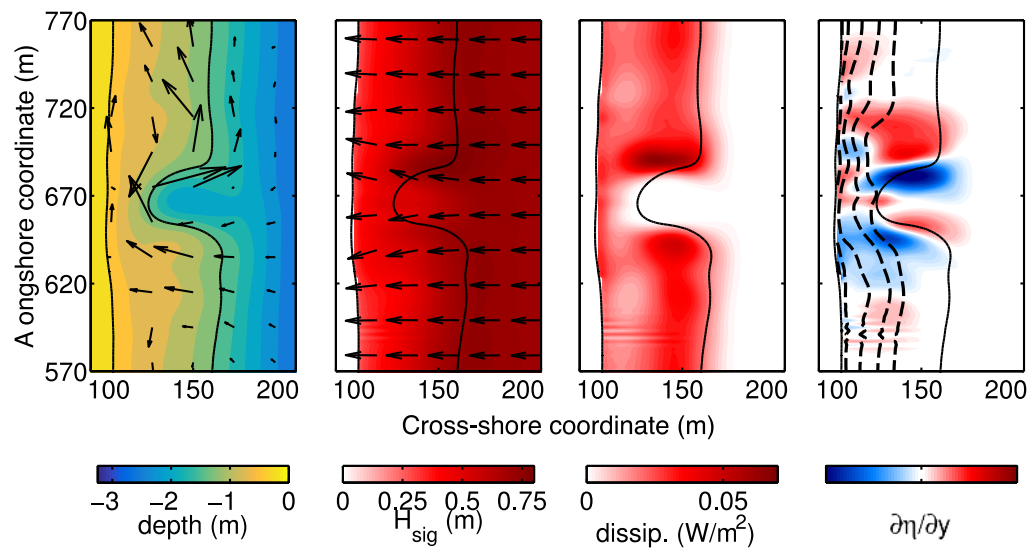

Figure 4.8. Simulation results for observed wave conditions, tidal elevation, and bathymetry for $22 \mathrm{Jul} 06: 00$, with incident waves with offshore $H_{s i g}=0.84 \mathrm{~m}$ and $\theta=1^{\circ}$ and a 0.94-m deep channel. (A) Model bathymetry (relative to mean sea level, color contours) with black contours at -1.25 , and $0 \mathrm{~m}$ (shown in all panels) and depth-averaged flows (arrows plotted every $20 \mathrm{~m}$, maximum magnitude $=0.53 \mathrm{~m} / \mathrm{s}$ ), (B) wave height (color contours) and wave angle (direction of arrows), (C) wave dissipation (color contours), and (D) mean sea level $\eta$ (dashed contours every $0.01 \mathrm{~m}$ beginning at $0.01 \mathrm{~m}$ and increasing shoreward) and $\partial \eta / \partial y$ (color contours) as a function of cross- and alongshore coordinate. 


\subsubsection{Momentum balances}

To investigate the dynamics of the flow pattern changes, the relative sizes of terms in the depth-averaged cross- and alongshore momentum balances are considered, including advective accelerations, the vortex force (wave refraction on mean flows) [Smith, 2006], pressure gradients (mean sea-surface tilts), wave breaking accelerations (nonconservative wave forcing, including both depth-limited breaking and roller contributions), bottom stress (computed with a quadratic drag law), and viscosity (horizontal mixing) [Kumar et al., 2012].

For the idealized case with offshore $H_{\text {sig }}=0.8 \mathrm{~m}$ and $\theta=0^{\circ}$, on the sides of the channel $(y<-40 \mathrm{~m}$ and $y>40 \mathrm{~m}$ in Figures 4.9 and 4.10$)$ cross-shore wave breaking accelerations (Figure 4.9D, Figure 4.10A green curve) are balanced by pressure gradients (Figure 4.9C, Figure $4.10 \mathrm{~A}$ red curve), while the other terms are small. The breaking waves drive a cross-shore setup on the sides of the channel. In the middle of the channel $(-20 \mathrm{~m}<y<20$ $\mathrm{m}$, Figures 4.9 and 4.10), the water depth is large and there is little depth-induced wave breaking, so the wave breaking accelerations are small. In this region, a large cross-shore pressure gradient (Figure 4.9C and Figure 4.10A red curve) near the center of the channel is balanced by horizontal advection (Figure 4.9A and Figure 4.10A grey curve) representing the spatial accelerations of the rip current jet. Waves that propagated through the channel without breaking subsequently break near the shoreline, and wave breaking accelerations (Figure 4.9D) are balanced by a wave setup at the shoreline onshore of the channel (Figure 4.9C). On the edges of the channel (-40 $\mathrm{m}<y<-20 \mathrm{~m}$ and $20 \mathrm{~m}<y<40 \mathrm{~m}$ ), cross-shore wave breaking accelerations, pressure gradient, and advection are in balance. The sea level is lower on the edges of the channel $(-40 \mathrm{~m}<y<$ $-20 \mathrm{~m}$ and $20 \mathrm{~m}<y<40 \mathrm{~m})$ than farther from the channel $(y<-40 \mathrm{~m}$ and $y>40 \mathrm{~m})$ because of the presence of the rip current circulation pattern. Thus the wave-breaking acceleration (Figure $4.10 \mathrm{~A}$ green curve) partially is balanced by the pressure gradient (Figure 4.10A red curve) and partially by advective accelerations (Figure 4.10A grey curve) driving onshore flows in this region. 


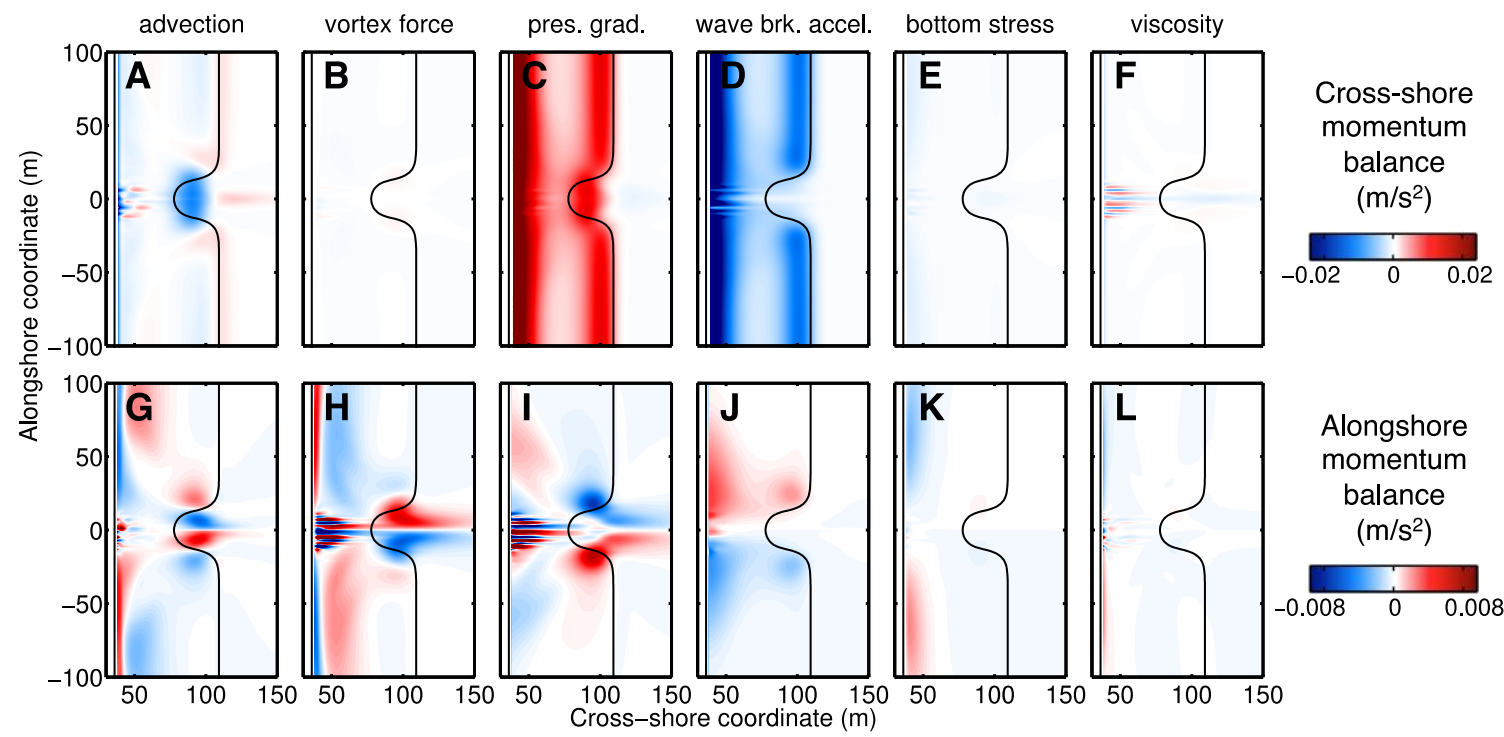

Figure 4.9. Contours (scales on the right) of depth-averaged cross- (top row) and alongshore (bottom row) momentum balance terms (terms labeled above top row) for the simulation with offshore $H_{\text {sig }}=0.8 \mathrm{~m}$ and $\theta=0^{\circ}$ (shore-normal) and idealized bathymetry (also see Figure 4.6) with -1.25 and $0 \mathrm{~m}$ bathymetric contours (black curves).

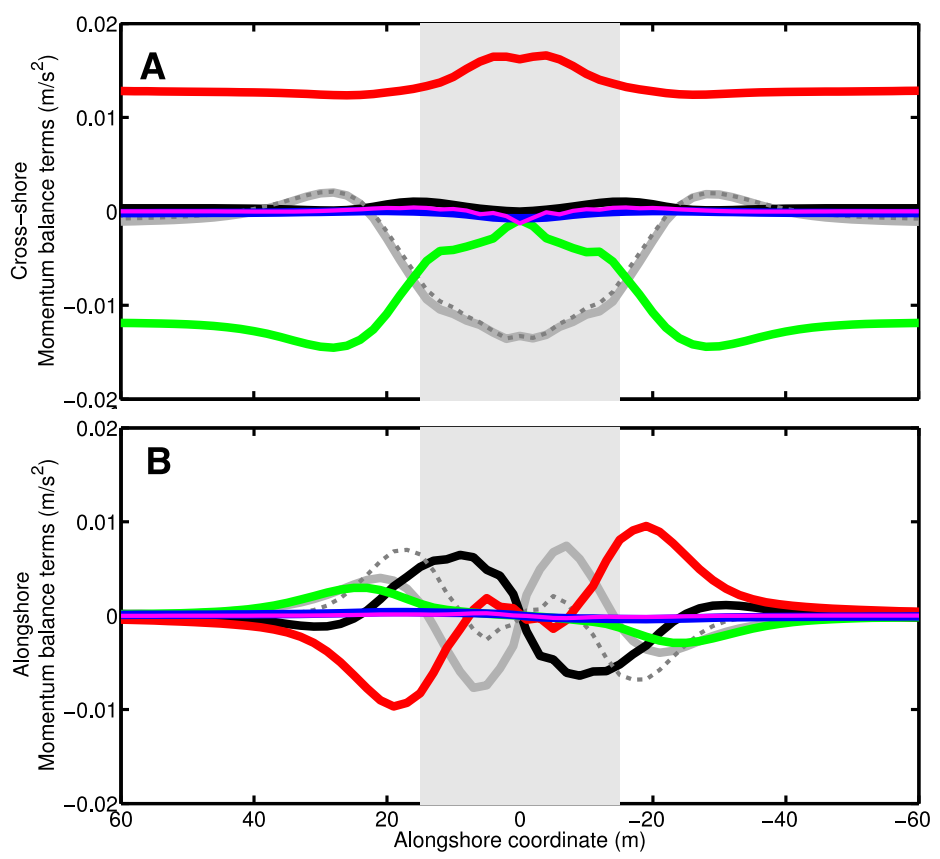

Figure 4.10. Depth-averaged (A) cross- and (B) alongshore pressure gradient (red curves), wave breaking acceleration (green), horizontal advection (grey), horizontal vortex force (black), horizontal mixing (purple), bottom stress (blue), and the sum of advection and vortex force (dashed grey) versus alongshore coordinate for the simulation with offshore $H_{\text {sig }}=0.8 \mathrm{~m}$ and $\theta=0^{\circ}$ (shore-normal). The terms are from model results at cross-shore coordinate $x=88 \mathrm{~m}$. 
In the alongshore balance (Figure 4.9, bottom row, Figure 4.10B) for the simulation with offshore $H_{\text {sig }}=0.8 \mathrm{~m}$ and $\theta=0^{\circ}$ (also see Figure 4.6), near and in the channel, the pressure gradients (Figure 4.9I, Figure 4.10B red curve) are approximately in balance with the sum of the advection terms and the vortex force (Figure 4.9G and Figure 4.10B green curve), representing the spatial accelerations of the feeder currents and rip jet caused by the sea-level tilts (spatial pattern of breaking-wave-driven setup, Figure 4.9J and Figure 4.10B red curve) and the effect of waves refracting on currents. The alongshore component of wave breaking accelerations (caused by waves refracting away from the channel) is directed away from the channel and opposes the pressure gradients that drive feeder currents (compare green with red curve in Figure 4.10B). Advective accelerations and the vortex force (resulting from waves refracting on currents) (Figure $4.9 \mathrm{H}$ and Figure 4.10B black curve) also are important outside of the channel, with the sum of advection and vortex force (Figure 4.10B dashed grey curve) approximately balancing the sum of pressure gradients (Figure 4.10B red curve) and wave breaking accelerations (Figure 4.10B green curve).

The cross-shore momentum balance for the idealized case with offshore $H_{s i g}=0.8 \mathrm{~m}$ and $\theta=10^{\circ}$ (Figure 4.11A, also see Figure 4.7) is similar to the shore-normal wave case (Figure 4.10A), but the cross-shore wave breaking accelerations and setup are reduced, and there is an alongshore asymmetry owing to a breaking-wave driven northward alongshore flow. The alongshore balance (Figure 4.11B) near the channel is similar to the shore-normal case (Figure 4.10B), but the alongshore current shifts features downstream (to the left in Figures 4.10 and 4.11) and suppresses the rip jet. Far from the channel (not shown), the alongshore balance is between bottom stress, breaking acceleration, advection, and the vortex force (with advection and vortex force terms approximately in balance) [Kumar et al., 2012], similar to the balance of bottom stress and the cross-shore gradient of the shear component of the wave radiation stress [Thornton and Guza, 1986; Guza et al., 1986; Feddersen et al., 1998; Apotsos et al., 2008b, Hansen et al., 2015; and many others]. 


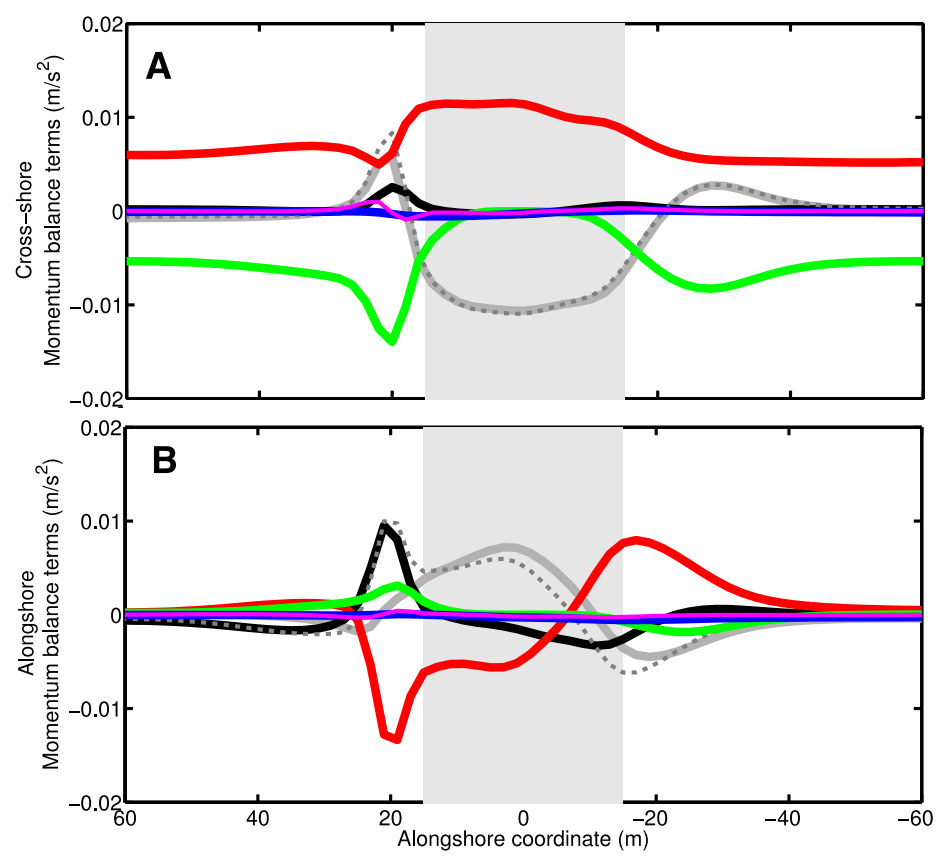

Figure 4.11. Depth-averaged (A) cross- and (B) alongshore pressure gradient (red curves), wave breaking acceleration (green), horizontal advection (grey), horizontal vortex force (black), horizontal mixing (purple), bottom stress (blue), and the sum of advection and vortex force (dashed grey) versus alongshore coordinate for the simulation with offshore $H_{s i g}=0.8 \mathrm{~m}$ and $\theta=10^{\circ}$ (shore-normal). The terms are from model results at cross-shore coordinate $x=88 \mathrm{~m}$.

The momentum balances for the conditions observed on $22 \mathrm{Jul}$ 06:00 (incident waves with offshore $H_{\text {sig }}=0.84 \mathrm{~m}$ and $\theta=1^{\circ}$ ) (Figure 4.12, also see Figure 4.8) are more similar to the idealized oblique wave example (Figure 4.11, $\theta=10^{\circ}$ ) than to the idealized shorenormal example (Figures 4.9 and 4.10, $\theta=0^{\circ}$ ). In particular, the alongshore momentum balance terms for both $22 \mathrm{Jul}$ 06:00 (Figure 4.12) and the idealized case with $\theta=10^{\circ}$ (Figure 4.11) have similar patterns that are asymmetric about the channel and shifted downstream relative to the shore-normal wave case (Figure 4.10). The differences in the bathymetry (the observed bathymetry was similar to an incised terrace, whereas the simulations have a slightly more pronounced bar) lead to different patterns of wave breaking accelerations and setup. In the idealized cases (Figures 4.6 and 4.7), breaking and setup were large over the bar, near zero in the trough shoreward of the bar, and large near the shoreline. For simulations with the observed bathymetry, the weakening of the setup in the trough was less pronounced (Figure 4.8) In addition, estimates of the observed wave directions relative to shore normal may be corrupted by compass errors 
(few degrees) and ambiguity in defining the shoreline orientation on non-uniform bathymetry.

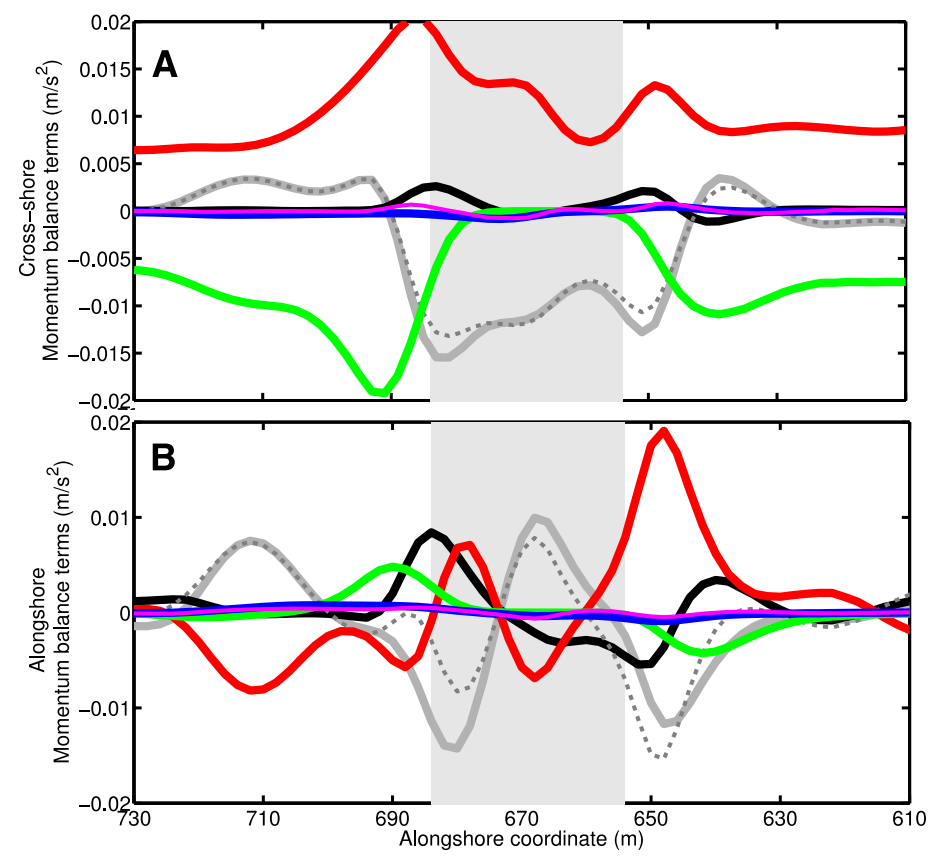

Figure 4.12. Depth-averaged (A) cross- and (B) alongshore pressure gradient (red curves), wave breaking acceleration (green), horizontal advection (grey), horizontal vortex force (black), horizontal mixing (purple), bottom stress (blue), and the sum of advection and vortex force (dashed grey) versus alongshore coordinate for the simulation of the observations on $22 \mathrm{Jul}$ 06:00 with offshore $H_{\text {sig }}=0.84 \mathrm{~m}$ and $\theta=1^{\circ}$ (south of shorenormal). The terms are from model results at cross-shore coordinate $x=131 \mathrm{~m}$.

\subsection{Discussion}

The spatial patterns of wave properties, wave dissipation, and sea-surface elevation (Figures 4.6-4.8) and depth-averaged momentum balances (Figures 4.9-4.12) suggest that for nearly shore-normal waves, the strength and pattern of the circulation is controlled primarily by alongshore gradients in wave dissipation, which for a given bathymetry are affected most strongly by the wave height and tidal elevation. For example, for a set of simulations with idealized bathymetry, fixed tidal elevation, and shore-normal waves, the patterns and strength of wave dissipation (Figure 4.13, top row) and setup (Figure 4.13, bottom row) change with changing wave height. For waves that are small relative to the bar crest elevation $\left(H_{s i g, b r}<\gamma_{b r} h_{b a r}\right.$, where $H_{s i g, b r}$ is the wave height at breaking and $h_{b a r}$ is the depth on the bar crest), there is little wave dissipation 
on the bar (Figure 4.13A, B), the waves break close to the shoreline, and the sea-level tilt $\Delta \eta$ in the alongshore is near zero (Figure $4.13 \mathrm{G}, \mathrm{H}$ ). For moderate wave heights $\left(\gamma_{b r} h_{b a r}<H_{s i g, b r}<\gamma_{b r} h_{c h a n}\right.$, where $h_{c h a n}$ is the depth in the channel), the waves are large enough that there is breaking on the bar, but small enough that there is little breaking in the channel $\left(0.4 \mathrm{~m}<H_{s i g}<1.0 \mathrm{~m}\right.$, Figure $\left.4.13 \mathrm{C}, \mathrm{D}\right)$. In this regime, the alongshore sea-level tilt increases with increasing wave height (Figure 4.13I, J). For large wave heights $\left(H_{s i g, b r}>\gamma_{b r} h_{c h a n}\right)$, the waves break offshore of the channel, and are depth-limited in the channel and on the shallow sides. In this regime, the sea-level tilt in the alongshore is limited by the difference in the depths in the channel and on the sides, and does not increase with wave height $\left(H_{\text {sig,br }}>1 \mathrm{~m}\right.$, Figure $\left.4.13 \mathrm{~K}, \mathrm{~L}\right)$.

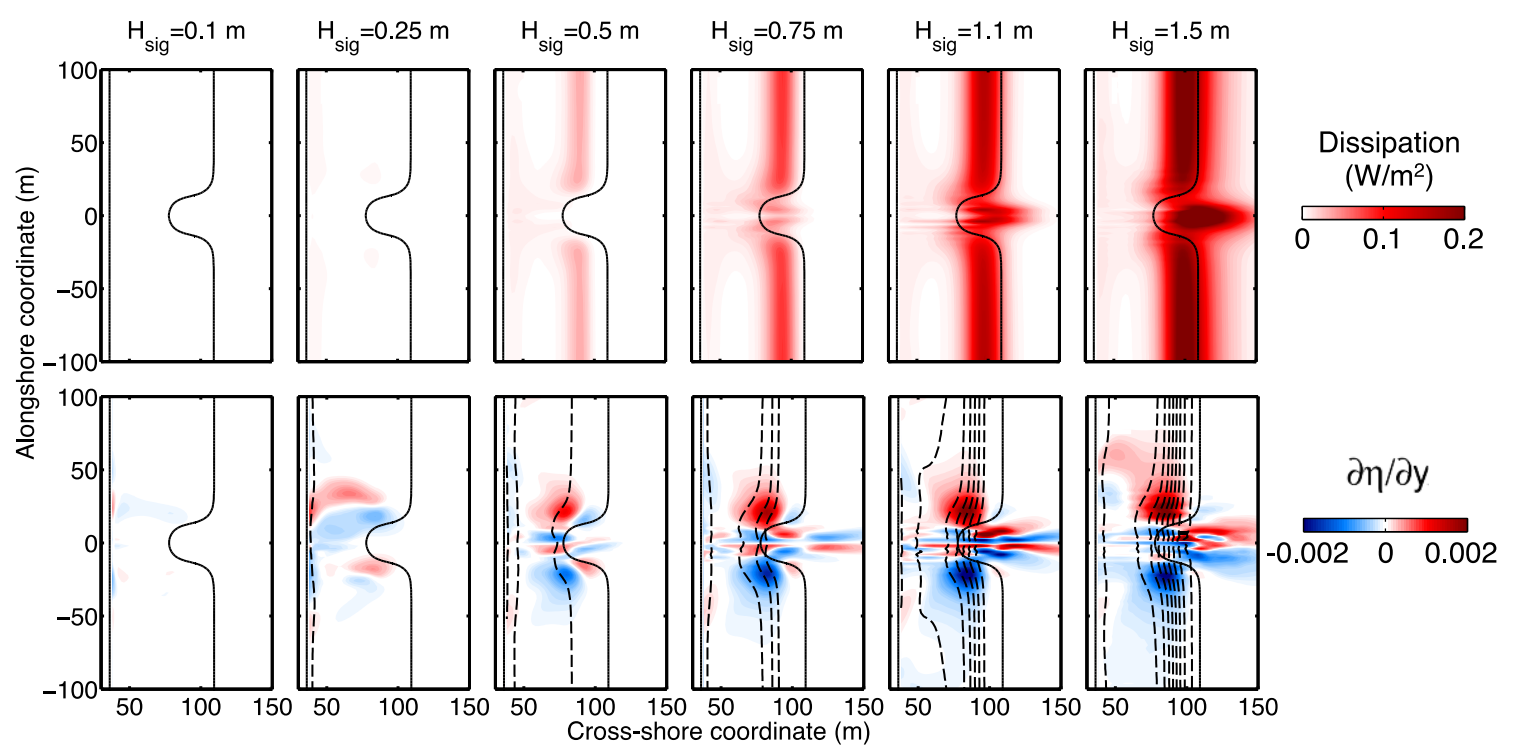

Figure 4.13. (A-F) Dissipation (color contours, scale on right) and (G-L) alongshore sea-surface tilts (color contours) and elevation (relative to mean sea level, dashed curves at $0.02 \mathrm{~m}$ intervals beginning at $0.01 \mathrm{~m}$ and increasing shoreward) for six model simulations for $0.1 \mathrm{~m}<H_{\text {sig }}<1.5 \mathrm{~m}$ (labeled above the top row of panels). The solid black curve in each panel is the $-1.25 \mathrm{~m}$ bathymetric contour.

A parameterization for the maximum alongshore sea-surface tilt $\Delta \eta$ and the corresponding maximum offshore-directed flow speed $U_{\max }$ based on wave and bathymetry properties (see Appendix) is correlated with results from the set of simulations with shore normal waves, fixed tidal elevation $(0.5 \mathrm{~m}$ depth on bar crest), fixed channel depth (1 $\mathrm{m}$ depth relative to bar crest), and a range of wave heights (Figure 
4.14). The sea-level tilt (Appendix, Equation 4.8.3) is near zero when waves are small and break only near the shoreline, increases with wave height when waves break on the shallow sides, but not in the channel, and reaches a maximum value (set by the difference in water depth between the channel and the bar) when waves break offshore of the bathymetric variability (Figure 4.14A). The corresponding parameterized $U_{\max }=$ $m(2 g \Delta \eta)^{1 / 2}$ (Appendix, Equation 4.8.6 with $f_{v}=1$ ) is correlated with sea-level tilts in the simulations (Figure 4.14B, $r^{2}=0.97$ for $m=1.1$ ). This fit excludes simulations with $H_{s i g, b r}<0.5 \mathrm{~m}$, for which the simulated sea-surface tilt is larger than the tilt (zero) from the parameterization (Figure 4.14A), and the rip current speed is weaker than estimated given the sea-level tilt (Figure 4.14B). This discrepancy could be caused by simplifications in the parameterization, including the representation of the breaking process by a bore with a single height and frequency that breaks at a threshold given by $\gamma_{b r}$, and by the neglect of refraction over the inhomogeneous bathymetry and circulation. Despite the errors for small waves, the simulated rip speed is parameterized well given wave and bathymetric properties (Equation 4.8.6 with $f_{v}=1$ ), with the sea-surface tilts estimated with Equation 4.8.3 (Figure 4.14C).
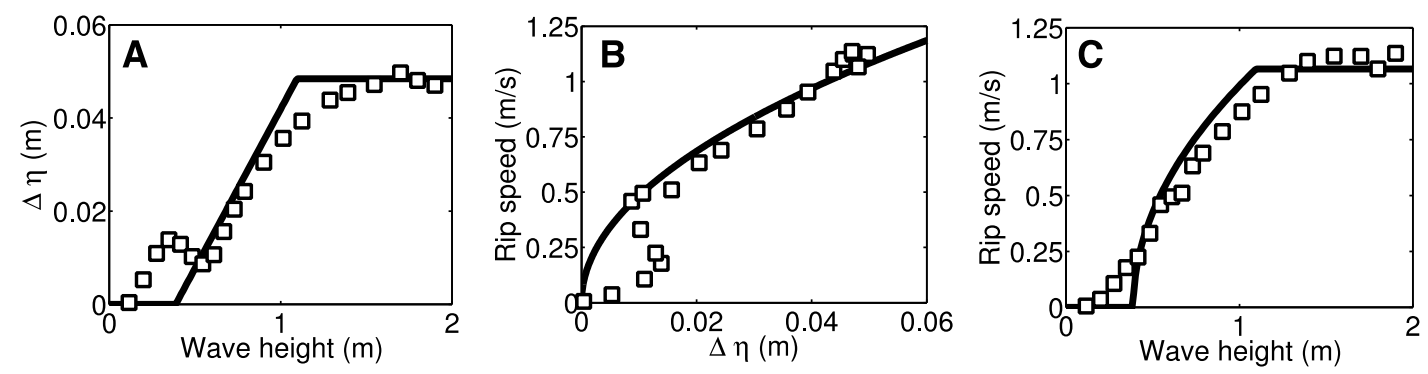

Figure 4.14. (A) Maximum alongshore sea-level tilt versus breaking wave height from simulations (squares) and estimated by a parameterization (curve, Appendix Equation 4.8.3). (B) Rip current speed versus maximum sea-level tilt $\Delta \eta$ from simulations (squares) and from a fit (curve) to $U_{\max }=m(2 g \Delta \eta)^{1 / 2}$ (Appendix Equation 4.8.6 for $f_{v}=1$, where $\Delta \eta$ is estimated from the simulated sea surfaces) that excludes simulations with $H_{\text {sig,br }}<0.5 \mathrm{~m}\left(r^{2}=0.97\right.$ for $\left.m=1.1\right)$. (C) Rip current speed versus breaking wave height from simulations (squares) and estimated by a parameterization (curve) using $U_{\max }=m(2 g \Delta \eta)^{1 / 2}$ with parameterized sea-surface tilt (Appendix Equation 4.8.3).

The dependence of the maximum offshore-directed flow speed on wave angle was tested for a set of idealized simulations with fixed wave height $\left(H_{\text {sig }}=0.75 \mathrm{~m}\right)$, fixed tidal 
elevation ( $0.5 \mathrm{~m}$ depth on bar crest), fixed channel depth ( $1 \mathrm{~m}$ relative to bar crest), and a range of wave angles (Figure 4.15). The parameterization for $U_{\max }$ (Appendix, Equation 4.8.6) suggests that for increasing wave angle, $U_{\max }$ is reduced owing to weakening of the setup and the sea-level tilt (Appendix, Equation 4.8.1) and to the suppression of cross-shore flows by the presence of an alongshore current. The factor $f_{v}$ is included to account for the presence of the alongshore flow (Appendix, Equation 4.8.6b), which can be approximated from wave properties and a drag coefficient. The sensitivity of the offshore-directed flow speed to wave angle in the parameterization (Figure 4.15, solid black curve) is similar to the numerical model results (Figure 4.15, squares). Differences between the simulations and the simple model may result from errors in estimates of the sea level tilt and the alongshore flow speed. The parameterization suggests that the presence of the alongshore current (Figure 4.15, red dashed curve, for which $\theta_{b r}=0$ in Equation 4.8.1a, but not in estimating the alongshore current and thus $f_{v}$ ) has a large effect on the offshore-directed flow speed, whereas the small reduction of the sea-level tilt with increasing wave angle has a small effect (Figure 4.15, gray dashed curve, for which $0<\theta_{b r}<20^{\circ}$ in Equation 4.8.1a, and $f_{v}=1$ ).

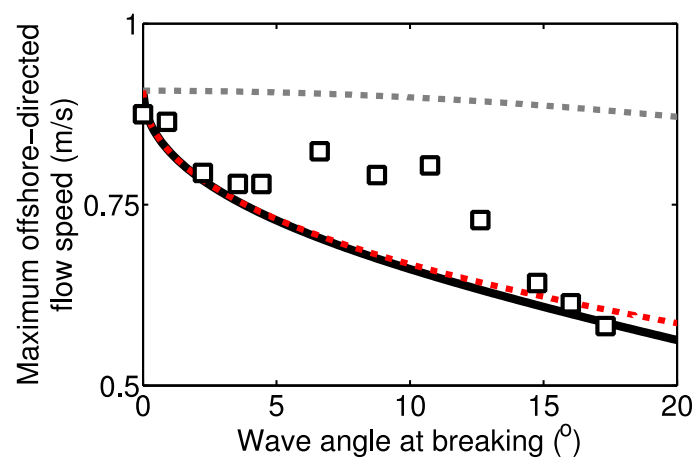

Figure 4.15. Maximum offshore-directed flow speed versus breaking wave angle from simulations with $H_{s i g}=0.75 \mathrm{~m}$ (squares) and estimated by a parameterization (black solid curve) using $U_{\max }=m(2 g \Delta \eta)^{1 / 2} f_{v}$ with parameterized sea-surface tilt (Appendix Equation 4.8.3). The weakening of the offshore-directed flow speed that results from the presence of an alongshore current (red dashed curve, with $\theta_{b r}=0^{\circ}$ in Appendix Equation 4.8.1) is larger than the weakening resulting from reduced setup for obliquely incident waves (gray dashed curve, with $f_{v}=1$ ).

For all of the observations and for the simulations with idealized bathymetry and wave conditions, the maximum offshore-directed flow speeds also are correlated with the 
parameter based on the wave height and angle and the depths on the bar and in the channel (Figure 4.16, Appendix, Equations 4.8.3 and 4.8.6). The factor $f_{v}$ is included to account for the presence of the alongshore flow (Appendix, Equation 4.8.6b). The ratio of wave height to water depth at breaking $\gamma_{b r}$ was treated as a free parameter (the values of $\gamma_{b r}$ used in the model wave dissipation formulation and in the parameterization are not expected to be the same), and $\gamma_{b r}=0.55$ and $\gamma_{b r}=0.75$ yielded the best fits for the observations and simulations, respectively (fits are not sensitive to changes in $\gamma_{b r}$ of $20 \%$ ). The simulations use synthetic rip channel bathymetries with a range of depths that incise the bar, a range of tidal elevations, and a range of wave heights and angles. Both the simulated $\left(r^{2}=0.85\right)$ and observed $\left(r^{2}=0.45\right)$ maximum rip speeds are correlated with the parameter $(2 g \Delta \eta)^{1 / 2} f_{v}$ (Figure 4.16). The correlations are lower $\left(r^{2}=0.75\right.$ and $r^{2}=0.35$ for simulations and observations, respectively) if $f_{v}$ is excluded (i.e., if $f_{v}=1$ ) (Appendix, Figure 4.17). Errors in the estimate of the alongshore flow speed may lead to errors in the rip speed, and estimates of the observed alongshore flow speed may be improved by using a drag law accounting for wave orbital velocities [Longuet-Higgins, 1970; Grant and Madsen, 1979].

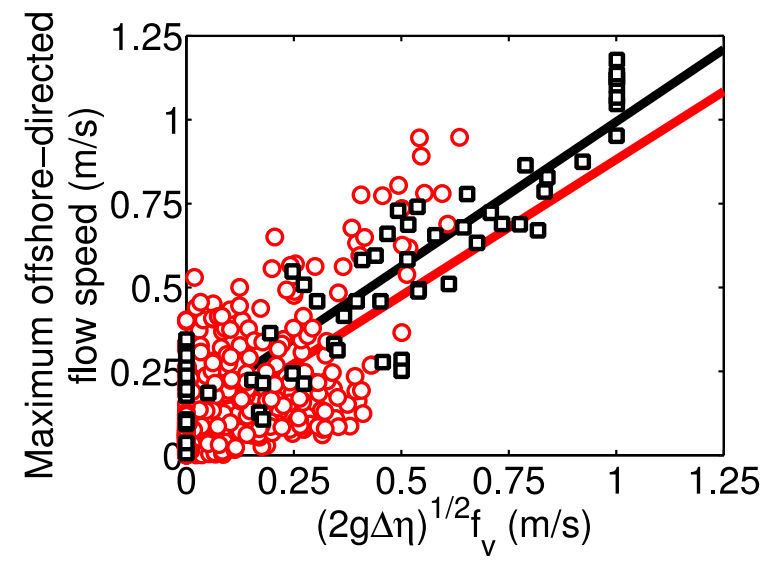

Figure 4.16. Maximum offshore-directed flow speed $U_{\max }$ for the observations (red circles) and a set of simulations (black squares) with a range of wave heights and angles, tidal elevations, and channel depths versus $x=(2 g \Delta \eta)^{1 / 2} f_{v}$. The maximum offshoredirected flow speed can be estimated from a least squares linear fit with slope $m$ and intercept $b$ to the simulations (black line, $m=0.86, b=0.13, r^{2}=0.85$ ) and the observations (red line, $m=0.81, b=0.07, r^{2}=0.45$ ). 
The assumption of a simplified bar-trough geometry is satisfied for the simulations with idealized interrupted bar bathymetry (Figure 4.16 black symbols), but not for the observations. For example, in some cases the dredged channels had a shallow bump offshore of the deepest part of the channel, and thus waves may have broken offshore of the location of the deepest part of the channel (Figure 4.2). The observed bathymetry sometimes had a bar-trough configuration, but at other times was closer to a shallow terrace (Figure 4.2). Although the bathymetry was surveyed densely with a watercraft system when conditions permitted, the spatially sparse in situ altimeters may not have resolved all the bathymetric variability and evolution between watercraft surveys. In addition, the observed bathymetry was not necessarily nearly alongshore uniform far from the channel, and larger-scale circulation patterns may influence the flows near the channel.

Disagreement between the observations, simulations, and the parameterization may be caused by representing the wave field in simulation boundary conditions and in the parameterization with the bulk parameters $H_{s i g, b r}$ and $\theta_{b r}$, rather than the full frequencydirectional spectrum. In addition, rip jets may oscillate in strength and position owing to wave groups [Shepard et al., 1941; Sonu, 1972; Kennedy and Dalrymple, 2001; MacMahan et al., 2004], short-crested breaking [Peregrine, 1998; Clark et al., 2012], and instabilities [Haller and Dalrymple, 2001; Kennedy and Zhang, 2008; Geiman and Kirby, 2013], which may impact the mean rip current speed. COAWST is a phaseaveraged model and does not include infragravity or short-crested wave effects (important to eddy generation) [Olabarrieta and Warner, 2012; Kumar and Feddersen, 2014].

\subsection{Conclusions}

In conclusion, observations and numerical simulations (COAWST) of rip currents and alongshore flows in channels dredged across the surfzone were used to determine the dominant controls on breaking-wave driven circulation patterns near strong bathymetric inhomogeneities. The model simulates the observations accurately, including the dependence of the rip current speed on the wave height and angle, tidal elevation, and 
bathymetry. Depth-averaged momentum balances from simulations suggest that alongshore gradients in wave breaking on non-uniform bathymetry lead to sea-level patterns that drive rip current circulation patterns and spatial accelerations of alongshore flows. Small increases in the wave angle result in asymmetries in the flow patterns and dynamical balances, and significant reduction of the rip current speed. Alongshore sealevel tilts and rip current speeds are weak when the wave height is small relative to the depth on the bar crest, increase with wave height when waves break on the bar, but not in the channel, and plateau at a maximum value when waves are large enough that they break in the channel. Both the observed and simulated (for a wider range of conditions than observed) rip speeds are correlated with a parameterization based on the incident wave height and angle, the water depth in the channel and on the bar, the criterion for depth-limited wave breaking, and the alongshore flow speed (which can be parameterized with wave height and angle and a drag coefficient).

\subsection{Appendix: Offshore-directed flow speed}

Alongshore gradients in breaking-wave-driven setup drive spatial accelerations of alongshore flows and rip current circulation patterns. Here, a parameter is derived that approximates the strength of offshore-directed flows in the surf zone as a function of wave properties, bathymetry, and tidal elevation. The size of the alongshore sea-level differences that drive the feeder currents and alongshore flow speed changes is estimated using cross-shore momentum balances. The speed of feeder currents (or the change in speed of an alongshore flow) is estimated as a function of the alongshore sea-level differences. Based on observations and simulations, the offshore-directed flow near the channel is assumed to scale with the feeder current speed (or the change in speed of an alongshore flow).

\subsubsection{Alongshore sea-level tilt}

Cross-shore sea-surface elevation profiles are estimated on one of the shallow sides of the channel and near the channel center. Assuming that the cross-shore pressure gradient and wave breaking accelerations are the dominant terms [Longuet-Higgins and Stewart, 1964; Lentz and Raubenheimer, 1999; Raubenheimer et al., 2001], and that the wave height is 
depth-limited at breaking $H_{s i g, b r}=\gamma_{b r}(h+\eta)$, the sea-level profile $\eta(x)$ is given by [Bowen et al., 1968]:

$$
\begin{gathered}
\frac{\partial \eta}{\partial x}=-\frac{1}{16} \gamma_{b r}^{2}\left(\cos ^{2} \theta_{b r}+\frac{1}{2}\right) \frac{\partial h}{\partial x} \text { if } H_{s i g, b r}=\gamma_{b r} h \\
\frac{\partial \eta}{\partial x}=0 \text { if } H_{s i g, b r}<\gamma_{b r} h
\end{gathered}
$$

These relationships assume that $\eta$ is small compared with the total water depth, and that bottom stress and wave rollers do not have a first-order impact on the sea-level profile [Apotsos et al., 2007], and ignore setdown of the water level during wave shoaling and the effects of wave refraction and wave-current interaction. The wave angle is approximated as constant and equal to the wave angle at breaking $\theta_{b r}$. The alongshore position of the cross-shore profile of setup on the shallow sides $\eta_{b a r}(x)$ is chosen to be far enough from the channel that the setup is not influenced by the near-channel circulation pattern (the setup is the same as if there were an alongshore uniform beach). The alongshore position of the profile in the channel $\eta_{\text {chan }}(x)$ is just alongshore of the center of the channel where there is expected to be a relatively high sea surface associated with converging flows. Equation 4.8.1a and 4.8.1b can be solved for $\eta(x)$ at a given alongshore position at each time using incident wave properties, cross-shore profiles of the bathymetry, and relationships governing wave shoaling, refraction, and depth-limited breaking. The maximum of the difference between the two profiles is chosen as a scale for the alongshore sea-level difference that drives feeder currents:

$$
\Delta \eta=\max \left(\eta_{b a r}(x)-\eta_{c h a n}(x)\right)
$$

(Equation 4.8.2)

To find an approximate analytical expression for $\Delta \eta$ as a function of incident wave properties and the geometry of the bathymetry, Equations 4.8 .1 and 4.8 .2 can be solved analytically under further simplifying assumptions. The pattern of wave breaking on an interrupted-bar bathymetric geometry differs for different wave heights, tidal elevations, and channel depths. If waves are small relative to the depth on the bar and break onshore of the alongshore variability $\left(H_{s i g, b r}<\gamma_{b r} h_{b a r}\right.$, regime $\left.1, \mathrm{R} 1\right)$ in a region near the shoreline where the beach is alongshore uniform, there is no alongshore variability in the setup and $\Delta \eta \approx 0$. If waves break on the shallow sides, but not in the deeper channel $\left(\gamma_{b r} h_{b a r}<H_{s i g, b r}<\gamma_{b r} h_{c h a n}\right.$, regime 2, R2), the setup on the sides of the channel scales 
with the change in water depth from breaking $\left(h_{b}=H_{s i g, b r} / \gamma_{b r}\right)$ to the bar crest $\left(h_{b a r}\right.$, the depth on the bar at the cross-shore position of the maximum alongshore sea-level difference). Ignoring setdown, the setup in the middle of the channel is approximately zero, and the sea-level difference is given by $\Delta \eta \approx \frac{1}{16} \gamma_{b r}^{2}\left(\frac{H_{s i g, b r}}{\gamma_{b r}}-h_{b a r}\right)\left(\cos ^{2} \theta_{b}+\frac{1}{2}\right)$. If waves are large relative to the depths in the channel and on the bar, and thus break offshore of the alongshore variability $\left(H_{s i g, b r}>\gamma h_{c h a n}\right.$, regime $\left.3, \mathrm{R} 3\right)$, the waves are depth limited in the channel and on the bar, and $\Delta \eta \approx \frac{1}{16} \gamma_{b r}^{2}\left(h_{c h a n}-h_{b a r}\right)\left(\cos ^{2} \theta_{b}+\right.$ $\left.\frac{1}{2}\right)$, where $h_{\text {chan }}$ and $h_{b a r}$ are the depths at the cross-shore position of maximum alongshore difference in sea level. In summary:

$$
\Delta \eta \approx \frac{1}{16} \gamma_{b r}^{2}\left(\cos ^{2} \theta_{b}+\frac{1}{2}\right)\left(\begin{array}{cc}
0 & \text { if } H_{\text {sig,br }}<\gamma_{b r} h_{b a r}(R 1) \\
H_{\text {sig,br }} / \gamma_{b r}-h_{\text {bar }} & \text { if } \gamma_{b r} h_{b a r}<H_{s i g, b r}<\gamma_{b r} h_{\text {chan }}(R 2) \\
h_{\text {chan }}-h_{\text {bar }} & \text { if } H_{\text {sig,br }}>\gamma_{b r} h_{\text {chan }}(R 3)
\end{array}\right)
$$

\subsubsection{Flow speed as a function of alongshore sea-level difference}

The surfzone momentum balance can be expressed in vector form as:

$$
\frac{\partial \vec{v}}{\partial t}-\vec{v} \times \vec{\omega}+\nabla\left(\frac{1}{2}|\vec{v}|^{2}\right)=-\nabla(g \eta)+\vec{F}
$$

where $\vec{v}$ is the velocity, $\eta$ is the mean sea level, and $\vec{\omega}=\nabla \times \vec{v}$. The term $-\nabla(g \eta)$ is the pressure gradient term, and $\vec{F}$ represents the other forcing terms (bottom stress, wave breaking accelerations, horizontal mixing). Assuming steady flow, taking the dot product with a unit vector in the flow direction, and integrating along a streamline, the first and second terms on the left hand side go to zero. With the additional assumption that the sealevel tilt is the dominant forcing term $(\vec{F} \approx 0)$, then $\nabla\left(\frac{1}{2}|\vec{v}|^{2}+g \eta\right) \approx 0$. Considering alongshore flows from a region of high sea level far from the channel toward the region of lower sea level near the channel:

$$
v_{\text {chan }}^{2}-v_{\text {bar }}^{2} \approx 2 g \Delta \eta
$$

where $\Delta \eta$ is the alongshore sea-level difference, $v_{b a r}$ is the flow speed far from the channel, and $v_{\text {chan }}$ is the flow speed on the edge of the channel (just outside of the region where flows change direction). For shore-normal waves and approximately alongshore uniform bathymetry, the alongshore flows on the bar far from the channel are zero $\left(v_{b a r}=0\right)$, and the speed of flows accelerated by the alongshore sea-level tilt $\Delta \eta$ can be 
estimated approximately as $v_{\text {chan }} \approx(2 g \Delta \eta)^{1 / 2}$ If the waves are obliquely incident and there is a nonzero alongshore flow $v_{A}$ far from the channel, the speed of the flows near the channel can be estimated approximately from Equation 4.8 .5 as $v_{\text {chan }} \approx$ $\left(2 g \Delta \eta+v_{A}^{2}\right)^{1 / 2}$. The alongshore current $v_{A}$ can be estimated in many ways [Bowen, 1969; Longuet-Higgins, 1970; Thornton, 1970; Thornton and Guza, 1986; Guza et al., 1986; Feddersen et al., 1998; and many others] given wave heights and angles, bathymetry, and a drag coefficient. Here, $v_{A}$ was estimated using a balance between wave breaking accelerations (breaking obliquely incident waves) and a quadratic bottom stress formulation $\left(C_{d} v^{2}\right)$ with a drag coefficient $C_{d}=0.0033$. Rearranging the expression for $v_{\text {chan }}$ to solve for the change in speed of the alongshore flow $\Delta v=\left(v_{\text {chan }}-v_{A}\right)$ gives $\Delta v \approx(2 g \Delta \eta)^{1 / 2}\left[\left(1+\frac{v_{A}^{2}}{2 g \Delta \eta}\right)^{1 / 2}-\frac{v_{A}}{(2 g \Delta \eta)^{1 / 2}}\right]$. Based on observations and simulations, it is assumed that the speed of offshore-directed flows near channels scales with the feeder current speed or with the change in the alongshore flow speed, and thus:

$$
\begin{aligned}
& U_{\max } \approx m(2 g \Delta \eta)^{1 / 2} f_{v} \\
& f_{v}=\left[\left(1+\frac{v_{A}^{2}}{2 g \Delta \eta}\right)^{1 / 2}-\frac{v_{A}}{(2 g \Delta \eta)^{1 / 2}}\right]
\end{aligned}
$$

where $m$ is an unknown coefficient that is expected to be order one, $\Delta \eta$ is the alongshore sea-level tilt (Equations 4.8.3), and $f_{v}$ is a factor accounting for the effect of the presence of the alongshore flow $v_{A}$ on the offshore-directed flow speed.

For shore normal waves, $f_{v}=0$, and the estimated maximum offshore-directed flow speed is:

$$
U_{0} \approx m(2 g \Delta \eta)^{1 / 2}
$$

When an alongshore flow is present, $0<f_{v}<1$, and $U_{\max } / U_{0}$ is expected to be reduced. Comparison of observed and simulated $U_{\max } / U_{0}$ (symbols in Figure 4.17) with the parameter $f_{v}$ (curve in Figure 4.17, Equation 4.8.6b) as a function of $v_{A} / U_{0}$ suggests that $f_{v}$ qualitatively describes the reduction in the maximum offshore-directed flow speed resulting from the presence of an alongshore flow. All of the observations with $U_{\max } /$ $U_{0}>2$ (not shown in Figure 4.17, less than $5 \%$ of the observations) had $U_{0}<0.2 \mathrm{~m} / \mathrm{s}$, and thus are sensitive to small errors in the denominator $U_{0}$. Although the correlations 
between the parameterization and the simulations $\left(r^{2}=0.21\right)$ and observations $\left(r^{2}=0.06\right)$ are low, they are statistically different than 0 at the $95 \%$ level.

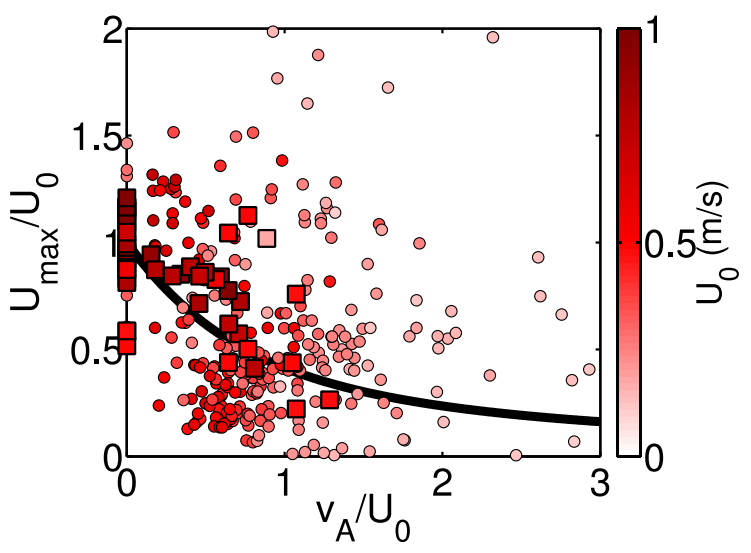

Figure 4.17. Simulated (squares), observed (circles), and parameterized (curve, Equation 4.8.6b) maximum offshore-directed flow speed $U_{\max }$ (Equation 4.8.6a) normalized by $U_{0}$ versus $v_{A} / U_{0}$, where $U_{0}=(2 g \Delta \eta)^{1 / 2}$ (color contours) is the estimated offshore-directed flow for shore normal waves (Equation 4.8.7, $m$ is chosen to be 1) and $v_{A}$ is the estimated alongshore flow speed.

\subsection{Acknowledgements}

Data are available via e-mail to the corresponding author. We thank the PVLAB field crew for rapidly deploying a remarkable number of sensors in five surfzone rip channels in difficult conditions, the USACE Field Research Facility for excellent field support, and members of the COAWST user community for assistance with the model development. We thank John Warner, Nirnimesh Kumar, Tuba Özkan-Haller, Steve Lentz, John Trowbridge, and Matthieu de Schipper for helpful discussions. Support was provided by ASDR\&E, NDSEG, ONR, and NSF. 


\subsection{References}

Aagaard, T., B. Greenwood, and J. Nielsen (1997), Mean currents and sediment transport in a rip channel, Mar. Geol., 140(1-2), 25-45, doi:10.1016/S00253227(97)00025-X.

Apotsos, A., B. Raubenheimer, S. Elgar, R. T. Guza, and J. A. Smith (2007), Effects of wave rollers and bottom stress on wave setup, J. Geophys. Res., 112, C02003, doi:10.1029/2006JC003549.

Apotsos, A., B. Raubenheimer, S. Elgar, and R. T. Guza (2008a), Wave-driven setup and alongshore flows observed onshore of a submarine canyon, J. Geophys. Res., 113(C7), C07025. doi:10.1029/2007JC004514.

Apotsos, A., B. Raubenheimer, S. Elgar, and R. T. Guza (2008b), Testing and calibrating parametric wave transformation models on natural beaches, Coast. Eng., 55(3), 224-235, doi:10.1016/j.coastaleng.2007.10.002.

Austin, M., T. Scott, Jeff Brown, Jenna Brown, J. MacMahan, G. Masselink, and P. Russell (2010), Temporal observations of rip current circulation on a macro-tidal beach, Cont. Shelf. Res., 30, 1149-1165, doi:10.1016/j.csr.2010.03.005.

Austin, M. J., G. Masselink, T. M. Scott, and P. E. Russell (2014), Water-level controls on macro-tidal rip currents, Cont. Shelf Res., 75(C), 28-40, doi:10.1016/j.csr.2013.12.004.

Battjes, J. A. and J. Janssen (1978), Energy loss and setup due to breaking of random waves, Proc. $16^{\text {th }}$ Int. Conf. on Coast. Eng., ASCE, 569-587.

Booij, N., R. Ris, and L. H. Holthuijsen (1999), A third-generation wave model for coastal regions: 1. Model description and validation, J. Geophys. Res., 104, 76497666, doi:10.1029/98jc02622.

Borthwick, A. G. L., and Y. L. M. Foote (2002), Wave-induced nearshore currents at a tri-cuspate beach in the UKCRF, Proc. ICE-Water and Maritime Eng., 154(4), 251-263, doi:10.1680/wame.2002.154.4.251

Bowen, A. J., D. L. Inman, and V. P. Simmons (1968), Wave 'set-down' and set-up, J. Geophys. Res., 73(8), 2569-2577, doi:10.1029/JB073i008p02569.

Bowen, A. J., and D. L. Inman (1969), Rip currents: 2. Laboratory and field observations, J. Geophys. Res., 74(23), 5479-5490 doi:10.1029/JC074i023p05479.

Bowen, A. J. (1969), The generation of longshore currents on a plane beach, J. Mar. Res., 27, 206-215.

Brander, R. W., and A. D. Short (2001), Flow kinematics of low-energy rip current systems, J. Coast. Res., 17(2), 468-481. 
Bruneau, N., B. Castelle, P. Bonneton, R. Pedreros, R. Almar, N. Bonneton, P. Bretel, J.P. Parisot, and N. Sénéchal (2009), Field observations of an evolving rip current on a meso-macrotidal well-developed inner bar and rip morphology, Cont. Shelf Res., 29(14), 1650-1662, doi:10.1016/j.csr.2009.05.005.

Buhler, O., and T. E. Jacobson (2001), Wave-driven currents and vortex dynamics on barred beaches, J. Fluid. Mech., 449, 313-340, doi:10.1017/s0022112001006322.

Chapman, D. C. (1985), Numerical treatment of cross-shelf open boundaries in a barotropic coastal ocean model, J. Phys. Oc., 15, 1060-1075.

Chen, Q., R. Dalrymple, J. Kirby, A. Kennedy, and M. Haller (1999), Boussinesq modeling of a rip current system, J. Geophys. Res., 104(C9), 20617-20637, doi: 10.1029/1999JC900154.

Clark, D. B., S. Elgar, and B. Raubenheimer (2012), Vorticity generation by short-crested wave breaking, Geophys. Res. Lett., 39(24), doi:10.1029/2012GL054034.

Dalrymple, R. A. (1975), A mechanism for rip current generation on an open coast, $J$. Geophys Res., 80(24), 3485-3487, doi:10.1029/JC080i024p03485.

Dalrymple, R. A., and C. J. Lozano (1978), Wave-current interaction models for rip currents, J. Geophys. Res., 83(C12), 6063-6071, doi:10.1029/jc083ic12p06063.

Dalrymple, R., J. MacMahan, A. Reniers, and V. Nelko (2011), Rip Currents, Ann. Rev. Fluid. Mech., 43, 551-581, doi:10.1146/annurev-fluid-122109-160733.

Dusek, G., and H. Seim (2013), A probabilistic rip current forecast model. J. Coast. Res., 289, 909-925, doi:10.2112/JCOASTRES-D-12-00118.1.

Feddersen, F., R. T. Guza, S. Elgar, and T. H. C. Herbers (1998), Alongshore momentum balances in the nearshore, J. Geophys. Res., 103(C8), 15667-15676, doi:10.1029/98JC01270.

Feddersen, F., E. L. Gallagher, R. T. Guza, and S. Elgar (2003), The drag coefficient, bottom roughness, and wave breaking in the nearshore, Coast. Eng., 48, 189-195, doi:10.1016/s0378-3839(03)00026-7.

Feddersen, F. and J. H. Trowbridge (2005), The effect of wave breaking on surf-zone turbulence and alongshore currents: a modeling study, J. Phys. Oc., 35(11), 21872203, doi:10.1175/jpo2800.1.

Flather, R. A. (1976), A tidal model of the northwest European continental shelf, Memoires de la Societe Royale de Sciences de Liege, 6, 141-164.

Garnier, R., A. Falqués, D. Calvete, J. Thiebot, and F. Ribas (2013), A mechanism for sandbar straightening by oblique wave incidence, Geophys. Res. Lett., 40(11), 2726-2730, doi:10.1002/grl.50464. 
Geiman, J. D., and J. T. Kirby (2013), Unforced oscillation of rip-current vortex cells, $J$. Phys. Oc., 43(3), 477-497, doi:10.1175/JPO-D-11-0164.1.

Gorrell, L., B. Raubenheimer, S. Elgar, and R. T. Guza (2011), SWAN predictions of waves observed in shallow water onshore of complex bathymetry, Coast. Eng., 58(6), 510-516, doi:10.1016/j.coastaleng.2011.01.013.

Grant, W., and O. Madsen (1979), Combined wave and current interaction with a rough bottom, J. Geophys. Res., 84, 1797-1808.

Guza, R., E. Thornton, and N. Christensen, Jr. (1986), Observations of steady longshore currents in the surf zone, J. Phys. Oc., 16(11), 1959-1969, doi:10.1175/15200485(1986)016<1959:ooslci>2.0.co;2.

Haas, K. A., and I. A. Svendsen (2002), Laboratory measurements of the vertical structure of rip currents, J. Geophys. Res., 107(C5), 3047, doi:10.1029/2001JC000911.

Haas, K. A., I. A. Svendsen, M. C. Haller, and Q. Zhao (2003), Quasi-three-dimensional modeling of rip current systems, J. Geophys. Res., 108(C7), doi:10.1029/2002JC001355.

Haidvogel, D. B., H. G. Arango, K. Hedstrom, A. Beckmann, P. Malanotte-Rizzoli, and A. F. Shchepetkin (2000), Model evaluation experiments in the North Atlantic Basin: Simulations in nonlinear terrain-following coordinates, Dyn. Atm. Oc., 32(3-4), 239-281, doi:10.1016/s0377-0265(00)00049-x.

Haidvogel, D., H. Arango, W. P. Budgell, B. D. Cornuelle, E. Curchitser, E. Di Lorenzo, K. Fennel, W. R. Geyer, A. J. Hermann, L. Lanerolle, J. Levin, J. C. McWilliams, A. J. Miller, A. M. Moore, T. M. Powell, A. F. Shchepetkin, C. R. Sherwood, R. P. Signell, J. C. Warner, and J. Wilkin (2008), Ocean forecasting in terrainfollowing coordinates: model formulation and skill assessment of the Regional Ocean Modeling System, J. Comp. Phys, 227(7), 3595-3624, doi:10.1016/j.jcp.2007.06.016.

Haller, M. C., and R. A. Dalrymple (2001), Rip current instabilities, J. Fluid Mech., 433, 161-192, doi:10.1017/s0022112000003414.

Haller, M. C., R. A. Dalrymple, and I. A. Svendsen (2002), Experimental study of nearshore dynamics on a barred beach with rip channels, J. Geophys. Res., 107(C6), doi:10.1029/2001JC000955.

Hansen, J., B. Raubenheimer, J. List, and S. Elgar (2015), Modeled alongshore circulation and force balances onshore of a submarine canyon, J. Geophys. Res., 120, doi:10.1002/2014JCO10555. 
Hanson, J. L., H. C. Friebel, and K. K. Hathaway (2009), Coastal wave energy dissipation: observations and STWAVE-FP performance, $11^{\text {th }}$ Int. Workshop on Wave Hindcasting and Forecasting and 2nd Coastal Hazards Symposium, Halifax, Nova Scotia, Canada.

Hasselmann, K., T. P. Barnett, E. Bouws, H. Carlson, D. E. Cartwright, K. Enke, J. A. Ewing, H. Gienapp, D. E. Hasselmann, P. Kruseman, A. Meerburg, P. Müller, D. J. Olbers, K. Richter, W. Sell, and H. Walden (1973), Measurements of windandwave growth and swell decay during the Joint North Sea Wave Project (JONSWAP), Dtsch. Hydrogr. Z. Suppl., 12, A8.

Henderson, S. M., J. S. Allen and P. A. Newberger (2004), Nearshore sandbar migration predicted by an eddy-diffusive boundary layer model. J. Geophys. Res., 109(C6), doi:10.1029/2003JC002137

Houser, C., R. Arnott, S. Ulzhöfer, and G. Barrett (2013), Nearshore circulation over transverse bar and rip morphology with oblique wave forcing, Earth Surf. Proc Landforms, 38(11), 1269-1279, doi:10.1002/esp.3413.

Kennedy, A. B., and R. A. Dalrymple (2001), Wave group forcing of rip currents, Proc. Oc. Wave Meas. Anal., 1, ASCE, San Francisco, CA, 1426-1435.

Kennedy, A. B., and Y. Zhang, Y. (2008), The stability of wave-driven rip current circulation, J. Geophys. Res., 113(C3), doi:10.1029/2006JC003814

Kumar, N., G. Voulgaris, and J. C. Warner (2011), Implementation and modification of a three-dimensional radiation stress formulation for surf zone and rip-current applications, Coast. Eng., 58(12), 1097-1117. doi:10.1016/j.coastaleng.2011.06.009.

Kumar, N., G. Voulgaris, J. C. Warner, and M. Olabarrieta (2012), Implementation of the vortex force formalism in the coupled ocean-atmosphere-wave-sediment transport (COAWST) modeling system for inner shelf and surf zone applications, $O c$. Mod., 47, 65-95, doi:10.1016/j.ocemod.2012.01.003.

Kumar, N., and F. Feddersen (2014), Parameterizing eddy generation due to finite crest wave breaking, Young Coast. Sci. Eng. Conf., University of Delaware.

Lentz, S., and B. Raubenheimer (1999), Field observations of wave setup, J. Geophys. Res., 104(C11), 25867-25875, doi:10.1029/1999jc900239.

Long, J. W., and H. T. Özkan-Haller (2005), Offshore controls on nearshore rip currents, J. Geophys. Res., 110(C12), C12007, doi:10.1029/2005jc003018.

Longuet-Higgins, M. S., and R. W. Stewart (1964), Radiation stresses in water waves; a physical discussion, with applications, Deep Sea Res., 11(4), 529-562, doi:10.1016/0011-7471(64)90001-4. 
Longuet-Higgins, M. S. (1970), Longshore currents generated by obliquely incident sea waves, 1, J. Geophys. Res., 75(33), 6778-6789, doi:10.1029/jc075i033p06778.

MacMahan, J. H., A. J. H. M. Reniers, E. B. Thornton, and T. P. Stanton (2004), Infragravity rip current pulsations, J. Geophys. Res., 109(C1), C01033, doi:10.1029/2003JC002068.

MacMahan, J. H., E. B. Thornton, T. P. Stanton, and A. J. H. M. Reniers (2005), RIPEX: Observations of a rip current system, Mar. Geol., 218(1-4), 113-134, doi:10.1016/j.margeo.2005.03.019.

MacMahan, J. H., E. B. Thornton, and A. J. H. M. Reniers (2006), Rip current review, Coast. Eng., 53(2-3), 191-208, doi:10.1016/j.coastaleng.2005.10.009.

MacMahan, J. H., E. B. Thornton, A. J. H. M. Reniers, T. P. Stanton, and G. Symonds (2008), Low-energy rip currents associated with small bathymetric variations, Mar. Geol., 255(3-4), 156-164, doi:10.1016/j.margeo.2008.08.006.

MacMahan, J., Jeff Brown, Jenna Brown, E. Thornton, A. Reniers, T. Stanton, M. Henriquez, E. Gallagher, J. Morrison, M. J. Austin, T. M. Scott, and N. Sénéchal (2010), Mean Lagrangian flow behavior on an open coast rip-channeled beach: A new perspective, Mar. Geol., 268(1-4), 1-15, doi:10.1016/j.margeo.2009.09.011.

McWilliams, J. C., J. M. Restrepo, and E. M. Lane (2004), An asymptotic theory for the interaction of waves and currents in coastal waters, J. Fluid Mech., 511, 135-178, doi:10.1017/s0022112004009358.

Moulton, M., S. Elgar, and B. Raubenheimer (2014), Improving the time resolution of surfzone bathymetry using in situ altimeters, Oc. Dynam., 64(5), 755-770, doi:10.1007/s10236-014-0715-8.

Mulligan, R. P., A. E. Hay, and A. J. Bowen (2010), A wave-driven jet over a rocky shoal, J. Geophys. Res., 115(C10), doi:10.1029/2009JC006027.

Olabarrieta, M., and J. C. Warner (2012), InWave: The infragravity driver of the COAWST system, COAWST Workshop, Woods Hole, MA. 23-27 July, 2012.

Oltman-Shay, J., P. A. Howd, and W. A. Birkemeier (1989), Shear instabilities of the mean longshore current: 2. Field observations, J. Geophys. Res., 94(C12), 1803, doi:10.1029/JC094iC12p18031.

Peregrine, D. H. (1998), Surf zone currents, Theor. Comp. Fluid Dynam., 10(1-4), 295309, doi:10.1007/s001620050065.

Putrevu, U., J. Oltman-Shay, and I. A. Svendsen (1995), Effect of alongshore nonuniformities on longshore current predictions, J. Geophys. Res., 100, 16,11916,130 . 
Raubenheimer, B., R. T. Guza, and S. Elgar (1996), Wave transformation across the inner surf zone, J. Geophys. Res., 101(C11), 25589-25597, doi:10.1029/96jc02433.

Raubenheimer, B., S. Elgar, and R. T. Guza (2001), Field observations of wave-driven setdown and setup, J. Geophys. Res., 106(C3), 4629-4638, doi:10.1029/2000jc000572.

Reniers, A. J. H. M., E. B. Thornton, and J. A. Roelvink (2004), Morphodynamic modeling of an embayed beach under wave-group forcing, J. Geophys. Res., 109, C01030, doi:10.1029/2002JC001586.

Sancho, F. (1998), Unsteady nearshore currents on longshore varying topographies, Ph.D. thesis, Cent. for Appl. Coastal Res., Univ. of Del., Newark, Del.

Shchepetkin, A. F. and J. C. McWilliams (2005), The Regional Ocean Modeling System (ROM S): a split-explicit, free-surface, topography-following-coordinate ocean model, Oc. Mod., 9, 347-404, doi:10.1016/j.ocemod.2004.08.002.

Shchepetkin, A. F. and J. C. McWilliams (2009), Correction and commentary for " Ocean forecasting in terrain-following coordinates: Formulation and skill assessment of the Regional Ocean Modeling System'" by Haidvogel et al., J. Comp. Phys., 227, 3595-3624. J. Comp. Phys, 228, 8985-9000. doi:10.1016/j.jcp.2009.09.002.

Shepard, F. P., K. O. Emery, and E. C. La Fond (1941), Rip currents: a process of geological importance, J. Geol., 49(4), 337-369, doi:10.1086/624971.

Slinn, D. N., J. S. Allen, and R. A. Holman (2000), Alongshore currents over variable beach topography, J. Geophys. Res., 105(C7), 16971-16998, doi:10.1029/2000jc900051.

Smith, J. A. (2006), Wave-current interactions in finite depth, J. Phys. Oc., 36, 14031419, doi:10.1175/JPO2911.1.

Sonu, C. J. (1972), Field observation of nearshore circulation and meandering currents, $J$. Geophys. Res., 77(18), 3232-3247, doi:10.1029/JC077i018p03232.

Svendsen, I. A., and U. Putrevu (1990), Nearshore circulation with 3-d profiles, in Proc. 22nd Int. Coast. Eng. Conf., 241-254, Am. Soc. of Civ. Eng., New York.

Svendsen, I. A., K. A. Haas, and Q. Zhao (2000), Analysis of rip current systems, Proc. $27^{\text {th }}$ Coast. Eng. Conf., ASCE, Sydney, 1127-1140.

Tajima, Y. and O. S. Madsen (2006), Modeling near-shore waves, surface rollers and undertow velocity profiles, J. Waterways, Port, Coast. Ocean Eng., ASCE, 132(6), 429-438, doi:10.1061/ASCE0733-950X2006132:6429.

Thornton, E. B. (1970), Variation of longshore current across the surfzone, Proc. $12^{\text {th }}$ Int. Conf. Coast. Eng., New York, 291-308. 
Thornton, E. B., and R. T. Guza (1983), Transformation of wave height distribution, $J$. Geophys. Res., 88, 5925-5938.

Thornton, E. B., and R. T. Guza (1986), Surf zone longshore currents and random waves: Field data and models, J. Phys. Oc., 16, 1165-1178, doi:10.1175/15200485(1986)016<1165:szlcar>2.0.co;2.

Uchiyama, Y., J. C. McWilliams, and A. F. Shchepetkin (2010), Wave-current interaction in an oceanic circulation model with a vortex-force formalism: Application to the surf zone, Oc. Mod, 34(1-2), doi:10.1016/ j.ocemod.2010.04.002.

ver der Westhuysen, A. J. (2010), Modeling of depth-induced wave breaking under finite depth wave growth conditions, J. Geophys. Res., 115(C1), doi:10.1029/2009JC005433.

Warner, J. C., C. R. Sherwood, H. G Arango, R. P. Signell, and B. Butman (2005), Performance of four turbulence closure models implemented using a generic length scale method, Oc. Mod., 8, 81-113.

Warner, J. C., C. R. Sherwood, R. P. Signell, C. K. Harris, and H. G. Arango (2008), Development of a three-dimensional, regional, coupled wave, current, and sediment-transport model, Comp. and Geosci., 34(10), 1284-1306, doi:10.1016/j.cageo.2008.02.012.

Warner, J. C., B. Armstrong, R. He, and J. B. Zambon (2010), Development of a Coupled Ocean-Atmosphere-Wave-Sediment Transport (COAWST) modeling system, $O c$. Mod., 35(3), 230-244, doi:10.1016/j.ocemod.2010.07.010.

Wilson, G. W., H. T. Özkan-Haller, and R. A. Holman (2013), Quantifying the lengthscale dependence of surf zone advection, J. Geophys. Res., 118(5), 2393-2407, doi:10.1002/jgrc.20190.

Winter, G., A. R. van Dongeren, M. A. de Schipper, and J. S. M. van Thiel de Vries (2014), Rip currents under obliquely incident wind waves and tidal longshore currents, Coast. Eng., 89, 106-119, doi:10.1016/j.coastaleng.2014.04.001.

Wu, C. S., and P.L-F. Liu (1984), Effects of nonlinear inertial forces on nearshore currents, Coast. Eng., 8, 15-32. doi:10.1016/0378-3839(84)90020-6.

Yu, J., and D. N. Slinn (2003), Effects of wave-current interaction on rip currents, $J$. Geophys. Res., 108(C3), 3088, doi:10.1029/2001JC001105. 


\section{Chapter 5:}

\section{Conclusions and future work}

\subsection{Conclusions}

Seafloor perturbation experiments were performed to study the feedbacks between surfzone waves, currents, sediment transport, and evolving morphology. Holes were excavated in the inner surf zone and channels were dredged across the surf zone on an ocean beach near Duck, NC. The perturbations to the surfzone seafloor resulted in rapid bed-elevation changes and complex flow patterns. Observations of these strong morphodynamic and hydrodynamic responses, along with theory and numerical models, were used to answer questions about surfzone processes that could not have been addressed through passive observations. In particular:

- Observations of the evolving bathymetry in excavated holes were used to make the first field estimates of the surfzone morphological diffusivity, which describes the rate of seafloor smoothing by waves and currents on a sloping bed (Chapter 2) [Moulton et al., 2014a]. The diffusivity inferred from observations was consistent with a classic bedload transport theory [Meyer-Peter and Müller, 1948; Soulsby and Damgaard, 2005] in which the diffusivity scales with the three-halves power of the bed shear stress (computed from observed waves and currents). This study demonstrated that for some features, divergences in downslope transport are important or even dominant in controlling seafloor change. The results from investigating the evolution of steep morphological features can be used to constrain parameterizations of gravity-driven transport in nearshore sediment transport models.

- A method developed to combine observations from watercraft surveys and in situ altimeters was used to map evolving dredged rip channels and natural sandbars. The resulting maps were more accurate than maps made using either infrequent, spatially dense watercraft surveys or continuous, spatially sparse altimeter bed levels (Chapter 3) [Moulton et al., 2014b]. The framework to estimate a spatially smoothed bathymetry, along with estimates of mapping errors, accounts for unresolved scales 
and observational error statistics. This method, developed and applied for specific observational approaches and bathymetric features, will be useful in a wide range of studies requiring improved temporal resolution of surfzone bathymetry.

- Rip currents and alongshore flows were observed in dredged channels, and a numerical model (COAWST) [Warner et al., 2010] accurately simulated the observed flows. The observations and numerical simulations were used to determine the response of the circulation to a range of wave conditions and bathymetries and to describe the dynamics of a range of circulation patterns near non-uniform bathymetry (Chapter 4). It was found that pressure gradients, wave breaking accelerations, advection, and the horizontal vortex force are the dominant terms in depth-averaged momentum balances near deep channels. In addition, the observations and simulations were compared with a simple model for the offshore-directed flow speed as a function of alongshore gradients in breaking-wave-driven setup and the strength of an obliquely-incident breaking-wave-driven alongshore flow. The dominant controls on the strength of offshore-directed flows were identified as wave height and angle at breaking, the depths in the channel center and on the bar crest, the threshold for wave breaking (ratio of wave height to water depth), and the alongshore flow speed (estimated from wave properties and a drag coefficient). The results will be used to improve models and tools for forecasting surfzone circulation.

\subsection{Future work}

While progress has been made in predicting coastal change, numerical models have limited skill forecasting the evolution of morphology including rip channels, sandbars, and shorelines. To protect coastal communities and infrastructure, forecasting systems should be improved and tested with observations at times when the morphology and flows are evolving rapidly, particularly during large storm events [Elko et al., 2014]. The observations from the seafloor perturbation experiments, including dense arrays of wavecurrent sensors and hourly bathymetric maps, provide a large signal with which to test predictive tools. In addition, future observational studies of waves, flows, and complex morphology during storms will help to improve the understanding of processes driving 
beach erosion and sandbar evolution. Remote sensing methods may be necessary to observe waves, currents, and bathymetry during storms when watercraft cannot be operated and in situ sensors are often buried, lost, or damaged.

Additional process studies of the feedbacks between waves, currents, and morphology are needed to improve models of morphological evolution. The observations from the dredged rip channel experiment could be used to study the coupling of and feedbacks between hydrodynamics and morphology in channels. For example, the dataset and simulations could be used to investigate under what wave and flow conditions channels migrate, grow, or decay [Garnier et al., 2013, Moulton et al., 2014b]. This could be addressed initially with an advection-diffusion framework [van de Kreek et al., 2002]. Similar to inlets on sandy beaches [O'Brien and Dean, 1972], the morphology of a rip current channel may evolve until the channel size, current strength, and sediment transport are in equilibrium. 


\subsection{References}

Elko, N., R. Holman, F. Feddersen, D. Foster, J. McNinch, H. T. Özkan-Haller, N. Plant, and B. Raubenheimer (2014), The Past and Future of Nearshore Processes Research: Reflections on the Sallenger Years and a New Vision for the Future, Shore and Beach, 83(1), 13-38.

Garnier, R., A. Falqués, D. Calvete, J. Thiebot, and F. Ribas (2013), A mechanism for sandbar straightening by oblique wave incidence, Geophys. Res. Lett., 40(11), 2726-2730, doi:10.1002/grl.50464.

Meyer-Peter, E., and R. Müller (1948), Formulas for bed-load transport, in Proc. Second Meeting International Association Hydraulic Structures Research, pp. 39-64, IAHR, Stockholm, Sweden.

Moulton, M., S. Elgar, and B. Raubenheimer (2014a), Improving the time resolution of surfzone bathymetry using in situ altimeters, Oc. Dynam., 64(5), 755-770, doi:10.1007/s10236-014-0715-8.

Moulton, M., S. Elgar, and B. Raubenheimer (2014b), A surfzone morphological diffusivity estimated from the evolution of excavated holes, Geophys. Res. Lett., 41, doi:10.1002/2014GL060519.

O'Brien, M., and R. Dean (1972), Hydraulics and sedimentary stability of coastal inlets, Proc. 13th Int. Conf. on Coastal Eng.

Soulsby, R. L., and J. S. Damgaard (2005), Bedload sediment transport in coastal waters, Coastal Eng., 52(8), 673-689, doi:10.1016/j.coastaleng.2005.04.003.

Warner, J. C., B. Armstrong, R. He, and J. B. Zambon (2010), Development of a Coupled Ocean-Atmosphere-Wave-Sediment Transport (COAWST) modeling system, $O c$. Mod., 35(3), 230-244, doi:10.1016/j.ocemod.2010.07.010.

van de Kreeke, J., S. Hoogewoning, and M. Verlaan (2002), An analytical model for the morphodynamics of a trench in the presence of tidal currents, Cont. Shelf Res., 22(11-13), 1811-1820, doi:10.1016/S0278-4343(02)00039-0. 